\title{
Aerosol indirect effect on the grid-scale clouds in the two-way coupled WRF-CMAQ: model description, development, evaluation and regional analysis
}

\author{
S. Yu ${ }^{1}$, R. Mathur ${ }^{2}$, J. Pleim ${ }^{2}$, D. Wong ${ }^{2}$, R. Gilliam ${ }^{2}$, K. Alapaty ${ }^{2}$, C. Zhao ${ }^{3}$, and X. Liu ${ }^{3}$, \\ ${ }^{1}$ Research Center for Air Pollution and Health, College of Environmental and Resource Sciences, Zhejiang University, \\ Hangzhou, Zhejiang 310058, P.R. China \\ ${ }^{2}$ Atmospheric Modeling and Analysis Division, National Exposure Research Laboratory, US Environmental Protection \\ Agency, Research Triangle Park, NC 27711, USA \\ ${ }^{3}$ Atmospheric Sciences and Global Change Division, Pacific Northwest National Laboratory, Richland, WA 99352, USA \\ * now at: Department of Atmospheric Science, University of Wyoming, Laramie, WY 82071, USA
}

Correspondence to: S. Yu (shaocaiyu@ zju.edu.cn)

Received: 9 August 2013 - Published in Atmos. Chem. Phys. Discuss.: 7 October 2013

Revised: 25 April 2014 - Accepted: 12 September 2014 - Published: 24 October 2014

\begin{abstract}
This study implemented first, second and glaciation aerosol indirect effects (AIE) on resolved clouds in the two-way coupled Weather Research and Forecasting Community Multiscale Air Quality (WRF-CMAQ) modeling system by including parameterizations for both cloud drop and ice number concentrations on the basis of CMAQpredicted aerosol distributions and WRF meteorological conditions. The performance of the newly developed WRFCMAQ model, with alternate Community Atmospheric Model (CAM) and Rapid Radiative Transfer Model for GCMs (RRTMG) radiation schemes, was evaluated with observations from the Clouds and the See http://ceres.larc. nasa.gov/. Earth's Radiant Energy System (CERES) satellite and surface monitoring networks (AQS, IMPROVE, CASTNET, STN, and PRISM) over the continental US (CONUS) (12 km resolution) and eastern Texas ( $4 \mathrm{~km}$ resolution) during August and September of 2006. The results at the Air Quality System (AQS) surface sites show that in August, the normalized mean bias (NMB) values for $\mathrm{PM}_{2.5}$ over the eastern US (EUS) and the western US (WUS) are $5.3 \%(-0.1 \%)$ and $0.4 \%(-5.2 \%)$ for WRF-CMAQ/CAM (WRF-CMAQ/RRTMG), respectively. The evaluation of $\mathrm{PM}_{2.5}$ chemical composition reveals that in August, WRF-CMAQ/CAM (WRF-CMAQ/RRTMG) consistently underestimated the observed $\mathrm{SO}_{4}^{2-}$ by $-23.0 \%$ $(-27.7 \%),-12.5 \%(-18.9 \%)$ and $-7.9 \%(-14.8 \%)$ over
\end{abstract}

the EUS at the Clean Air Status Trends Network (CASTNET), Interagency Monitoring of Protected Visual Environments (IMPROVE) and Speciated Trends Network (STN) sites, respectively. Both configurations (WRF-CMAQ/CAM, WRF-CMAQ/RRTMG) overestimated the observed mean organic carbon (OC), elemental carbon (EC) and and total carbon (TC) concentrations over the EUS in August at the IMPROVE sites. Both configurations generally underestimated the cloud field (shortwave cloud forcing, SWCF) over the CONUS in August due to the fact that the AIE on the subgrid convective clouds was not considered when the model simulations were run at the $12 \mathrm{~km}$ resolution. This is in agreement with the fact that both configurations captured SWCF and longwave cloud forcing (LWCF) very well for the $4 \mathrm{~km}$ simulation over eastern Texas, when all clouds were resolved by the finer resolution domain. The simulations of WRF-CMAQ/CAM and WRF-CMAQ/RRTMG show dramatic improvements for SWCF, LWCF, cloud optical depth (COD), cloud fractions and precipitation over the ocean relative to those of WRF default cases in August. The model performance in September is similar to that in August, except for a greater overestimation of $\mathrm{PM}_{2.5}$ due to the overestimations of $\mathrm{SO}_{4}^{2-}, \mathrm{NH}_{4}^{+}, \mathrm{NO}_{3}^{-}$, and TC over the EUS, less underestimation of clouds (SWCF) over the land areas due to the lower SWCF values, and fewer convective clouds in September. This work shows that inclusion of indirect aerosol effect 
treatments in WRF-CMAQ represents a significant advancement and milestone in air quality modeling and the development of integrated emissions control strategies for air quality management and climate change mitigation.

\section{Introduction}

Atmospheric emissions resulting from consumption of fossil fuels by human activities contribute to climate change and degrade air quality. Aerosol particles can influence the earth's climate both directly by scattering and absorption of incoming solar radiation and terrestrial outgoing radiation, and indirectly by affecting cloud radiative properties through their role as cloud condensation nuclei (CCN) and ice nuclei (IN) (Twomey, 1974, 1991; Charlson et al., 1992; Yu, 2000; Yu et al., 2000, 2001a, b, 2003, 2006; Yu and Zhang, 2011; Lohmann and Feichter, 2005; Menon et al., 2002, 2008; IPCC, 2007; DeFelice et al., 1997; Chapman et al., 2009; Gustafson et al., 2007; Zhang et al., 2010a, b, 2012; Tao et al., 2012; Hansen et al., 1997; Haywood and Boucher, 2000; Ramanathan et al., 2001; Rosenfeld et al., 2008; Saxena and Yu, 1998; Saxena et al., 1997; H. Yu et al., 2006; F. Yu et al., 2012a, b; Saide et al., 2012; Yang et al., 2011; Liu et al., 2011; McKeen et al., 2007; Yu et al., 2004, 2007b, 2008). The aerosol indirect effect (AIE) can be split into the first, second, and glaciation aerosol indirect effects. For a given cloud liquid water content, an increase in the cloud droplet number concentration implies a decrease in the effective radius, thus increasing the cloud albedo; this is known as the first AIE (or cloud albedo effect), and was first estimated by Twomey (1974). The second AIE is based on the idea that decreasing the mean droplet size in the presence of enhanced aerosols decreases the cloud precipitation efficiency, producing clouds with a larger liquid water content and a longer lifetime (cloud lifetime effect), and its recognition is commonly attributed to Albrecht (1989). The glaciation AIE is based on the idea that increases in IN because of enhanced aerosols (dust, organic carbon, black carbon and sulfate) result in more frequent glaciation of a supercooled liquid water cloud due to the difference in vapor pressure over ice and water and an increase in the amount of precipitation via the ice phase, leading to a decrease in cloud cover and a shorter cloud lifetime (IPCC, 2007; Lohmann, 2002). The first and second AIEs have a negative radiative effect at the top of the atmosphere (TOA), while the glaciation AIE has a positive effect. As summarized by Lohmann and Feichter (2005) and the IPCC (2007), other aerosol indirect effects may include the semi-direct effect, which refers to an evaporation of cloud droplets caused by the absorption of solar radiation by soot, and the thermodynamic effect that refers to a delay in the onset of freezing by the smaller cloud droplets, causing supercooled clouds to extend to colder temperatures (precipitation suppression). The IPCC (2007) concludes that increasing concentrations of the long-lived greenhouse gases have led to a combined radiative forcing of $+2.63[ \pm 0.26] \mathrm{W} \mathrm{m}^{-2}$, and the total direct aerosol radiative forcing is estimated to be $-0.5[ \pm 0.4] \mathrm{W} \mathrm{m}^{-2}$, with a medium to low level of scientific understanding, while the radiative forcing due to the cloud albedo effect (also referred to as first indirect) is estimated to be $-0.7[-1.1,+0.4] \mathrm{W} \mathrm{m}^{-2}$, with a low level of scientific understanding.

Numerous investigations provide observational evidence of the AIE. For example, the presence of non-precipitating supercooled liquid water near cloud tops because of the overseeding from both smoke over Indonesia and urban pollution over Australia (Rosenfeld, 1999, 2000) has been identified. Rosenfeld et al. (2007) found that on the basis of the analysis of more than 50 years of observations at Mt. Hua near Xi' an in China, the observed orographic precipitation decreased by $30-50 \%$ during the hazy conditions in the presence of high levels of aerosols and small CCN. On the basis of the extensive ground-based and global A-Train (CALIPSO and MODIS) observations during the past 10 years, Li et al. (2011) found the strong climate effects of aerosols on clouds and precipitation. Lin et al. (2006) found evidence that high biomass burning-derived aerosols were correlated with elevated cloud top heights, large anvils and more rainfall on the basis of satellite observations over the Amazon basin. Enhanced rainfall in the coastal northwestern Atlantic region (Cerveny et al., 1998) and downwind of the Mexico City urban area (Jauregui and Romales, 1996) and paper mills (Eagen et al., 1974) is attributed to the effects of giant CCN. However, it is impossible to evaluate the AIE with observations directly, because the AIE is traditionally estimated on the basis of the difference in model results between the present day and pre-industrial times, and the observational records (satellite and other long-term records) are not long enough to characterize conditions during the pre-industrial times (IPCC, 2007). However, the satellite retrievals of various cloud parameters provide a way to evaluate the model simulations indirectly. For example, the cloud droplet effective radii retrieved from the satellite of the Advanced Very High Resolution Radiometer (AVHRR) (Han et al., 1994) have been used to evaluate the global model simulations (Rotstayn, 1999; Ghan et al., 2001a, b, c; Ghan and Easter, 2006).

The chemistry-aerosol-cloud-radiation-climate interactions are complex and can be nonlinear. To simulate these interactions realistically, a fully online coupled meteorologyatmospheric chemistry model is needed, although there are a large number of online coupled global meteorologyatmospheric chemistry models with various degrees of coupling (very limited prognostic gaseous and aerosol species and/or aerosol-cloud-radiation process representation) to atmospheric chemistry (Granier and Brasseur, 1991; Rasch et al., 2000; Taylor and Penner, 1994; Jacobson, 1994, 2006). The history and current status of the development and application of online coupled meteorology and atmospheric chemistry models have been reviewed by Zhang (2008). As 


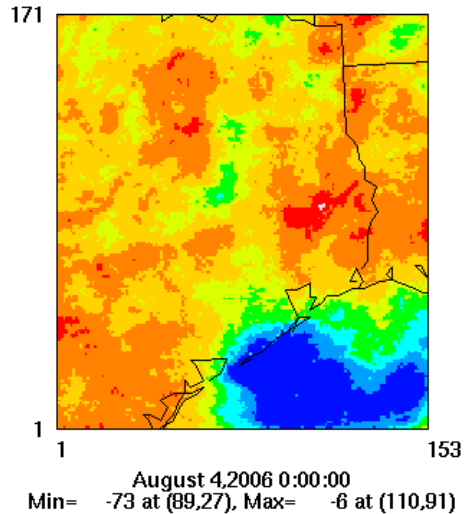

(a)

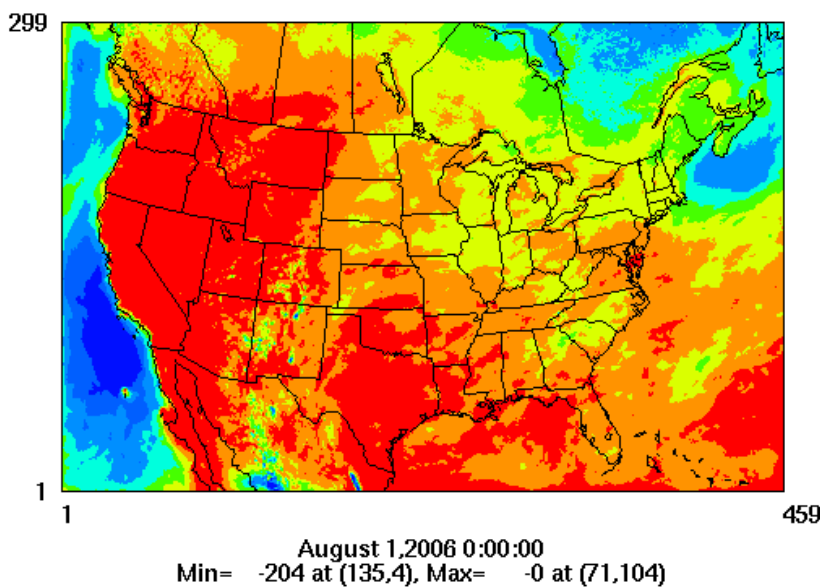

(b)

Figure 1. The model domains of WRF-CMAQ for (a) a $4 \mathrm{~km}$ resolution model grid over eastern Texas and (b) a $12 \mathrm{~km}$ resolution model grid over the continental US for the monthly mean results of SWCF in August of 2006.

summarized by Pleim et al. (2008), there are two approaches to coupling meteorology and atmospheric chemistry models. The first approach is to integrate meteorology and atmospheric chemistry such as in the MM5/Chem (Grell et al., 2000), WRF/Chem (Grell et al., 2005) and GATORGCMOM (Gas, Aerosol, TranspOrt, Radiation, General Circulation, Mesoscale, and Ocean Model) models (Jacobson, 2001a, b) that are created by adding atmospheric chemistry to the existing meteorology models. The second approach is to combine existing meteorology and atmospheric chemistry models into a single executable program with two-way meteorological and chemical data exchange such as in the twoway coupled Weather Research and Forecasting Community Multiscale Air Quality (WRF-CMAQ) model (Wong et al., 2012). Each approach has its own advantages and disadvantages. For example, the advantage of the second approach is to allow the use of the existing computational and numerical techniques in each model (meteorology and atmospheric chemistry) and to leverage future development in each model by maintaining equivalent one-way capability. The two-way coupled WRF-CMAQ model is developed with the second approach by integrating the WRF and CMAQ models into a single executable program in which CMAQ can be executed as a stand-alone model or as part of the coupled system without any code changes (Wong et al., 2012). The WRF-CMAQ model is a community online coupled model that is publicly available (http://www.cmascenter.org/cmaq/) and that allows contributions from the community.

On the other hand, including aerosol indirect effects does not necessarily mean climate change, because aerosol can influence clouds via shorter timescales (e.g., weather or cloud scales). In the WRF-only default case, the cloud drop number and effective radius information have been assumed and then used. This means that the aerosol indirect effect has been assumed in the WRF-only default case, although aerosol fields have not been simulated in this meteorological model. The improvement in the meteorological field simulations by including the aerosol indirect effects can help enhance the model simulation of air quality. Inclusion of indirect aerosol effect treatments in CMAQ represents a significant advancement and milestone in air quality modeling in terms of scientific understanding of the complex relationship between air pollutants and climate change and the development of integrated win-win emissions control strategies for air quality management and climate change mitigation.

The purpose of this paper is twofold. First, this study implements the indirect effects of aerosols on the microphysical and radiative properties of clouds (including first, second and glaciation indirect aerosol effects) in the two-way coupled WRF-CMAQ. The cloud droplet number concentrations were calculated from the CMAQ-predicted aerosol particles using a parameterization based on a maximum supersaturation determined from a Gaussian spectrum of updraft velocities and the internally mixed aerosol properties within each mode (Abdul-Razzak and Ghan, 2002). The cloud condensation nuclei $(\mathrm{CCN})$ concentrations at six supersaturations $(0.02,0.05,0.1,0.2,0.5$, and $1.0 \%)$ are estimated. The cloud ice number concentrations for the CMAQ-predicted sulfate, black carbon and dust were estimated with an ice nucleation scheme in the NCAR Community Atmospheric Model (CAM) (Liu et al., 2007). The resulting cloud drop and ice number concentrations are added to the Morrison cloud microphysics scheme (Morrison et al., 2009, 2005), and this allows us to estimate aerosol effects on cloud and ice optical depth and microphysical process rates for indirect aerosol radiative forcing (including first, second and glaciation indirect aerosol forcing) by tying a two-moment treatment of cloud water (mass and number) and cloud ice (mass and number) to precipitation (the Morrison et al. two-moment cloud microphysics scheme, Morrison et al., 2009, 2005) and two radiation schemes (the Rapid Radiative Transfer Model for General Circulation Models (GCMs) (RRTMG), Iacono et al., 2008, and CAM, Collins et al., 2004) in the WRF model. 


\section{Two-way coupled WRF-CMAQ modeling System (Interaction and feedback)}

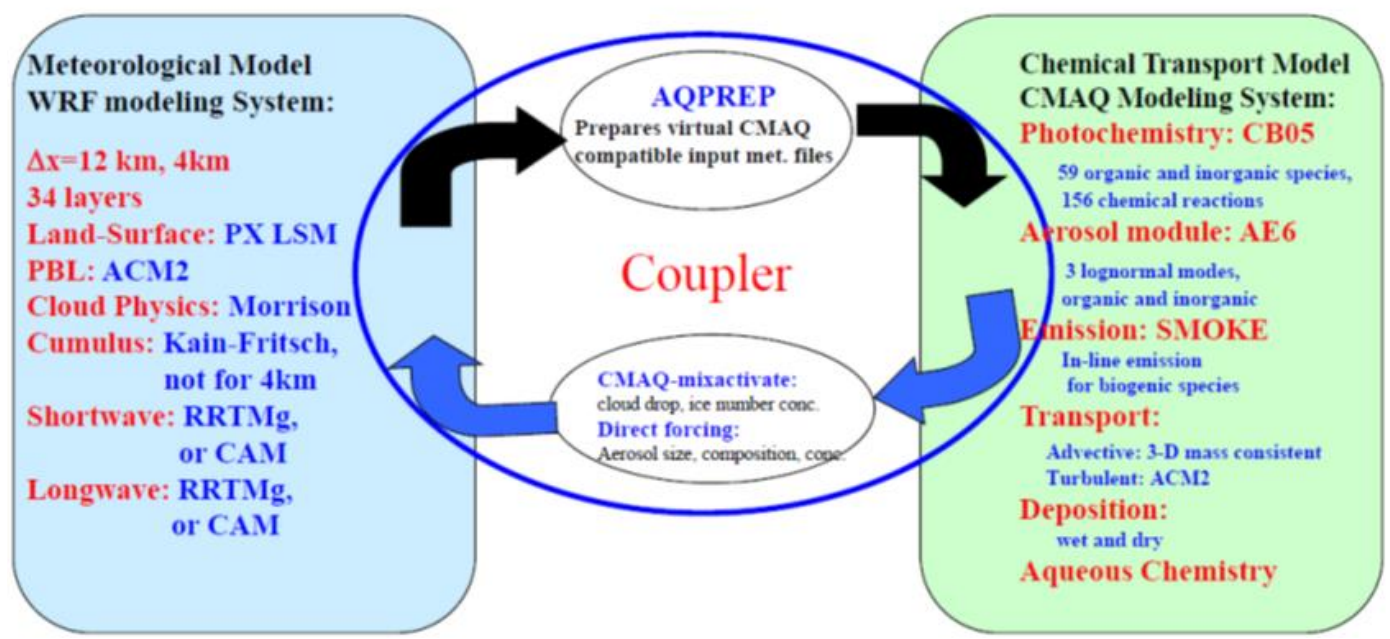

Figure 2. The two-way coupled WRF-CMAQ modeling system.

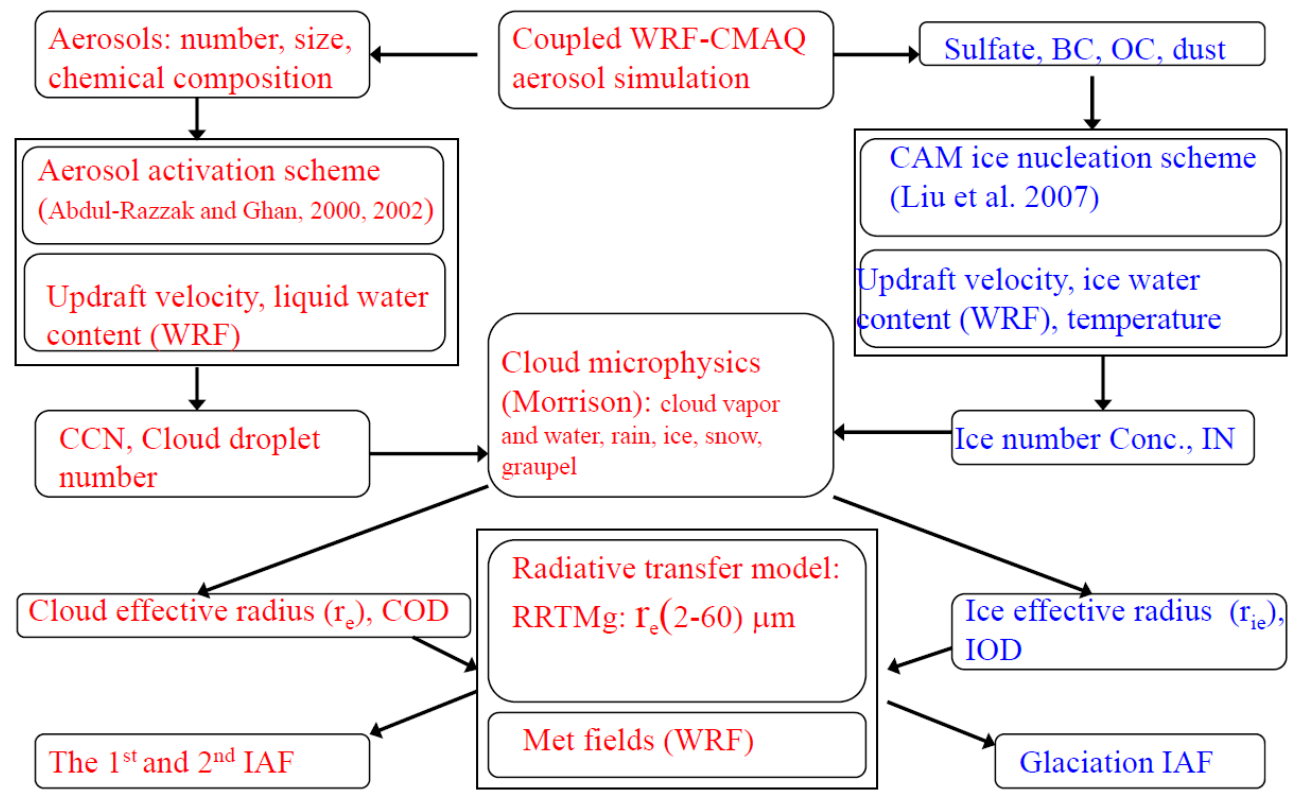

Figure 3. Flow diagram for calculation of the aerosol indirect effect (AIE) in the two-way coupled WRF-CMAQ modeling system.

The RRTMG and CAM radiation schemes are selected because these two schemes are used in many studies (Liu et al., 2007; Collins et al., 2004; Iacono et al., 2008; Yang et al., 2011; Saide et al., 2012). The comparison results of the WRF-CMAQ/CAM and WRF-CMAQ/RRTMG simulations can indicate the effects of radiation schemes on the model performance on air quality and cloud properties. For reference, the WRF/CAM and WRF/RRTMG simulations are also carried out to show how the CMAQ air quality model can help improve the WRF performance on cloud properties. The simulations with the newly developed WRF3.3CMAQ5.0 model are carried out on a $4 \mathrm{~km}$ resolution model grid over eastern Texas (Fig. 1a) and a $12 \mathrm{~km}$ resolution model grid over the continental US (Fig. 1b) for the typical summer of 2006 when routine data are normally available. Second, this study examines the model performance for cloud properties (e.g., cloud optical depth (COD), cloud fractions), shortwave cloud forcing (SWCF), longwave cloud 
forcing (LWCF) and $\mathrm{PM}_{2.5}$, its chemical composition and precursors with satellite observational data (CERES) and the surface monitoring networks (AIRNOW, IMPROVE, CASTNET, STN, PRISM) during August and September of 2006. The paper represents the first documentation of the two-way coupled WRF-CMAQ with aerosol indirect effect and the first comprehensive evaluation of its capability in reproducing shortwave cloud forcing and other cloud properties.

\section{Model description and simulation design}

\subsection{Two-way coupled WRF-CMAQ}

The two-way coupled WRF-CMAQ modeling system (Pleim et al., 2008; Mathur et al., 2010; Wong et al., 2012) was developed by linking the Weather Research and Forecasting (WRF) model (Skamarock et al., 2008) and the CMAQ model (Eder and Yu, 2006; Mathur et al., 2008; Eder et al., 2009, 2010). A brief summary relevant to the present study is presented here. In this system, radiative effects of aerosols and the cloud droplets diagnosed from the activation of CMAQ-predicted aerosol particles interact with the WRF radiation calculations, resulting in a "two-way" coupling between atmospheric dynamic and chemical modeling components (Pleim et al., 2008; Mathur et al., 2010). Figure 2 shows a schematic coupling for the WRF and CMAQ modeling systems that includes three components: WRF, CMAQ and a coupler. In the coupled system, CMAQ is added as a subroutine in WRF, and can be executed as a stand-alone model or as part of the coupled system without any code changes. The coupler serves as an inter-model translator by transferring meteorological data from WRF to CMAQ and CMAQ-predicted aerosol data from CMAQ to WRF in memory. In the coupler, a subroutine called AQPREP prepares virtual meteorological files in forms compatible for CMAQ to use directly without writing the physical files, and another subroutine (FEEDBACK), which is called within the aerosol module in CMAQ, is used to compute aerosol properties and to transfer the related aerosol data from CMAQ to WRF for direct and indirect aerosol forcing calculations. The call frequency is a user-defined environmental variable as a ratio of the WRF to CMAQ time steps, and is used in the coupled system to determine how many times WRF is called for each CMAQ call. WRF is integrated at a very fine time step, while the minimum synchronization time step in CMAQ is determined by the horizontal wind speed Courant condition in model layers lower than $\sim 700 \mathrm{hPa}$; the coupling frequency is flexible, and can be specified by the user. This is a mechanism to balance computational performance while allowing the user to couple the models as tightly as needed.

While CMAQ uses an advection scheme and a time step that is different from WRF, a methodology has been implemented to minimize the resultant inconsistencies between meteorological and chemical fields. The vertical velocity is re-derived in CMAQ using the identical integrated continuity equation used in WRF, but with the horizontal mass divergence computed in CMAQ using the CMAQ advection scheme. Thus, mass continuity is assured in CMAQ, as it is in WRF. Also, to avoid drift between CMAQ and WRF mass fields, the chemical concentrations are re-normalized every CMAQ time step by the air density from WRF. The vertical diffusion of meteorological and chemical variables is simulated using the identical PBL scheme, namely the ACM2, in WRF and CMAQ, although it is applied at different points in the coupled WRF-CMAQ processing. Future work will include experiments with more integrated transport modeling where advection and diffusion processing of chemical and meteorological tracers will both be handled in the WRF part of the system. Thus, errors associated with the current coupled system will be quantified.

For the $12 \mathrm{~km}$ grid resolution simulations, the WRF time step is $60 \mathrm{~s}$, and CMAQ is called every fifth WRF step. We assume that the aerosol concentrations and characteristics are not changing so rapidly that coupling at $1 \mathrm{~min}$ rather than at 5 min makes a significant difference. While we have not done this sensitivity study with the indirect aerosol effects activated, we have compared WRF-CMAQ model runs with direct aerosol feedback at various coupling frequencies, including 1-to-1 and 5-to-1, and seen very few differences. The preliminary results of the two-way coupled WRF-CMAQ model with the direct aerosol effect only for a ten-day simulation of a wildfire event in California from 20 to 29 June 2008 showed that the coupled model can improve the accuracy of both meteorology and air quality simulations for these cases with high aerosol loading when the direct aerosol effect is included (Wong et al., 2012). In this work, the AIE in the two-way coupled WRF-CMAQ model is implemented by adding a subroutine called CMAQ-mixactivate that is created by modifying the existing mixactivate subroutine in WRF/Chem. The CMAQ-mixactivate subroutine calculates both cloud droplet and ice number concentrations on the basis of the CMAQ-predicted aerosol particles and the WRF meteorological conditions (see Figs. 2 and 3), and will be described in detail below. Note that the ice nucleation scheme is not included in the publicly available mixactivate subroutine of WRF/Chem. Like CMAQ, the CMAQ-mixactivate subroutine is added as a subroutine in WRF, and is called just after CMAQ is called in order to use the results of CMAQ simulations.

Table 1 summarizes the model configurations and components used in this study. The physics package of the WRF3.3 (ARW) includes the Kain-Fritsch (KF2) cumulus cloud parameterization (Kain and Fritsch, 1990, 1993; Kain, 2004), the Asymmetric Convective Model (ACM2), a planetary boundary layer (PBL) scheme (Pleim, 2007a, b), RRTMG (Iacono et al., 2008) and CAM (Collins et al., 2004) shortwave and longwave radiation schemes, Morrison et al. two-moment cloud microphysics (Morrison et al., 2009, 2005; Morrison and Pinto, 2006), and the Pleim-Xiu (PX) 
Table 1. Model configurations and components.

\begin{tabular}{ll}
\hline Simulation period & 1 Aug to 15 Oct 2006 \\
\hline Domain & Continental US (CONUS), eastern Texas \\
Horizontal grid spacing & 12 km (continental US), 4 km (eastern Texas) \\
Number of vertical levels & 34 layers \\
Shortwave radiation scheme & CAM scheme (Collins et al., 2004), rrtmg scheme \\
& (Iacono et al., 2008) \\
Longwave radiation scheme & CAM scheme (Collins et al., 2004), rrtmg scheme \\
& (Iacono et al., 2008) \\
Land-surface model & Pleim-Xiu LSM (Pleim and Xiu, 1995; Xiu and \\
& Pleim, 2001) \\
Planetary boundary layer & Asymmetrical Convective Model version 2 (ACM2) \\
& PBL (Pleim, 2007) \\
Cloud microphysics & Morrison et al. two-moment scheme (Morrison et al., \\
& 2009, 2005; Morrison and Pinto, 2006) \\
Cumulus parameterization & Kain-Fritsch scheme (Kain and Fritsch, 1990, 1993) \\
& for CONUS (12 km), none for the 4km resolution \\
run. & NAM-218 \\
Meteorological initial & NAM-218 \\
conditions & CB05 (Yarwood et al., 2005) \\
Meteorological boundary & AERO-6 \\
conditions & GEOS-CHEM simulations (Bey et al., 2001); BCs at \\
Gas-phase chemistry & 4 km resolution are from the 12 km resolution simu- \\
Aerosol module & lations over the CONUS. \\
Chemical BC & 2005 NEI \\
& \\
Emissions inventory & \\
\hline & \\
&
\end{tabular}

Table 2. Aerosol species for each mode in AERO6 of CMAQ* (see the explanations in the text).

\begin{tabular}{|c|c|c|}
\hline Nucleation (I) & Accumulation $(\mathrm{J})$ & Coarse $(\mathrm{K})$ \\
\hline $\begin{array}{l}\text { ASO4I, ANH4I, } \\
\text { ANO3I, APOCI, } \\
\text { APNCOMI, AECI, } \\
\text { AOTHRI, AH2OI, } \\
\text { ANAI, ACLI }\end{array}$ & $\begin{array}{l}\text { ASO4J, ANH4J, ANO3J, AALKJ, AXYL1J, AXYL2J, } \\
\text { AXYL3J, ATOL1J, ATOL2J, ATOL3J, ABNZ1J, } \\
\text { ABNZ2J, ABNZ3J, ATRP1J, ATRP2J, AISO1J, } \\
\text { AISO2J, ASQTJ, AORGCJ, APOCJ, APNCOMJ, } \\
\text { AECJ, AOTHRJ, AH2OJ, ANAJ, ACLJ, AISO3J, } \\
\text { AOLGAJ, AOLGBJ, AFEJ, AALJ, ASIJ, ATIJ, ACAJ, } \\
\text { AMGJ, AKJ, AMNJ }\end{array}$ & $\begin{array}{l}\text { ASO4K, ANH4K, } \\
\text { ANO3K, AH2OK, } \\
\text { ACLK, ACORS, } \\
\text { ASOIL, ASEACAT }\end{array}$ \\
\hline
\end{tabular}

land-surface scheme (Pleim and Xiu, 1995, 2003; Xiu and Pleim, 2001). Note that the KF2 cumulus cloud scheme was turned off for the model simulations on the $4 \mathrm{~km}$ resolution model grid. The meteorological initial and lateral boundary conditions were derived from a combination of North American Mesoscale (NAM) model analyses and forecasts at $3 \mathrm{~h}$ intervals developed by the National Center for Environmental Prediction (NCEP). The carbon bond chemical mechanism (CB05) (Yarwood et al., 2005) has been used to represent photochemical reaction pathways. Emissions are based on the 2005 National Emission Inventory (NEI) (available at www.epa.gov/ttnchief1/net/2005inventory.html) and BEIS v3.14 for the year 2006. The mobile source emissions were generated by the EPA'S MOBILE6 model.

The aerosol module in CMAQ is described by Binkowski and Roselle (2003), and updates are described by Bhave et al. (2004), Yu et al. (2007a), Carlton et al. (2010), Foley et al. (2010), and Appel et al. (2013). The size distribution of aerosols in tropospheric air quality models can be represented by the sectional approach (Zhang et al., 2002, 2012), the moment approach (Yu et al., 2003), and the modal approach (Binkowski and Roselle, 2003). In the aerosol 
Table 3. Molecular weight $\left(\mathrm{g} \mathrm{mol}^{-1}\right)$, density $\left(\mathrm{g} \mathrm{cm}^{-3}\right)$ and hygroscopicity of each aerosol species used in this study (see the explanations in the text).

\begin{tabular}{lrrr}
\hline & Molecular weight & Density & Hygroscopicity \\
\hline ASO4 & 96.0 & 1.8 & 0.50 \\
ANO3 & 62.0 & 1.8 & 0.50 \\
ANH4 & 18.0 & 1.8 & 0.50 \\
AALK & 150.0 & 2.0 & 0.14 \\
AXYL & 192.0 & 2.0 & 0.14 \\
ATOL & 168.0 & 2.0 & 0.14 \\
ABNZ & 144.0 & 2.0 & 0.14 \\
ATRP & 168.0 & 2.0 & 0.14 \\
AISO & 96.0 & 2.0 & 0.14 \\
ASQT & 378.0 & 2.0 & 0.14 \\
AISO3 & 162.0 & 2.0 & 0.14 \\
AOLGA & 176.4 & 2.0 & 0.20 \\
AOLGB & 252.0 & 2.0 & 0.20 \\
AORGC & 177.0 & 2.0 & 0.50 \\
APOA & 220.0 & 2.0 & 0.14 \\
AEC & 12.0 & 2.2 & $1.0 \times 10^{-6}$ \\
AOTHR & 200.0 & 2.2 & 0.10 \\
ANA & 23.0 & 2.2 & 1.16 \\
ACL & 35.0 & 2.2 & 1.16 \\
ACORS & 100.0 & 2.2 & 0.03 \\
ASOIL & 100.0 & 2.6 & 0.03 \\
\hline
\end{tabular}

Table 4. Comparison of the WRF-CMAQ/CAM and WRF-CMAQ/RRTMG models for operational evaluation of maximum $1 \mathrm{~h}$ and $8 \mathrm{~h}$ $\mathrm{O}_{3}$ concentrations on the basis of the AQS data over the continental United States ( $12 \mathrm{~km}$ resolution model grid) and eastern Texas (4 km resolution model grid) for August of 2006. "Domain mean" means the results on the basis of all data at observational sites within the domain.

\begin{tabular}{|c|c|c|c|c|c|c|c|c|c|c|c|}
\hline $\mathrm{Max}_{3}$ & Model & $\begin{array}{r}\text { Data } \\
\text { points }\end{array}$ & $\begin{array}{c}\text { Doma } \\
\text { obs }\end{array}$ & $\begin{array}{r}\text { mean, ppbv } \\
\text { model }\end{array}$ & $\begin{array}{l}\text { MB, } \\
\text { ppbv }\end{array}$ & $\begin{array}{r}\text { RMSE, } \\
\text { ppbv }\end{array}$ & NMB $(\%)$ & NME $(\%)$ & $\operatorname{NMBF}(\%)$ & $\operatorname{NMEF}(\%)$ & $r$ \\
\hline \multicolumn{12}{|c|}{ Over the continental US ( $12 \mathrm{~km}$ resolution model grid) } \\
\hline \multicolumn{12}{|c|}{ All data } \\
\hline $8 \mathrm{~h}$ & WRF-CMAQ (CAM) & 33278 & 50.2 & 52.9 & 2.7 & 12.4 & 5.3 & 18.7 & 5.3 & 18.7 & 0.641 \\
\hline $8 \mathrm{~h}$ & WRF-CMAQ (RRTMG) & 33278 & 50.2 & 52.9 & 2.6 & 12.3 & 5.2 & 18.7 & 5.2 & 18.7 & 0.637 \\
\hline $1 \mathrm{~h}$ & WRF-CMAQ (CAM) & 33278 & 56.9 & 59.4 & 2.5 & 14.2 & 4.5 & 18.6 & 4.5 & 18.6 & 0.625 \\
\hline $1 \mathrm{~h}$ & WRF-CMAQ (RRTMG) & 33278 & 56.9 & 59.1 & 2.2 & 14.1 & 3.8 & 18.5 & 3.8 & 18.5 & 0.623 \\
\hline \multicolumn{12}{|c|}{ For $\mathrm{O}_{3}$ greater than $40 \mathrm{ppbv}$} \\
\hline $8 \mathrm{~h}$ & WRF-CMAQ (CAM) & 24628 & 56.7 & 56.7 & -0.1 & 11.5 & -0.1 & 15.0 & -0.1 & 15.0 & 0.511 \\
\hline $8 \mathrm{~h}$ & WRF-CMAQ (RRTMG) & 24628 & 56.7 & 56.5 & -0.3 & 11.3 & -0.4 & 14.8 & -0.4 & 14.8 & 0.511 \\
\hline $1 \mathrm{~h}$ & WRF-CMAQ (CAM) & 27527 & 62.0 & 62.4 & 0.5 & 13.7 & 0.7 & 16.1 & 0.7 & 16.1 & 0.518 \\
\hline $1 \mathrm{~h}$ & WRF-CMAQ (RRTMG) & 27527 & 62.0 & 62.0 & 0.0 & 13.5 & 0.0 & 15.9 & 0.0 & 15.9 & 0.516 \\
\hline \multicolumn{12}{|c|}{ Over eastern Texas ( $4 \mathrm{~km}$ resolution model grid)* } \\
\hline \multicolumn{12}{|c|}{ All data } \\
\hline $8 \mathrm{~h}$ & WRF-CMAQ (CAM) & 1854.0 & 43.1 & $59.3(50.2)$ & $16.2(7.1)$ & $22.0(14.7)$ & $37.5(16.4)$ & $42.8(28.3)$ & $37.5(16.4)$ & $42.8(28.3)$ & $0.562(0.664)$ \\
\hline $8 \mathrm{~h}$ & WRF-CMAQ (RRTMG) & 1854.0 & 43.1 & $59.5(50.2)$ & $16.3(7.1)$ & $21.3(14.5)$ & $37.8(16.4)$ & $42.0(27.8)$ & $37.8(16.4)$ & $42.0(27.8)$ & $0.607(0.656)$ \\
\hline $1 \mathrm{~h}$ & WRF-CMAQ (CAM) & 1854.0 & 51.2 & $68.1(57.6)$ & $16.9(6.5)$ & $25.1(17.1)$ & $33.1(12.6)$ & $40.2(26.6)$ & $33.1(12.6)$ & $40.2(26.6)$ & $0.538(0.644)$ \\
\hline $1 \mathrm{~h}$ & WRF-CMAQ (RRTMG) & 1854.0 & 51.2 & $67.3(56.8)$ & $16.2(5.7)$ & $23.3(16.8)$ & $31.6(11.1)$ & $37.7(26.1)$ & $31.6(11.1)$ & $37.7(26.1)$ & $0.606(0.645)$ \\
\hline \multicolumn{12}{|c|}{ For $\mathrm{O}_{3}$ greater than $40 \mathrm{ppbv}$} \\
\hline $8 \mathrm{~h}$ & WRF-CMAQ (CAM) & 996.0 & 55.7 & $66.1(56.4)$ & $10.4(0.7)$ & $17.7(12.5)$ & $18.7(1.2)$ & $25.7(17.1)$ & $18.7(1.2)$ & $25.7(17.1)$ & $0.296(0.389)$ \\
\hline $8 \mathrm{~h}$ & WRF-CMAQ (RRTMG) & 996.0 & 55.7 & $66.2(56.6)$ & $10.5(0.9)$ & $16.6(12.7)$ & $18.8(1.5)$ & $24.6(17.0)$ & $18.8(1.5)$ & $24.6(17.0)$ & $0.357(0.360)$ \\
\hline $1 \mathrm{~h}$ & WRF-CMAQ (CAM) & 1206.0 & 62.5 & $74.0(63.1)$ & $11.5(0.7)$ & $21.3(15.6)$ & $18.4(1.1)$ & $27.1(18.3)$ & $18.4(1.1)$ & $27.1(18.3)$ & $0.362(0.422)$ \\
\hline $1 \mathrm{~h}$ & WRF-CMAQ (RRTMG) & 1206.0 & 62.5 & $73.2(62.3)$ & $10.7(-0.2)$ & $19.3(15.9)$ & $17.1(-0.3)$ & $24.7(18.4)$ & $17.1(-0.3)$ & $24.7(18.4)$ & $0.446(0.392)$ \\
\hline
\end{tabular}


Table 5a. Comparison of observation and models (WRF-CMAQ/CAM and WRF-CMAQ/RRTMG) for PM 2.5 and its components for each network over the eastern United States (longitude greater than $-100^{\circ}$ ) for August of $2006^{*}$.

\begin{tabular}{|c|c|c|c|c|c|c|c|c|c|c|c|c|c|c|c|c|c|}
\hline & \multirow{2}{*}{$\begin{array}{r}\text { AIRNow } \\
\mathrm{PM}_{2.5}\end{array}$} & \multicolumn{4}{|c|}{ CASTNET } & \multicolumn{6}{|c|}{ IMPROVE } & \multicolumn{5}{|c|}{ STN } & \multirow[b]{2}{*}{$\mathrm{TC}$} \\
\hline & & $\mathrm{SO}_{4}^{2-}$ & $\mathrm{NH}_{4}^{+}$ & $\mathrm{NO}_{3}^{-}$ & $\mathrm{SO}_{2}$ & TotS & $\mathrm{PM}_{2.5}$ & $\mathrm{SO}_{4}^{2-}$ & $\mathrm{NO}_{3}^{-}$ & $\mathrm{OC}$ & $\mathrm{EC}$ & $\mathrm{TC}$ & $\mathrm{PM}_{2.5}$ & $\mathrm{SO}_{4}^{2-}$ & $\mathrm{NH}_{4}^{+}$ & $\mathrm{NO}_{3}^{-}$ & \\
\hline \multicolumn{18}{|c|}{ WRF-CMAQ/CAM } \\
\hline Mean (obs) & 15.26 & 5.59 & 1.62 & 0.35 & 0.91 & 3.16 & 10.81 & 4.73 & 0.28 & 1.50 & 0.39 & 1.89 & 17.47 & 4.94 & 1.58 & 0.54 & 4.72 \\
\hline Mean (model) & 16.08 & 4.05 & 1.25 & 0.41 & 1.83 & 3.97 & 9.38 & 4.14 & 0.43 & 1.89 & 0.61 & 2.50 & 17.35 & 4.55 & 1.63 & 0.89 & 4.83 \\
\hline Number & 7318 & 231 & 231 & 231 & 231 & 231 & 489 & 307 & 307 & 484 & 478 & 484 & 817 & 886 & 886 & 850 & 895 \\
\hline Correlation & 0.40 & 0.81 & 0.73 & 0.21 & 0.78 & 0.83 & 0.51 & 0.57 & 0.28 & 0.48 & 0.58 & 0.51 & 0.22 & 0.49 & 0.48 & 0.36 & 0.32 \\
\hline MB & 0.81 & -1.54 & -0.37 & 0.07 & 0.92 & 0.80 & -1.43 & -0.59 & 0.14 & 0.39 & 0.22 & 0.60 & -0.12 & -0.39 & 0.04 & 0.35 & 0.10 \\
\hline RMSE & 10.70 & 2.43 & 0.76 & 0.67 & 1.30 & 1.68 & 8.32 & 3.68 & 0.90 & 1.79 & 1.05 & 2.73 & 12.94 & 3.64 & 1.37 & 1.26 & 3.26 \\
\hline NMB (\%) & 5.3 & -27.6 & -23.0 & 19.4 & 101.1 & 25.3 & -13.2 & -12.5 & 50.4 & 25.9 & 54.9 & 31.9 & -0.7 & -7.9 & 2.8 & 64.2 & 2.2 \\
\hline NME (\%) & 49.9 & 33.3 & 35.0 & 112.1 & 105.5 & 35.6 & 51.4 & 53.5 & 141.9 & 62.7 & 97.5 & 68.0 & 53.9 & 53.1 & 61.5 & 130.7 & 48.9 \\
\hline NMBF (\%) & 5.3 & -38.1 & -29.9 & 19.4 & 101.1 & 25.3 & -15.2 & -14.3 & 50.4 & 25.9 & 54.9 & 31.9 & -0.7 & -8.5 & 2.8 & 64.2 & 2.2 \\
\hline NMEF (\%) & 49.9 & 46.0 & 45.4 & 112.1 & 105.5 & 35.6 & 59.2 & 61.2 & 141.9 & 62.7 & 97.5 & 68.0 & 54.3 & 57.6 & 61.5 & 130.7 & 48.9 \\
\hline \multicolumn{18}{|c|}{ WRF-CMAQ/RRTMG } \\
\hline Mean (obs) & 15.26 & 5.59 & 1.62 & 0.35 & 0.91 & 3.16 & 10.81 & 4.73 & 0.28 & 1.50 & 0.39 & 1.89 & 17.47 & 4.94 & 1.58 & 0.54 & 4.72 \\
\hline Mean (model) & 15.25 & 3.79 & 1.17 & 0.38 & 1.81 & 3.85 & 8.99 & 3.84 & 0.35 & 1.86 & 0.60 & 2.45 & 16.39 & 4.21 & 1.48 & 0.74 & 4.68 \\
\hline Number & 7318 & 231 & 231 & 231 & 231 & 231 & 489 & 307 & 307 & 484 & 478 & 484 & 817 & 886 & 886 & 850 & 895 \\
\hline Correlation & 0.40 & 0.81 & 0.74 & 0.21 & 0.78 & 0.83 & 0.51 & 0.59 & 0.26 & 0.50 & 0.60 & 0.54 & 0.23 & 0.54 & 0.52 & 0.34 & 0.33 \\
\hline $\mathrm{MB}$ & -0.02 & -1.80 & -0.45 & 0.03 & 0.90 & 0.69 & -1.82 & -0.90 & 0.06 & 0.36 & 0.20 & 0.56 & -1.08 & -0.73 & -0.11 & 0.20 & -0.04 \\
\hline RMSE & 10.20 & 2.62 & 0.79 & 0.64 & 1.26 & 1.55 & 8.02 & 3.59 & 0.69 & 1.68 & 0.99 & 2.57 & 12.56 & 3.45 & 1.25 & 1.06 & 3.12 \\
\hline NMB (\%) & -0.1 & -32.1 & -27.7 & 9.7 & 98.9 & 21.8 & -16.8 & -18.9 & 22.4 & 23.8 & 52.2 & 29.7 & -6.2 & -14.8 & -6.7 & 37.1 & -0.9 \\
\hline NME (\%) & 48.6 & 36.3 & 36.7 & 107.6 & 103.0 & 33.0 & 51.0 & 53.2 & 121.0 & 59.9 & 94.0 & 65.0 & 52.5 & 50.0 & 56.4 & 115.1 & 47.8 \\
\hline NMBF (\%) & -0.1 & -47.4 & -38.4 & 9.7 & 98.9 & 21.8 & -20.2 & -23.3 & 22.4 & 23.8 & 52.2 & 29.7 & -6.6 & -17.4 & -7.2 & 37.1 & -0.9 \\
\hline NMEF (\%) & 48.7 & 53.5 & 50.8 & 107.6 & 103.0 & 33.0 & 61.3 & 65.7 & 121.0 & 59.9 & 94.0 & 65.0 & 56.0 & 58.7 & 60.5 & 115.1 & 48.2 \\
\hline
\end{tabular}

* The unit of the mean, $\mathrm{MB}$, and RMSE is $\mu \mathrm{g} \mathrm{m}^{-3}$, for $\mathrm{SO}_{2}$ it is $\mathrm{ppb}$, and TotS is the total sulfur $\left(\mathrm{SO}_{4}^{2-}+\mathrm{SO}_{2}\right)$ concentrations $\left(\mu \mathrm{g} \mathrm{S} \mathrm{m}{ }^{-3}\right)$.

Table 5b. The same as Table 5a, but for $\mathrm{PM}_{2.5}$ and its components for each network over the western United States (longitude less than $-100^{\circ}$ ) for August of $2006^{*}$.

\begin{tabular}{|c|c|c|c|c|c|c|c|c|c|c|c|c|c|c|c|c|c|}
\hline & \multirow{2}{*}{$\begin{array}{l}\text { AIRNow } \\
\mathrm{PM}_{2.5}\end{array}$} & \multicolumn{4}{|c|}{ CASTNET } & \multirow[b]{2}{*}{ TotS } & \multicolumn{5}{|c|}{ IMPROVE } & \multicolumn{5}{|c|}{ STN } & \multirow[b]{2}{*}{$\mathrm{TC}$} \\
\hline & & $\mathrm{SO}_{4}^{2-}$ & $\mathrm{NH}_{4}^{+}$ & $\mathrm{NO}_{3}^{-}$ & $\mathrm{SO}_{2}$ & & $\mathrm{PM}_{2.5}$ & $\mathrm{SO}_{4}^{2-}$ & $\mathrm{NO}_{3}^{-}$ & OC & $\mathrm{EC}$ & $\mathrm{TC}$ & $\mathrm{PM}_{2.5}$ & $\mathrm{SO}_{4}^{2-}$ & $\mathrm{NH}_{4}^{+}$ & $\mathrm{NO}_{3}^{-}$ & \\
\hline \multicolumn{18}{|c|}{ WRF-CMAQ/CAM } \\
\hline Mean (obs) & 9.15 & 1.06 & 0.34 & 0.37 & 0.18 & 0.61 & 5.61 & 0.77 & 0.22 & 1.83 & 0.28 & 2.11 & 11.37 & 1.68 & 0.79 & 1.26 & 5.32 \\
\hline Mean (model) & 9.19 & 0.81 & 0.23 & 0.07 & 0.27 & 0.65 & 6.45 & 0.88 & 0.11 & 2.77 & 0.59 & 3.36 & 11.53 & 1.61 & 0.42 & 0.24 & 4.94 \\
\hline Number & 1988 & 94 & 94 & 94 & 94 & 94 & 705 & 501 & 501 & 701 & 701 & 701 & 253 & 269 & 269 & 261 & 252 \\
\hline Correlation & 0.18 & 0.70 & 0.32 & 0.13 & 0.34 & 0.48 & 0.38 & 0.37 & 0.24 & 0.61 & 0.52 & 0.60 & 0.14 & 0.50 & 0.35 & 0.02 & 0.33 \\
\hline MB & 0.04 & -0.25 & -0.12 & -0.30 & 0.08 & 0.04 & 0.84 & 0.11 & -0.12 & 0.94 & 0.31 & 1.25 & 0.17 & -0.07 & -0.37 & -1.02 & -0.37 \\
\hline RMSE & 11.63 & 0.40 & 0.18 & 0.47 & 0.23 & 0.36 & 14.51 & 0.57 & 0.46 & 7.11 & 1.60 & 8.63 & 9.69 & 1.04 & 0.97 & 2.25 & 4.10 \\
\hline NMB (\%) & 0.4 & -23.9 & -34.1 & -80.6 & 47.0 & 6.0 & 15.0 & 13.9 & -51.9 & 51.4 & 110.6 & 59.2 & 1.5 & -4.2 & -47.3 & -81.1 & -7.0 \\
\hline NME (\%) & 50.9 & 29.3 & 42.9 & 91.1 & 77.6 & 39.4 & 79.9 & 51.5 & 102.9 & 101.8 & 153.2 & 107.3 & 51.5 & 42.9 & 61.7 & 89.1 & 48.5 \\
\hline NMBF (\%) & 0.4 & -31.4 & -51.7 & -415.3 & 47.0 & 6.0 & 15.0 & 13.9 & -107.7 & 51.4 & 110.6 & 59.2 & 1.5 & -4.4 & -89.6 & -427.9 & -7.6 \\
\hline NMEF (\%) & 50.9 & 38.5 & 65.1 & 469.2 & 77.6 & 39.4 & 79.9 & 51.5 & 213.8 & 101.8 & 153.2 & 107.3 & 51.5 & 44.8 & 117.0 & 470.3 & 52.2 \\
\hline \multicolumn{18}{|c|}{ WRF-CMAQ/RRTMG } \\
\hline Mean (obs) & 9.15 & 1.06 & 0.34 & 0.37 & 0.18 & 0.61 & 5.61 & 0.77 & 0.22 & 1.83 & 0.28 & 2.11 & 11.37 & 1.68 & 0.79 & 1.26 & 5.32 \\
\hline Mean (model) & 8.67 & 0.80 & 0.22 & 0.07 & 0.27 & 0.65 & 6.01 & 0.86 & 0.09 & 2.54 & 0.54 & 3.08 & 10.77 & 1.52 & 0.37 & 0.20 & 4.65 \\
\hline Number & 1988 & 94 & 94 & 94 & 94 & 94 & 705 & 501 & 501 & 701 & 701 & 701 & 253 & 269 & 269 & 261 & 252 \\
\hline Correlation & 0.18 & 0.70 & 0.33 & 0.16 & 0.36 & 0.50 & 0.38 & 0.38 & 0.25 & 0.61 & 0.52 & 0.60 & 0.13 & 0.48 & 0.30 & -0.01 & 0.36 \\
\hline $\mathrm{MB}$ & -0.48 & -0.26 & -0.12 & -0.30 & 0.09 & 0.04 & 0.40 & 0.09 & -0.14 & 0.71 & 0.26 & 0.97 & -0.60 & -0.16 & -0.42 & -1.06 & -0.66 \\
\hline RMSE & 10.06 & 0.41 & 0.19 & 0.47 & 0.22 & 0.35 & 13.20 & 0.55 & 0.39 & 6.38 & 1.45 & 7.76 & 8.26 & 1.04 & 1.00 & 2.27 & 3.41 \\
\hline NMB (\%) & -5.2 & -24.5 & -35.9 & -82.3 & 47.5 & 5.9 & 7.1 & 11.6 & -61.1 & 38.6 & 94.5 & 46.0 & -5.3 & -9.5 & -53.6 & -84.1 & -12.5 \\
\hline NME (\%) & 48.7 & 29.6 & 43.6 & 90.2 & 77.2 & 39.0 & 74.7 & 49.8 & 97.4 & 92.8 & 140.0 & 97.4 & 48.8 & 41.2 & 63.9 & 90.4 & 45.5 \\
\hline NMBF (\%) & -5.5 & -32.5 & -56.1 & -464.6 & 47.5 & 5.9 & 7.1 & 11.6 & -157.0 & 38.6 & 94.5 & 46.0 & -5.6 & -10.5 & -115.5 & -528.5 & -14.3 \\
\hline NMEF (\%) & 51.4 & 39.2 & 68.0 & 509.4 & 77.2 & 39.0 & 74.7 & 49.8 & 250.3 & 92.8 & 140.0 & 97.4 & 51.5 & 45.6 & 137.8 & 567.9 & 52.0 \\
\hline
\end{tabular}

* The unit of the mean, $\mathrm{MB}$, and RMSE is $\mu \mathrm{g} \mathrm{m}^{-3}$, for $\mathrm{SO}_{2}$ it is ppb, and TotS is the total sulfur $\left(\mathrm{SO}_{4}^{2-}+\mathrm{SO}_{2}\right)$ concentrations $\left(\mu \mathrm{g} \mathrm{m}^{-3}\right)$.

module of CMAQ, the aerosol distribution is modeled as a superposition of three lognormal modes that correspond nominally to the ultrafine (diameter $\left(D_{\mathrm{p}}\right)<0.1 \mu \mathrm{m}$ ), fine $\left(0.1 \mu \mathrm{m}<D_{\mathrm{p}}<2.5 \mu \mathrm{m}\right)$, and coarse $\left(D_{\mathrm{p}}>2.5 \mu \mathrm{m}\right)$ particle size ranges. Each lognormal mode is characterized by total number concentration, geometric mean diameter, and geometric standard deviation. Table 2 lists the aerosol species for each mode in the latest AERO6 aerosol module of CMAQ version 5.0 that is used in this study. As summarized by Foley et al. (2010), there are three main increments for the new aerosol module, including improved treatment of secondary organic aerosol (SOA), a new heterogeneous $\mathrm{N}_{2} \mathrm{O}_{5}$ hydrolysis parameterization and a new treatment of gas-to-particle mass transfer for coarse particles with the 


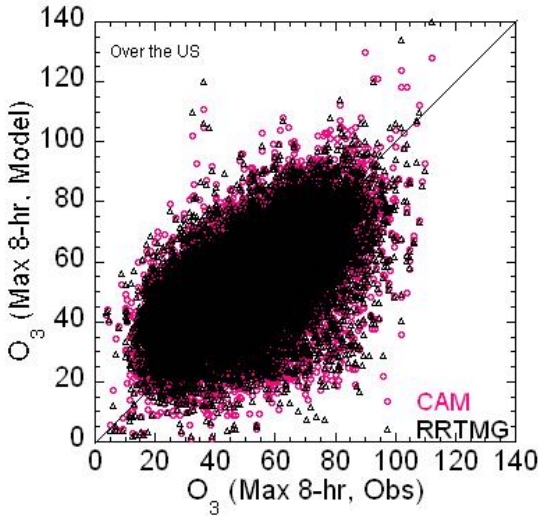

(a)

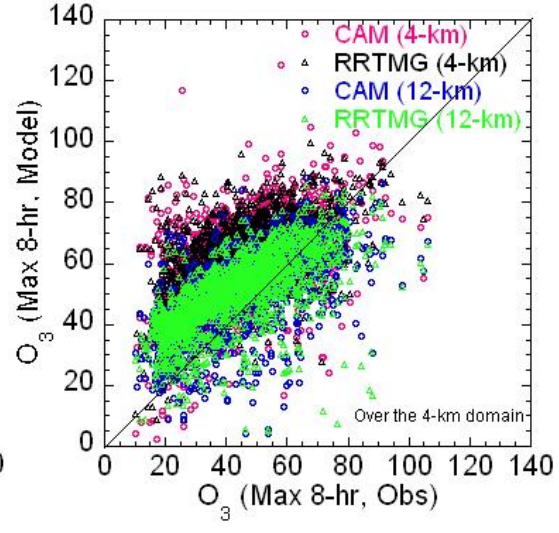

(b)

Figure 4. Scatter plots of the modeled CAM (WRF-CMAQ/CAM), RRTMG (WRF-CMAQ/RRTMG) and observed $8 \mathrm{~h} \mathrm{O}_{3}$ concentrations (ppbv) at the AIRNow monitoring sites (a) over the continental US (12 km resolution model grid), and (b) the results over eastern Texas from the simulations on the $4 \mathrm{~km}$ and $12 \mathrm{~km}$ resolution model grids for August of 2006.

update of the in-line treatment of sea-salt emissions. In the previous aerosol module, SOA was formed by absorptive partitioning of condensable oxidation products of monoterpenes (ATRP1, ATRP2), long alkanes $(\sim 8$ carbon atoms) (AALK), low-yield aromatic products (based on m-xylene data) (AXYL1, AXYL2), and high-yield aromatics (based on toluene data) (ATOL1, ATOL2). The updates to the representation of SOA include several recently identified SOA formation pathways from isoprene (AISO1, AISO2), benzene (ABNZ1, ABNZ2), sesquiterpenes (ASQT), in-cloud oxidation of glyoxal and methylglyoxal (AORGC), particlephase oligomerization (aged SOA, AOLGA, and AOLGB), acid enhancement of isoprene SOA (AISO3), and $\mathrm{NO}_{\mathrm{x}}-$ dependent SOA yields from aromatic compounds (ATOL3, AXYL3, ABNZ3) (see Table 2, Carlton et al., 2010). Note that ATOL3, AXYL3, ABNZ3, AISO3, AOLGA, AOLGB, and AORGC are nonvolatile SOA. Primary organic aerosols (POA) are separated into primary organic carbon (APOC) and primary noncarbon organic mass (APNCOM) (POA $=\mathrm{APOC}+\mathrm{APNCOM})$, and soil is calculated as SOIL $=2.20 \mathrm{Al}+2.49 \mathrm{Si}+1.63 \mathrm{Ca}+2.42 \mathrm{Fe}+1.94 \mathrm{Ti}(\mathrm{Simon}$ et al., 2011). Note that the "OTHR" species in Table 2 refers to the unspecified anthropogenic mass that comes from the emissions inventory in $\mathrm{PM}_{2.5}$, i.e., $\left[\mathrm{PM}_{2.5}\right]=\left[\mathrm{SO}_{4}^{2-}\right]+$ $\left[\mathrm{NH}_{4}^{+}\right]+\left[\mathrm{NO}_{3}^{-}\right]+[\mathrm{OM}]+[\mathrm{EC}]+[\mathrm{SOIL}]+[\mathrm{OTHR}]$. The model results for $\mathrm{PM}_{2.5}$ concentrations are obtained by summing aerosol species concentrations over the first two modes. The chemical boundary conditions (BCs) for the CMAQ model simulation over the CONUS were provided by an annual 2006 GEOS-Chem (Bey et al., 2001) simulation. A detailed description of mapping GEOS-Chem species to CMAQ species for LBCs is presented by Henderson et al. (2014).

\subsection{Aerosol-cloud-radiation interaction: indirect effects}

A flow diagram for calculation of AIE in the two-way coupled WRF-CMAQ model is shown in Fig. 3.

\subsubsection{First and second indirect aerosol forcing}

To estimate the first and second indirect aerosol forcing, the cloud droplet number concentrations are diagnosed from the activation of CMAQ-predicted aerosol particles using a aerosol activation scheme for multiple externally mixed lognormal modes, with each mode composed of uniform internal mixtures of soluble and insoluble material developed by Abdul-Razzak and Ghan $(2002,2000)$. The detailed description of the aerosol activation scheme is given by AbdulRazzak and Ghan (2002, 2000). Here, a brief summary relevant to the present study is presented. The aerosol number concentration of a multimode lognormal distribution can be expressed as

$$
\frac{\mathrm{d} n}{\mathrm{~d} r}=\sum_{i=1}^{I} \frac{N_{i}}{\sqrt{2 \pi} \ln \sigma_{i}} \exp \left(-\frac{1}{2} \frac{\ln ^{2}\left(\frac{r}{r_{\mathrm{g}, i}}\right)}{\ln ^{2}\left(\sigma_{i}\right)}\right),
$$

where $N_{i}$ is the total number concentrations, $r_{\mathrm{g}, i}$ is the geometric mean dry radius, and $\sigma_{i}$ is the geometric standard deviation for each aerosol mode $i, i=1,2, \ldots \mathrm{I}$. The smallest activation dry radius $\left(r_{\mathrm{cut}, i}\right)$ for each mode is (Abdul-Razzak and Ghan, 2002, 2000)

$r_{\mathrm{cut}, i}=r_{\mathrm{g}, i}\left(\frac{S_{\mathrm{m}, i}}{S_{\max }}\right)^{\frac{2}{3}}$

where the critical supersaturation $\left(S_{\mathrm{m}, i}\right)$ for activating particles and the ambient maximum supersaturation $\left(S_{\max }\right)$ are given by (Abdul-Razzak and Ghan, 2000, 2002; 
Table 6. Comparison of observation and models (WRF-CMAQ/CAM and WRF-CMAQ/RRTMG) for PM 2.5 and its components for each network over the eastern Texas domain from the simulations of the 4 and $12 \mathrm{~km}$ resolution model grids for August of $2006^{*}$.

\begin{tabular}{|c|c|c|c|c|c|c|c|c|c|c|c|c|}
\hline & $\begin{array}{r}\text { AIRNow } \\
\mathrm{PM}_{2.5} \\
\end{array}$ & $\mathrm{PM}_{2.5}$ & $\mathrm{SO}_{4}^{2-}$ & $\begin{array}{c}\mathrm{STN} \\
\mathrm{NH}_{4}^{+} \\
\end{array}$ & $\mathrm{NO}_{3}^{-}$ & $\mathrm{TC}$ & $\begin{array}{r}\text { AIRNow } \\
\mathrm{PM}_{2.5} \\
\end{array}$ & $\mathrm{PM}_{2.5}$ & $\mathrm{SO}_{4}^{2-}$ & $\begin{array}{c}\mathrm{STN} \\
\mathrm{NH}_{4}^{+} \\
\end{array}$ & $\mathrm{NO}_{3}^{-}$ & $\mathrm{TC}$ \\
\hline & \multicolumn{6}{|c|}{ WRF-CMAQ/CAM-4 km } & \multicolumn{6}{|c|}{ WRF-CMAQ/CAM-12 km } \\
\hline Mean (obs) & 12.45 & 12.55 & 3.32 & 0.41 & 1.01 & 2.71 & 12.45 & 12.55 & 3.32 & 0.41 & 1.01 & 2.71 \\
\hline Mean (model) & 20.59 & 24.14 & 3.54 & 0.32 & 0.85 & 6.57 & 17.06 & 17.95 & 1.91 & 0.17 & 0.44 & 5.50 \\
\hline Number & 245 & 17 & 46 & 19 & 46 & 50 & 245 & 17 & 46 & 19 & 46 & 50 \\
\hline Correlation & 0.37 & -0.49 & 0.33 & 0.41 & 0.44 & 0.19 & 0.38 & 0.15 & 0.46 & 0.70 & 0.59 & 0.24 \\
\hline $\mathrm{MB}$ & 8.14 & 11.59 & 0.22 & -0.09 & -0.17 & 3.86 & 4.61 & 5.41 & -1.42 & -0.23 & -0.58 & 2.79 \\
\hline RMSE & 18.45 & 17.00 & 1.92 & 0.26 & 0.60 & 5.36 & 14.15 & 9.59 & 1.94 & 0.27 & 0.72 & 5.00 \\
\hline NMB (\%) & 65.4 & 92.4 & 6.7 & -22.2 & -16.4 & 142.7 & 37.1 & 43.1 & -42.6 & -57.3 & -56.9 & 103.1 \\
\hline NME (\%) & 85.1 & 112.2 & 47.7 & 53.7 & 46.0 & 149.4 & 65.2 & 60.3 & 48.6 & 60.7 & 60.4 & 121.2 \\
\hline NMBF (\%) & 65.4 & 92.4 & 6.7 & -28.6 & -19.7 & 142.7 & 37.1 & 43.1 & -74.3 & -134.0 & -131.8 & 103.1 \\
\hline \multirow[t]{2}{*}{ NMEF $(\%)$} & 85.1 & 112.2 & 47.7 & 69.1 & 55.1 & 149.4 & 65.2 & 60.3 & 84.7 & 142.0 & 139.9 & 121.2 \\
\hline & \multicolumn{6}{|c|}{ WRF-CMAQ/RRTMG-4 km } & \multicolumn{6}{|c|}{ WRF-CMAQ/RRTMG-12 km } \\
\hline Mean (obs) & 12.45 & 12.55 & 3.32 & 0.41 & 1.01 & 2.71 & 12.45 & 12.55 & 3.32 & 0.41 & 1.01 & 2.71 \\
\hline Mean (model) & 17.06 & 19.25 & 3.07 & 0.16 & 0.67 & 5.12 & 12.70 & 14.15 & 1.73 & 0.06 & 0.38 & 4.58 \\
\hline Number & 245 & 17 & 46 & 19 & 46 & 50 & 245 & 17 & 46 & 19 & 46 & 50 \\
\hline Correlation & 0.38 & -0.44 & 0.40 & 0.60 & 0.57 & 0.12 & 0.33 & 0.10 & 0.53 & 0.70 & 0.64 & 0.26 \\
\hline MB & 4.61 & 6.71 & -0.25 & -0.25 & -0.34 & 2.41 & 0.25 & 1.60 & -1.60 & -0.35 & -0.64 & 1.88 \\
\hline RMSE & 14.15 & 12.42 & 1.70 & 0.28 & 0.58 & 3.89 & 11.40 & 5.94 & 1.99 & 0.37 & 0.76 & 4.01 \\
\hline NMB (\%) & 37.06 & 53.4 & -7.6 & -61.1 & -33.8 & 89.1 & 2.0 & 12.7 & -48.0 & -84.3 & -62.9 & 69.3 \\
\hline NME (\%) & 65.24 & 81.7 & 42.5 & 62.0 & 44.8 & 101.8 & 61.7 & 40.9 & 49.8 & 84.3 & 62.9 & 94.1 \\
\hline $\operatorname{NMBF}(\%)$ & 37.06 & 53.4 & -8.3 & -157.0 & -51.0 & 89.1 & 2.0 & 12.7 & -92.4 & -538.6 & -169.7 & 69.3 \\
\hline NMEF (\%) & 65.24 & 81.7 & 46.0 & 159.2 & 67.7 & 101.8 & 61.7 & 40.9 & 95.9 & 538.6 & 169.7 & 94.1 \\
\hline
\end{tabular}

* The unit of the mean, MB, and RMSE is $\mu \mathrm{g} \mathrm{m}^{-3}$.

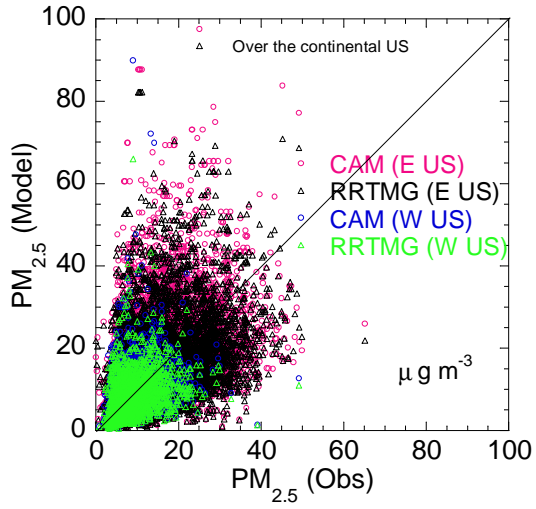

(a)

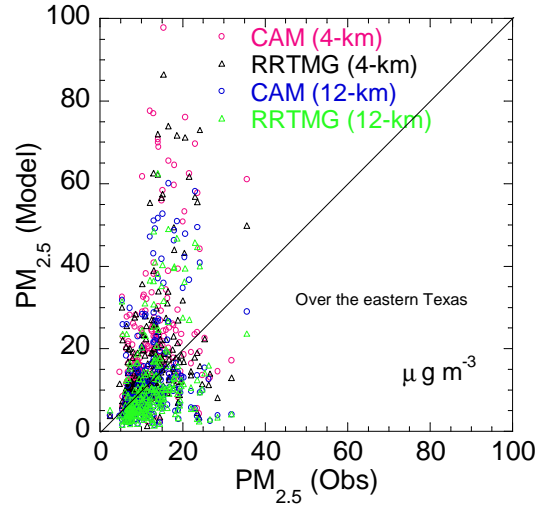

(b)

Figure 5. Scatter plots of the modeled CAM (WRF-CMAQ/CAM), RRTMG (WRF-CMAQ/RRTMG) and observed daily PM 2.5 concentrations at the AIRNow monitoring sites (a) over the continental US (12 km resolution model grid) and (b) over eastern Texas from the simulations on the $4 \mathrm{~km}$ and $12 \mathrm{~km}$ resolution model grids.

Abdul-Razzak et al., 1998)

$S_{\mathrm{m}, i}=\frac{2}{\sqrt{\overline{B_{i}}}}\left(\frac{A}{3 r_{\mathrm{g}, i}}\right)^{\frac{3}{2}}$

$S_{\max }=\frac{1}{\left\{\sum \frac{1}{S_{\mathrm{m}, i}^{2}}\left[0.5 \exp \left(2.5 \ln ^{2} \sigma_{i}\right)\left(\frac{\xi}{\eta_{i}}\right)^{\frac{3}{2}}+\left(1+0.25 \ln \sigma_{i}\right)\left(\frac{S_{\mathrm{m}, i}^{2}}{\eta_{i}+3 \xi}\right)^{\frac{3}{4}}\right]\right\}^{\frac{1}{2}}}$, where

$$
\begin{aligned}
\xi & =\frac{2 A}{3}\left(\frac{\alpha V}{G}\right)^{\frac{1}{2}} \\
\eta_{i} & =\frac{(\alpha V / G)^{\frac{3}{2}}}{2 \pi \rho_{\mathrm{w}} \gamma N_{i}} \\
A & =\frac{2 \sigma_{\mathrm{w}} M_{\mathrm{w}}}{\rho_{\mathrm{W}} R T} .
\end{aligned}
$$


Table 7a. The same as Table 5a, but for September of 2006 for EUS.

\begin{tabular}{|c|c|c|c|c|c|c|c|c|c|c|c|c|c|c|c|c|c|}
\hline & \multirow{2}{*}{$\begin{array}{r}\text { AIRNow } \\
\mathrm{PM}_{2.5}\end{array}$} & \multicolumn{5}{|c|}{ CASTNET } & \multicolumn{6}{|c|}{ IMPROVE } & \multicolumn{5}{|c|}{ STN } \\
\hline & & $\mathrm{SO}_{4}^{2-}$ & $\mathrm{NH}_{4}^{+}$ & $\mathrm{NO}_{3}^{-}$ & $\mathrm{SO}_{2}$ & TotS & $\mathrm{PM}_{2.5}$ & $\mathrm{SO}_{4}^{2-}$ & $\mathrm{NO}_{3}^{-}$ & OC & $\mathrm{EC}$ & $\mathrm{TC}$ & $\mathrm{PM}_{2.5}$ & $\mathrm{SO}_{4}^{2-}$ & $\mathrm{NH}_{4}^{+}$ & $\mathrm{NO}_{3}^{-}$ & $\mathrm{TC}$ \\
\hline \multicolumn{18}{|c|}{ WRF-CMAQ/CAM } \\
\hline Mean (obs) & 11.84 & 4.39 & 0.36 & 1.35 & 0.72 & 2.49 & 8.01 & 3.07 & 0.29 & 1.27 & 0.37 & 1.64 & 12.04 & 3.83 & 1.35 & 0.59 & 4.04 \\
\hline Mean (model) & 15.44 & 3.96 & 0.54 & 1.20 & 1.66 & 3.69 & 8.89 & 3.66 & 0.52 & 1.68 & 0.55 & 2.23 & 16.57 & 4.60 & 1.69 & 1.11 & 4.56 \\
\hline Number & 7182 & 170 & 170 & 170 & 170 & 170 & 515 & 351 & 351 & 508 & 507 & 508 & 806 & 842 & 842 & 807 & 858 \\
\hline Correlation & 0.48 & 0.94 & 0.35 & 0.86 & 0.79 & 0.87 & 0.49 & 0.64 & 0.50 & 0.48 & 0.65 & 0.52 & 0.50 & 0.69 & 0.64 & 0.53 & 0.48 \\
\hline MB & 3.60 & -0.43 & 0.18 & -0.15 & 0.94 & 1.20 & 0.88 & 0.60 & 0.23 & 0.41 & 0.18 & 0.59 & 4.53 & 0.77 & 0.34 & 0.53 & 0.52 \\
\hline RMSE & 10.42 & 1.03 & 0.61 & 0.45 & 1.18 & 1.61 & 8.36 & 2.78 & 0.92 & 1.86 & 1.05 & 2.81 & 11.33 & 2.73 & 1.13 & 1.30 & 3.37 \\
\hline NMB (\%) & 30.42 & -9.82 & 50.33 & -11.37 & 130.87 & 48.26 & 11.00 & 19.41 & 80.65 & 32.22 & 49.46 & 36.07 & 37.63 & 19.99 & 25.10 & 89.51 & 12.96 \\
\hline NME (\%) & 56.18 & 16.29 & 109.08 & 24.14 & 132.06 & 51.09 & 53.56 & 54.66 & 151.43 & 71.91 & 90.54 & 74.33 & 60.07 & 48.15 & 57.36 & 129.95 & 55.23 \\
\hline $\operatorname{NMBF}(\%)$ & 30.42 & -10.89 & 50.33 & -12.83 & 130.87 & 48.26 & 11.00 & 19.41 & 80.65 & 32.22 & 49.46 & 36.07 & 37.63 & 19.99 & 25.10 & 89.51 & 12.96 \\
\hline NMEF (\%) & 56.18 & 18.07 & 109.08 & 27.23 & 132.06 & 51.09 & 53.56 & 54.66 & 151.43 & 71.91 & 90.54 & 74.33 & 60.07 & 48.15 & 57.36 & 129.95 & 55.23 \\
\hline \multicolumn{18}{|c|}{ WRF-CMAQ/RRTMG } \\
\hline Mean (obs) & 11.84 & 4.39 & 0.36 & 1.35 & 0.72 & 2.49 & 8.01 & 3.07 & 0.29 & 1.27 & 0.37 & 1.64 & 12.04 & 3.83 & 1.35 & 0.59 & 4.04 \\
\hline Mean (model) & 15.07 & 3.91 & 0.53 & 1.18 & 1.68 & 3.70 & 8.84 & 3.54 & 0.54 & 1.72 & 0.56 & 2.28 & 16.31 & 4.40 & 1.62 & 1.08 & 4.57 \\
\hline Number & 7182 & 170 & 170 & 170 & 170 & 170 & 515 & 351 & 351 & 508 & 507 & 508 & 806 & 842 & 842 & 807 & 858 \\
\hline Correlation & 0.49 & 0.93 & 0.32 & 0.87 & 0.79 & 0.87 & 0.53 & 0.69 & 0.42 & 0.50 & 0.65 & 0.53 & 0.53 & 0.72 & 0.68 & 0.56 & 0.49 \\
\hline MB & 3.23 & -0.48 & 0.17 & -0.17 & 0.96 & 1.21 & 0.83 & 0.47 & 0.25 & 0.45 & 0.19 & 0.64 & 4.27 & 0.57 & $\begin{array}{l}0.00 \\
0.27\end{array}$ & 0.49 & 0.53 \\
\hline RMSE & 9.83 & 1.13 & 0.59 & 0.44 & 1.18 & 1.60 & 7.44 & 2.37 & 0.97 & 1.79 & 1.00 & 2.70 & 10.56 & 2.45 & 1.02 & 1.28 & 3.22 \\
\hline NMB $(\%)$ & 27.29 & -10.91 & 48.26 & -12.27 & 132.81 & 48.43 & 10.35 & 15.35 & 86.29 & 35.25 & 51.55 & 38.90 & 35.46 & 14.81 & 20.01 & 83.97 & 13.04 \\
\hline NME (\%) & 54.20 & 18.14 & 108.30 & 23.97 & 134.56 & 50.77 & 52.74 & 51.71 & 159.45 & 70.65 & 89.26 & 72.93 & 57.54 & 45.95 & 54.00 & 126.77 & 53.23 \\
\hline $\operatorname{NMBF}(\%)$ & 27.29 & -12.25 & 48.26 & -13.99 & 132.81 & 48.43 & 10.35 & 15.35 & 86.29 & 35.25 & 51.55 & 38.90 & 35.46 & 14.81 & 20.01 & 83.97 & 13.04 \\
\hline NMEF (\%) & 54.20 & 20.36 & 108.30 & 27.32 & 134.56 & 50.77 & 52.74 & 51.71 & 159.45 & 70.65 & 89.26 & 72.93 & 57.54 & 45.95 & 54.00 & 126.77 & 53.23 \\
\hline
\end{tabular}

Table 7b. The same as Table 5b, but for September of 2006 for WUS.

\begin{tabular}{|c|c|c|c|c|c|c|c|c|c|c|c|c|c|c|c|c|c|}
\hline & \multirow{2}{*}{$\begin{array}{r}\text { AIRNow } \\
\mathrm{PM}_{2.5}\end{array}$} & \multicolumn{5}{|c|}{ CASTNET } & \multicolumn{6}{|c|}{ IMPROVE } & \multicolumn{5}{|c|}{ STN } \\
\hline & & $\mathrm{SO}_{4}^{2-}$ & $\mathrm{NH}_{4}^{+}$ & $\mathrm{NO}_{3}^{-}$ & $\mathrm{SO}_{2}$ & TotS & $\mathrm{PM}_{2.5}$ & $\mathrm{SO}_{4}^{2-}$ & $\mathrm{NO}_{3}^{-}$ & OC & $\mathrm{EC}$ & $\mathrm{TC}$ & $\mathrm{PM}_{2.5}$ & $\mathrm{SO}_{4}^{2-}$ & $\mathrm{NH}_{4}^{+}$ & $\mathrm{NO}_{3}^{-}$ & $\mathrm{TC}$ \\
\hline \multicolumn{18}{|c|}{ WRF-CMAQ/CAM } \\
\hline Mean (obs) & 9.80 & 0.81 & 0.34 & 0.29 & 0.14 & 0.47 & 5.17 & 0.64 & 0.22 & 1.68 & 0.28 & 1.95 & 12.03 & 1.43 & 0.75 & 1.33 & 5.92 \\
\hline Mean (model) & 16.17 & 0.72 & 0.09 & 0.19 & 0.28 & 0.63 & 6.43 & 0.75 & 0.16 & 2.64 & 0.54 & 3.17 & 22.12 & 1.59 & 0.70 & 1.42 & 11.02 \\
\hline Number & 1992 & 75 & 75 & 75 & 75 & 75 & 712 & 562 & 562 & 703 & 710 & 706 & 251 & 252 & 252 & 245 & 250 \\
\hline Correlation & 0.48 & 0.80 & 0.07 & 0.50 & 0.43 & 0.58 & 0.66 & 0.59 & 0.28 & 0.60 & 0.34 & 0.57 & 0.24 & 0.53 & 0.29 & 0.19 & 0.39 \\
\hline MB & 6.37 & -0.09 & -0.25 & -0.10 & 0.13 & 0.16 & 1.26 & 0.11 & -0.06 & 0.96 & 0.26 & 1.22 & 10.10 & 0.16 & -0.05 & 0.09 & 5.11 \\
\hline RMSE & 15.19 & 0.28 & 0.47 & 0.16 & 0.22 & 0.32 & 9.53 & 0.48 & 0.51 & 4.81 & 1.22 & 5.86 & 27.76 & 1.06 & 1.25 & 3.53 & 14.80 \\
\hline NME (\%) & 89.46 & 22.74 & 85.92 & 44.67 & 107.42 & 46.94 & 71.31 & 48.55 & 103.08 & 100.50 & 141.18 & 105.74 & 108.48 & 48.17 & 79.37 & 108.25 & 112.65 \\
\hline $\operatorname{NMBF}(\%)$ & 65.01 & -12.74 & -269.13 & -49.39 & 95.02 & 34.45 & 24.29 & 17.46 & -38.06 & 57.48 & 93.52 & 62.71 & 83.97 & 11.25 & -7.27 & 6.77 & 86.34 \\
\hline $\operatorname{NMEF}(\%)$ & 89.46 & 25.64 & 317.16 & 66.73 & 107.42 & 46.94 & 71.31 & 48.55 & 142.31 & 100.50 & 141.18 & 105.74 & 108.48 & 48.17 & 85.14 & 108.25 & 112.65 \\
\hline \multicolumn{18}{|c|}{ WRF-CMAQ/RRTMG } \\
\hline Mean (obs) & 9.80 & 0.81 & 0.34 & 0.29 & 0.14 & 0.47 & 5.17 & 0.64 & 0.22 & 1.68 & 0.28 & 1.95 & 12.03 & 1.43 & 0.75 & 1.33 & 5.92 \\
\hline Mean (model) & 15.16 & 0.71 & 0.08 & 0.19 & 0.28 & 0.63 & 5.94 & 0.74 & 0.13 & 2.39 & 0.50 & 2.88 & 20.37 & 1.47 & 0.60 & 1.18 & 10.21 \\
\hline Number & 1992 & 75 & 75 & 75 & 75 & 75 & 712 & 562 & 562 & 703 & 710 & 706 & 251 & 252 & 252 & 245 & 250 \\
\hline Correlation & 0.47 & 0.80 & 0.13 & 0.52 & 0.43 & 0.58 & 0.64 & 0.56 & 0.32 & 0.60 & 0.33 & 0.57 & 0.25 & 0.51 & 0.25 & 0.18 & 0.40 \\
\hline $\mathrm{MB}$ & 5.36 & -0.10 & -0.26 & -0.10 & 0.14 & 0.16 & 0.77 & 0.10 & -0.09 & 0.72 & 0.22 & 0.94 & 8.35 & 0.04 & -0.16 & -0.15 & 4.30 \\
\hline $\operatorname{NMB}(\%)$ & 54.74 & -12.03 & -75.47 & -34.10 & 95.21 & 34.11 & 14.89 & 15.82 & -39.94 & 42.83 & 78.81 & 48.05 & 69.40 & 2.69 & -20.73 & -11.13 & 72.66 \\
\hline NME (\%) & 81.22 & 22.66 & 84.16 & 44.33 & 107.42 & 46.88 & 64.32 & 47.73 & 94.15 & 87.99 & 127.87 & 93.06 & 96.46 & 45.98 & 76.83 & 102.99 & 100.57 \\
\hline NMBF (\%) & 54.74 & -13.68 & -307.65 & -51.76 & 95.21 & 34.11 & 14.89 & 15.82 & -66.51 & 42.83 & 78.81 & 48.05 & 69.40 & 2.69 & -26.15 & -12.53 & 72.66 \\
\hline NMEF (\%) & 81.22 & 25.76 & 343.09 & 67.27 & 107.42 & 46.88 & 64.32 & 47.73 & 156.77 & 87.99 & 127.87 & 93.06 & 96.46 & 45.98 & 96.92 & 115.89 & 100.57 \\
\hline
\end{tabular}

Here, $A$ is the coefficient of the curvature effect (Kelvin term) in the Köhler equation, $V$ is the updraft velocity, the growth coefficient $(G)$ represents the diffusion of heat and moisture to the particles (gas kinetic effects), $\rho_{\mathrm{w}}$ is the water density, $M_{\mathrm{w}}$ is the molecular weight of water, $R$ is the molar gas constant, $T$ is the temperature, $\sigma_{\mathrm{w}}$ is the surface tension of water, and $\alpha$ and $\gamma$ are size-invariant coefficients in the supersaturation balance equation (Leaitch et al., 1986; AbdulRazzak et al., 1998). The hygroscopicity parameter $\left(B_{j}\right)$ (solute effect, Raoult term) in the Köhler equation for component $j$ can be expressed as (Pruppacher and Klett, 1997; Abdul-Razzak et al., 1998)
$B_{j}=\frac{M_{\mathrm{w}} v_{j} \varphi_{j} \varepsilon_{j} / M_{a, j}}{\rho_{\mathrm{w}} / \rho_{a, j}}$,

where $v_{j}, \varphi_{j}, \varepsilon_{j}, M_{a, j}$ and $\rho_{a, j}$ are the number of ions the salt dissociates into (the von't Hoff factor for solutes in solution), the osmotic coefficient, the mass fraction of soluble material ( 1 for water-soluble material and 0 for insoluble material), and the molecular weight and density for component $j$, respectively. The volume mean hygroscopicity parameter $\left(\overline{B_{i}}\right)$ for aerosol mode $i$ can be calculated as follows (Hanel, 1976; Pruppacher and Klett, 1997; Abdul-Razzak et al., 1998): 
Table 8. The same as Table 6, but for September of 2006.

\begin{tabular}{|c|c|c|c|c|c|c|c|c|c|c|c|c|}
\hline & $\begin{array}{r}\text { AIRNow } \\
\mathrm{PM}_{2.5}\end{array}$ & $\mathrm{PM}_{2.5}$ & $\mathrm{SO}_{4}^{2-}$ & $\begin{array}{l}\mathrm{STN} \\
\mathrm{NH}_{4}^{+}\end{array}$ & $\mathrm{NO}_{3}^{-}$ & $\mathrm{TC}$ & $\begin{array}{r}\text { AIRNow } \\
\mathrm{PM}_{2.5}\end{array}$ & $\mathrm{PM}_{2.5}$ & $\mathrm{SO}_{4}^{2-}$ & $\begin{array}{l}\mathrm{STN} \\
\mathrm{NH}_{4}^{+}\end{array}$ & $\mathrm{NO}_{3}^{-}$ & $\mathrm{TC}$ \\
\hline & & \multicolumn{5}{|c|}{ WRF-CMAQ/CAM-4 km } & & \multicolumn{5}{|c|}{ WRF-CMAQ/CAM-12 km } \\
\hline Mean (obs) & 12.65 & 15.05 & 4.31 & 1.68 & 0.50 & 4.41 & 12.65 & 15.05 & 4.31 & 1.68 & 0.50 & 4.41 \\
\hline Mean (model) & 22.73 & 27.03 & 4.47 & 1.28 & 0.37 & 8.66 & 21.45 & 27.64 & 4.38 & 1.38 & 0.87 & 8.38 \\
\hline Number & 264 & 19 & 48 & 48 & 19 & 52 & 264 & 19 & 48 & 48 & 19 & 52 \\
\hline Correlation & 0.40 & 0.71 & 0.73 & 0.65 & 0.12 & 0.53 & 0.33 & 0.74 & 0.75 & 0.63 & 0.08 & 0.74 \\
\hline $\mathrm{MB}$ & 10.08 & 11.98 & 0.16 & -0.40 & -0.13 & 4.25 & 8.80 & 12.59 & 0.07 & -0.29 & 0.38 & 3.97 \\
\hline RMSE & 19.38 & 15.18 & 1.94 & 1.13 & 0.47 & 5.79 & 20.39 & 14.40 & 1.81 & 1.13 & 1.20 & 4.70 \\
\hline $\mathrm{NMB}(\%)$ & 79.66 & 79.60 & 3.79 & -23.84 & -26.29 & 96.31 & 69.56 & 83.63 & 1.66 & -17.46 & 75.44 & 89.88 \\
\hline NME (\%) & 95.57 & 81.23 & 32.97 & 41.37 & 64.19 & 100.46 & 86.95 & 83.63 & 33.79 & 47.61 & 135.37 & 91.53 \\
\hline $\operatorname{NMBF}(\%)$ & 79.66 & 79.60 & 3.79 & -31.30 & -35.66 & 96.31 & 69.56 & 83.63 & 1.66 & -21.16 & 75.44 & 89.88 \\
\hline \multirow[t]{2}{*}{ NMEF (\%) } & 95.57 & 81.23 & 32.97 & 54.32 & 87.08 & 100.46 & 86.95 & 83.63 & 33.79 & 57.69 & 135.37 & 91.53 \\
\hline & & \multicolumn{5}{|c|}{ WRF-CMAQ/RRTMG-4 km } & & \multicolumn{5}{|c|}{ WRF-CMAQ/RRTMG-12 km } \\
\hline Mean (obs) & 12.65 & 15.05 & 4.31 & 1.68 & 0.50 & 4.41 & 12.65 & 15.05 & 4.31 & 1.68 & 0.50 & 4.41 \\
\hline Mean (model) & 20.68 & 23.45 & 4.07 & 1.16 & 0.37 & 7.21 & 20.53 & 25.95 & 4.15 & 1.27 & 0.77 & 7.85 \\
\hline Number & 264 & 19 & 48 & 48 & 19 & 52 & 264 & 19 & 48 & 48 & 19 & 52 \\
\hline Correlation & 0.42 & 0.78 & 0.76 & 0.67 & 0.18 & 0.52 & 0.32 & 0.60 & 0.75 & 0.57 & -0.03 & 0.70 \\
\hline $\mathrm{MB}$ & 8.03 & 8.39 & -0.24 & -0.52 & -0.13 & 2.80 & 7.88 & 10.90 & -0.16 & -0.40 & 0.28 & 3.43 \\
\hline RMSE & 16.84 & 10.42 & 1.73 & 1.17 & 0.42 & 4.17 & 19.25 & 13.83 & 1.79 & 1.22 & 1.60 & 4.20 \\
\hline NMB (\%) & 63.48 & 55.76 & -5.63 & -30.91 & -25.44 & 63.46 & 62.31 & 72.39 & -3.76 & -24.05 & 55.25 & 77.81 \\
\hline NME (\%) & 81.45 & 56.35 & 29.46 & 40.54 & 62.80 & 70.61 & 81.27 & 72.39 & 32.49 & 46.83 & 147.27 & 80.14 \\
\hline $\operatorname{NMBF}(\%)$ & 63.48 & 55.76 & -5.97 & -44.73 & -34.13 & 63.46 & 62.31 & 72.39 & -3.91 & -31.67 & 55.25 & 77.81 \\
\hline $\operatorname{NMEF}(\%)$ & 81.45 & 56.35 & 31.22 & 58.68 & 84.23 & 70.61 & 81.27 & 72.39 & 33.76 & 61.66 & 147.27 & 80.14 \\
\hline
\end{tabular}

$$
\overline{B_{i}}=\frac{\sum_{j=1}^{J}\left(B_{i, j} q_{i, j} / \rho_{a, i, j}\right)}{\sum_{j=1}^{J}\left(q_{i, j} / \rho_{a, i, j}\right)}
$$

where $q_{i, j}$ and $\rho_{a, i, j}$ are the mass mixing ratio and density, respectively, for component $j$ in aerosol mode $i$. Petters and Kreidenweis (2007) summarized the hygroscopicity $B$ value ranges for different compounds on the basis of different measurements and estimations from the different investigators. Note that the single parameter $\kappa$ value in Petters and Kreidenweis (2007) is practically equivalent to the hygroscopicity $B$ value here (Liu and Wang, 2010). Koehler et al. (2009) estimated that the hygroscopicity $B$ values for $\left(\mathrm{NH}_{4}\right)_{2} \mathrm{SO}_{4}$ and $\mathrm{NaCl}$ ranged from 0.33 to 0.72 and 0.91 to 1.33 , respectively. The hygroscopicity values for anthropogenic SOA range from 0.06 to 0.14 (Prenni et al., 2007), and for biogenic SOA, they range from 0.06 to 0.23 (Prenni et al., 2007; King et al., 2010). Elemental carbon is generally considered non-hygroscopic $(B=0)$. Jimenez et al. (2009) showed that the hygroscopicity of SOA changes from 0 to 0.2 because of its aging in the atmosphere. On the basis of the measurements for three mineral dust samples (dust from the Canary Islands, outside of Cairo, and Arizona Test Dust), Koehler et al. (2009) reported that the hygroscopicity values for the minimally processed dust particles vary from 0.01 to 0.08 , with a suggested median value of 0.03 . In this study, the hygro- scopicity $B$ values for ASO4, ANO3, ANH4 and AORGC are assumed to be 0.5 . The hygroscopicity $B$ value of 0.14 is used for the SOA species (AALK, AXYL, ATOL, ABNZ, ATRP, AISO and ASQT). The hygroscopicity $B$ value for aged SOA (AOLGA and AOLGB) is assumed to be 0.20 . Table 3 lists the molecular weight, density and hygroscopicity $B$ values for each component used in this study.

After the smallest activation, the dry radius $\left(r_{\mathrm{cut}, i}\right)$ for each mode is determined, the total number $\left(N_{\text {act }}\right.$, i.e., cloud droplet number) and mass $\left(M_{\text {act }}\right)$ activated for each mode can be calculated as follows (Abdul-Razzak and Ghan, 2002, 2000):

$$
\begin{aligned}
& N_{\text {act }}=\sum_{i=1}^{I} N_{i} \frac{1}{2}\left[1-\operatorname{erf}\left(u_{i}\right)\right], \\
& M_{\text {act }}=\sum_{i=1}^{I} M_{i} \frac{1}{2}\left[1-\operatorname{erf}\left(u_{i}-\frac{3 \sqrt{2}}{2} \ln \left(\sigma_{i}\right)\right)\right],
\end{aligned}
$$

where

$u_{i}=\frac{2 \ln \left(S_{\mathrm{m}, i} / S_{\max }\right)}{3 \sqrt{2} \ln \left(\sigma_{i}\right)}$.

The total aerosol number and mass concentrations are separated into interstitial (referring to aerosol particles that are not activated to form cloud droplets) and cloud-borne (activated) portions based on the values of activated fractions with the above equations. It is also assumed that all cloud droplets 

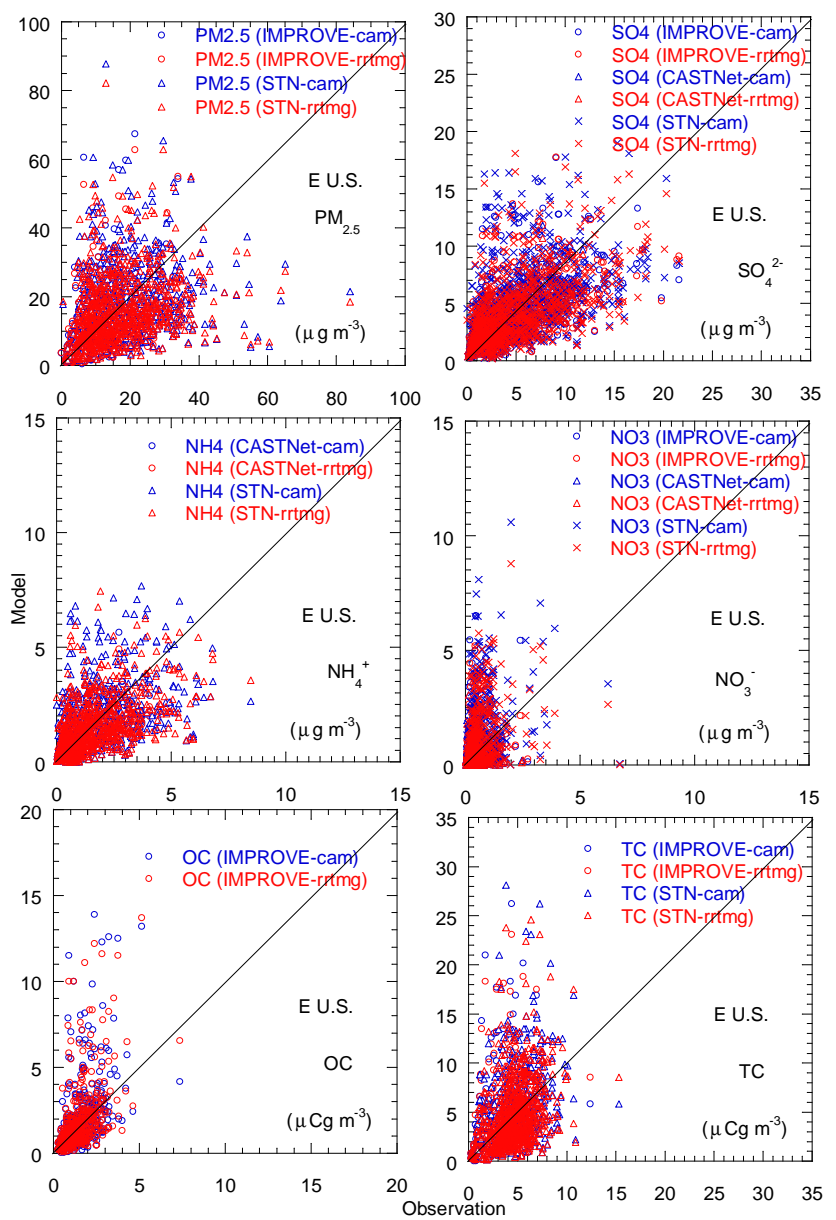

Figure 6a. Comparison of observed and modeled CAM (WRFCMAQ/CAM) and RRTMG (WRF-CMAQ/RRTMG) PM $_{2.5}$ and its chemical composition at the IMPROVE, CASTNET and STN sites over the eastern US (longitude $>100^{\circ}$ ).

are formed either when a cloud forms within a layer or as air flows into the cloud. For stratiform (resolved) clouds, the scheme of activation (Ghan et al., 1997; Abdul-Razzak and Ghan, 2002, 2000) only accounts for both resolved and turbulent transport of air into the base of the cloud, but neglects droplet formation on the sides and the top of the cloud. An implicit numerical integration scheme for the treatment of cloud droplet nucleation and vertical diffusion of cloud droplets simultaneously is performed by expressing cloud droplet nucleation in terms of a below-cloud droplet number concentration diagnosed from the nucleation flux and the eddy diffusivity (Abdul-Razzak and Ghan, 2002, 2000). When a cloud dissipates in a grid cell, cloud droplets evaporate and aerosols are resuspended; i.e., they are transferred from the cloud-borne to the interstitial state. The newly simulated cloud droplet number concentrations are updated due to the transport processes like other species in the model before being added to the Morrison et al. two-moment cloud microphysics scheme (Morrison et al., 2009, 2005). The Mor-
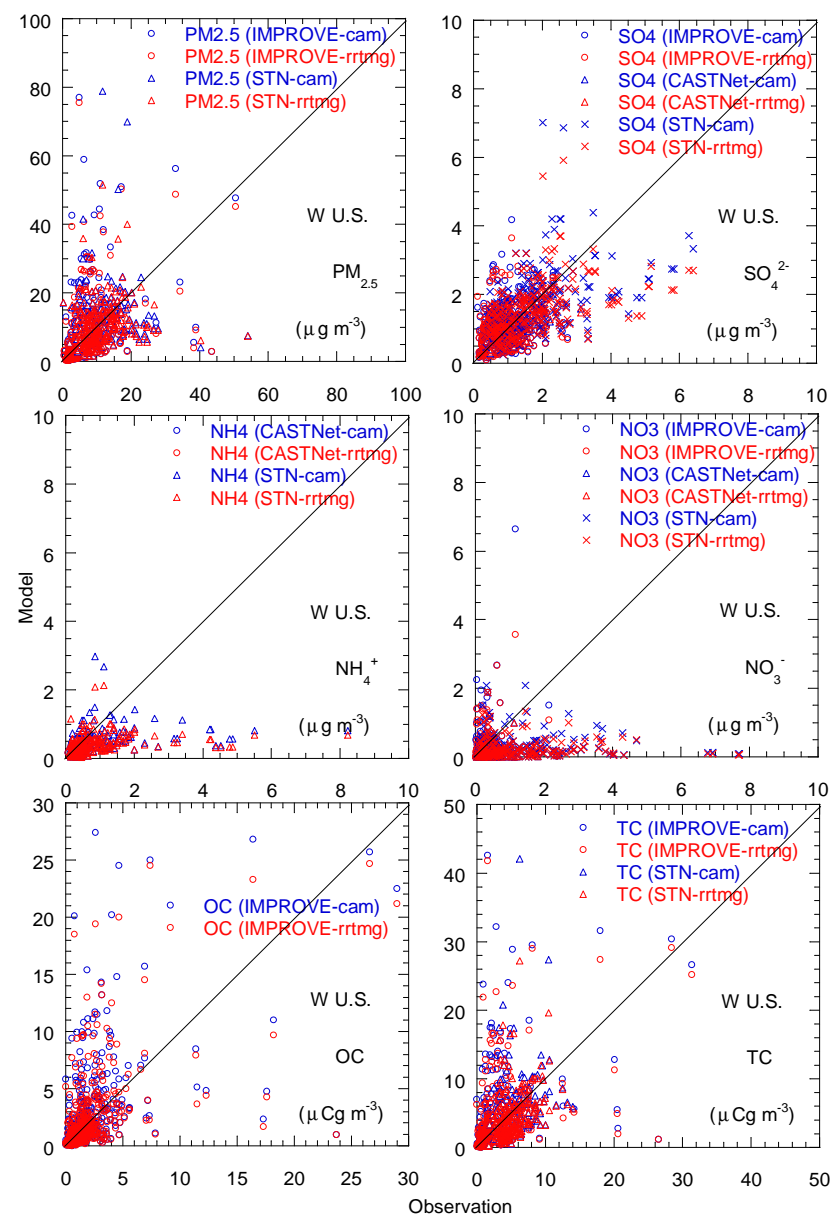

Figure 6b. Comparison of observed and modeled CAM (WRFCMAQ/CAM) and RRTMG (WRF-CMAQ/RRTMG) $\mathrm{PM}_{2.5}$ and its chemical composition at the IMPROVE, CASTNET and STN sites over the western US (longitude $<100^{\circ}$ ).

rison cloud microphysics scheme predicts both number concentrations and mass mixing ratios of five hydrometer types (cloud droplets, ice crystals, rain droplets, snow particles and graupel particles) and water vapor, and describes several microphysical processes that include auto-conversion, self collection, collection between hydrometeor species, freezing, cloud ice nucleation and droplet activation by aerosols and sedimentation. The resulting cloud drop number concentrations were supplied to the Morrison cloud microphysics scheme to allow estimation of aerosol effects on cloud optical depth and microphysical process rates for indirect aerosol radiative forcing (including first and second indirect aerosol forcing) by tying a two-moment treatment of cloud water (mass and number) to precipitation (the Morrison cloud microphysics scheme) and two alternative radiation schemes (RRTMG and CAM) in the WRF model. It should be noted that the original default aerosol activation processes that are based on Khvorostyanov and Curry (1999) were turned off in the study to avoid double accounting of the aerosol 
activation. Radiation schemes used in the numerical models are very sensitive to the effective radius; Slingo (1990) showed that decreasing the effective radius of cloud droplets from 10 to $8 \mu \mathrm{m}$ would result in atmospheric cooling that could offset global warming from doubling the $\mathrm{CO}_{2}$ content of the atmosphere. In the Morrison cloud microphysics scheme, the cloud drop effective radius $\left(r_{\mathrm{e}}\right)$ is defined as the ratio of the third to the second moment of the gamma droplet size distribution as follows (Morrison and Grabowski, 2007):

$r_{\mathrm{e}}=\frac{\Gamma(\mu+4)}{2 \lambda \Gamma(\mu+3)}$

where $\Gamma$ is the Euler gamma function and cloud droplet number concentrations $N_{\mathrm{c}}(D)$ are assumed to follow the gamma size distribution

$N_{\mathrm{c}}(D)=N_{\mathrm{c}, 0} D^{\mu} e^{-\lambda D}$,

where $D, N_{\mathrm{c}, 0}$ and $\lambda$ are the diameter, the intercept parameter, and the slope parameter, respectively. $\mu=1 / \eta^{2}-1$ is the spectral parameter ( $\eta$ is the ratio between the standard deviation of the spectrum and the mean radius for the relative radius dispersion), and $\eta$ is calculated as follows (Martin et al., 1994; Morrison and Grabowski, 2007):

$\eta=0.0005714 N_{\mathrm{c}}+0.2714$,

where $N_{\mathrm{c}}$ is the cloud droplet number concentration $\left(\mathrm{cm}^{-3}\right)$. These cloud droplet effective radii from the Morrison cloud microphysics scheme are used in the RRTMG (or CAM) radiation schemes directly, and this will affect the radiation fields accordingly.

\subsubsection{Glaciation indirect aerosol forcing}

To estimate the glaciation indirect aerosol forcing, the cloud ice number concentrations were estimated from the activation of the CMAQ-predicted sulfate, black carbon, dust and organic aerosols with an ice nucleation scheme used in the NCAR Community Atmospheric Model (CAM) (Liu et al., 2007). The detailed description of the ice nucleation scheme is given by Liu et al. (2007) and Liu and Penner (2005). Briefly, in this scheme, the ice crystal number concentration $\left(N_{\mathrm{i}, \mathrm{a}}\right)$ from homogeneous nucleation $\left(-60^{\circ} \mathrm{C}<T<-35^{\circ} \mathrm{C}\right)$ is a function of temperature $(T)$, updraft velocity $(w)$ and sulfate aerosol number concentration $\left(N_{\mathrm{a}}\right)$, and is calculated as follows:

For higher $T$ and lower $w$ (the fast-growth regime),

$N_{\mathrm{i}, \mathrm{a}}=\min \left\{\exp \left(a_{2}+b_{2} T+c_{2} \ln w\right) N_{\mathrm{a}}^{a_{1}+b_{1} T+c_{1} \ln w}, N_{\mathrm{a}}\right\}$,

while for lower $T$ and higher $w$ (the slow-growth regime),

$$
\begin{aligned}
N_{\mathrm{i}, \mathrm{a}}= & \min \left\{\exp \left(a_{2}+\left(b_{2}+b_{3} \ln w\right) T+c_{2} \ln w\right)\right. \\
& \left.N_{\mathrm{a}}^{a_{1}}+b_{1} T+c_{1} \ln w, N_{\mathrm{a}}\right\} .
\end{aligned}
$$
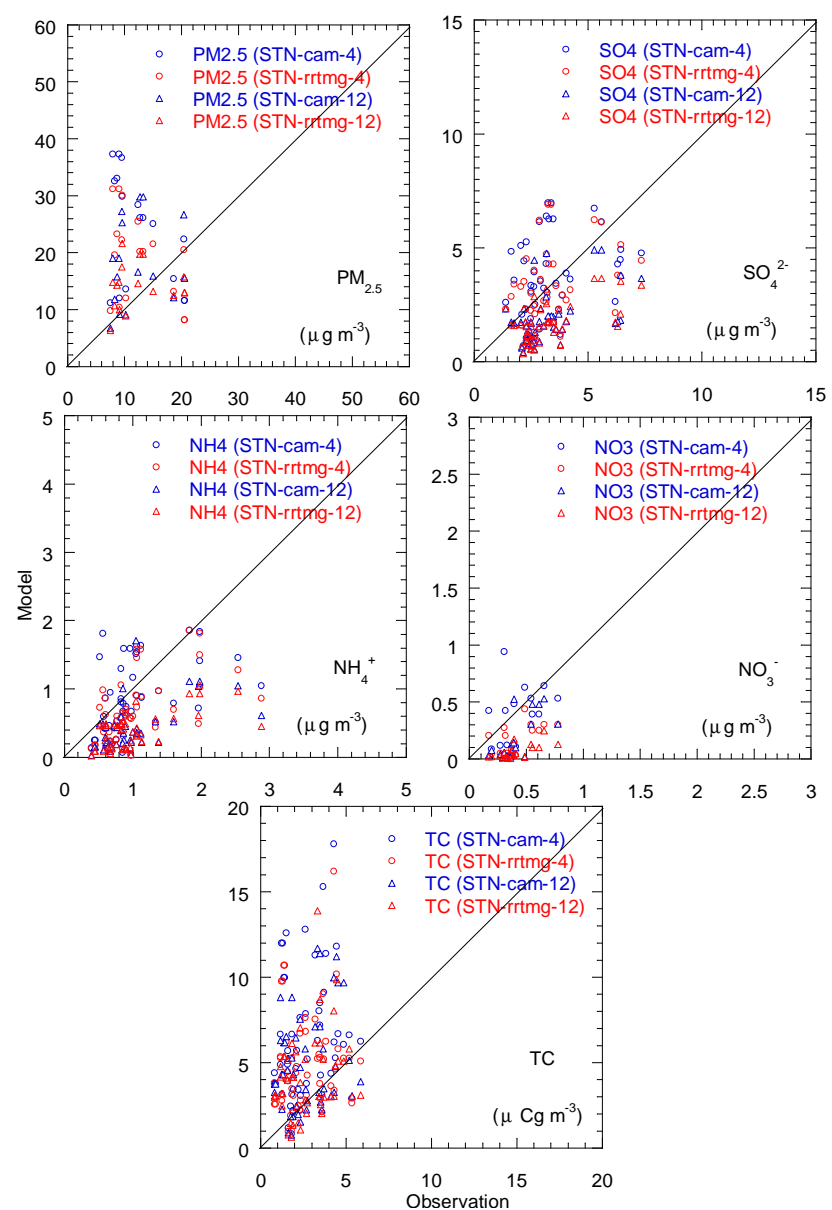

Figure 7. Comparison of observed and modeled CAM (WRFCMAQ/CAM) and RRTMG (WRF-CMAQ/RRTMG) $\mathrm{PM}_{2.5}$ and its chemical composition at the STN sites over eastern Texas from the simulations on the $4 \mathrm{~km}$ and $12 \mathrm{~km}$ resolution model grids.

In Eqs. (16) and (17), $a_{1}, a_{2}, b_{1}, b_{2}, b_{3}, c_{1}$ and $c_{2}$ are coefficients for the homogeneous nucleation parameterization. The ice crystal number concentrations $\left(N_{\mathrm{i}, \mathrm{s}}\right)$ formed from immersion nucleation of soot or mineral dust $\left(N_{\mathrm{s}}\right)$ through the heterogeneous nucleation on the basis of classic nucleation theory (Pruppacher and Klett, 1997) are calculated as follows:

$$
\begin{aligned}
N_{\mathrm{i}, \mathrm{s}}= & \min \left\{\exp \left(\left(a_{21} \ln w+a_{22}\right)+\left(a_{11} \ln w+a_{12}\right) T\right)\right. \\
& \left.N_{\mathrm{s}}^{\left(b_{21} \ln w+b_{22}\right)+\left(b_{11} \ln w+b_{12}\right) T}, N_{\mathrm{s}}\right\},
\end{aligned}
$$

where $a_{11}, a_{12}, a_{21}, a_{22}, b_{11}, b_{12}, b_{21}$, and $b_{22}$ are coefficients.

In the original version of the ice nucleation scheme in the NCAR Community Atmospheric Model (CAM) (Liu et al., 2007), the deposition/condensation nucleation of ice crystals in mixed-phase clouds is represented by the Meyers et al. (1992) formulation that does not allow ice number concentrations to depend on the aerosol number concentration. In the new version used in this work, the ice number 

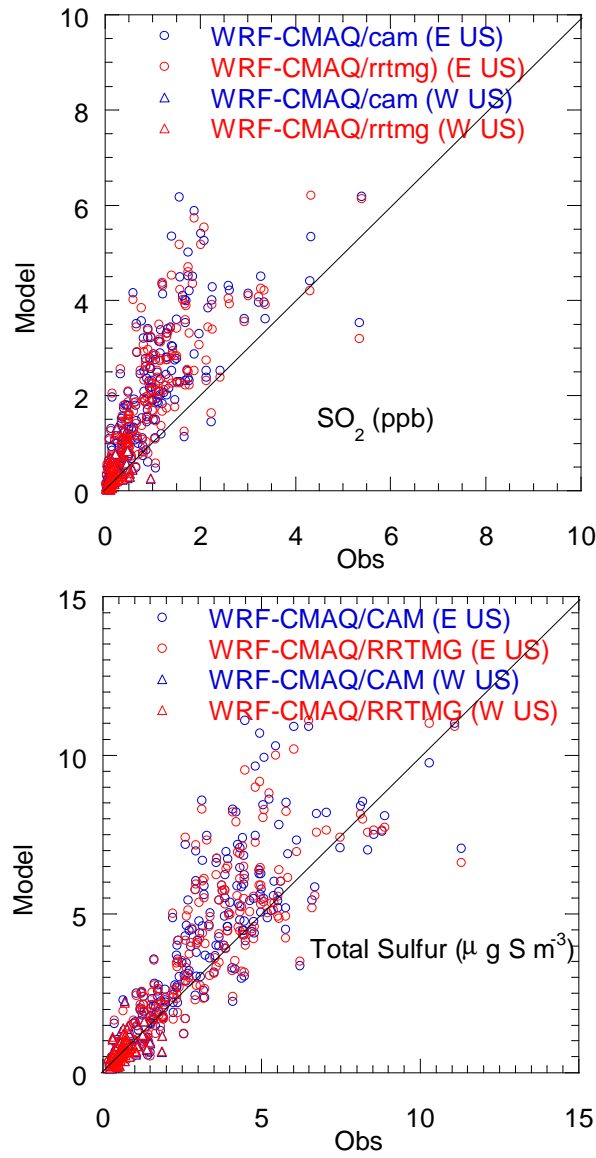

Figure 8. Comparison of observed and modeled (WRFCMAQ/CAM and WRF-CMAQ/RRTMG) $\mathrm{SO}_{2}$ and total sulfur $\left(\mathrm{SO}_{4}^{2-}+\mathrm{SO}_{2}\right)$ concentrations at CASTNET over the continental United States.

concentration from the deposition/condensation nucleation on dust/metallic, black carbon and organic aerosols with the size interval $d \log D x$ is estimated by the approach of Phillips et al. (2008) as follows:

$$
\begin{aligned}
& N_{i, X}=\int_{\log (0.1 \mu \mathrm{m})}^{\infty}\left\{1-\exp \left[-\mu_{X}\left(D_{X}, S_{i}, T\right)\right]\right\} \\
& \quad \times \frac{\mathrm{d} n_{X}}{\mathrm{~d} \log \left(D_{X}\right)} d \log \left(D_{X}\right) \\
& \mu_{X}=H_{X}\left(S_{i}, T\right) \xi(T)\left(\frac{a_{X} n_{I N, 1, *}}{\Omega_{X, 1, *}}\right) \times \frac{\mathrm{d} \Omega_{X}}{\mathrm{~d} n_{X}} \\
& \quad \text { for } T<0^{\circ} \mathrm{C} \text { and } 1<S_{i} \leq S_{i}^{w} \\
& n_{I N, 1, *}\left(T, S_{i}\right)=\psi c \exp \left[12.96\left(S_{i}-1\right)-0.639\right] \\
& \quad \text { for } T \geq-25^{\circ} \mathrm{C} \text { and } 1<S_{i} \leq S_{i}^{\mathrm{w}},
\end{aligned}
$$

where $X$ represents dust/metallic, black carbon and organic aerosols, $\mu_{X}$ is the average of the number of activated ice embryos per insoluble aerosol particle of size $D_{X}, \frac{\mathrm{d} \Omega_{X}}{\mathrm{~d} n_{X}} \approx \pi D_{X}$, $n_{X}$ is the number mixing ratio of aerosols in group $X, S_{i}$ is the saturation ratio of water vapor with respect to ice, $T$ is temperature, $\psi$ is assumed to be $0.058707 \gamma / \rho_{\mathrm{c}} \mathrm{m}^{3} \mathrm{~kg}^{-1}$ $\left(\gamma=2\right.$ and $\left.\rho_{\mathrm{c}}=0.76 \mathrm{~kg} \mathrm{~m}^{-3}\right), c=1000 \mathrm{~m}^{-3}$, and $H_{x}\left(S_{i}, T\right)$ is an empirically determined fraction (Phillips et al., 2008). The ice number concentrations from the contact freezing of cloud droplets by dust particles are estimated with the approach of Young (1974) as follows (Liu et al., 2007):

$n_{\mathrm{frz}, \mathrm{cnt}}=4 \pi r_{\mathrm{v}} N_{\mathrm{d}} N_{\mathrm{cnt}} D_{\mathrm{cnt}} / \rho_{0}$,

where

$N_{\mathrm{cnt}}=N_{\mathrm{a} 0}(270.16-T)^{1.3}$

$D_{\mathrm{cnt}}=\frac{k_{\mathrm{B}} T C_{\mathrm{c}}}{6 \pi \mu r_{\mathrm{cnt}}}$,

where $r_{\mathrm{v}}, N_{\mathrm{d}}, \rho_{0}, N_{\mathrm{a} 0}, k_{\mathrm{B}}, r_{\mathrm{cnt}}, C_{\mathrm{c}}, \mu$ and $T$ are the volume mean droplet radius, cloud droplet number concentration, air density, the number concentration of dust particles for each mode (dust accumulation and coarse modes), the Boltzmann constant, the aerosol (dust) number mean radius, the Cunningham correction factor, viscosity of air, and temperature, respectively. The original contact freezing scheme in the Morrison cloud microphysics scheme that is based on the approach of Meyers et al. (1992) is turned off in this study. The resulting cloud ice number concentrations were added to the Morrison cloud microphysics scheme to allow the estimation of aerosol effects on ice optical depth and microphysical process rates for indirect glaciation aerosol radiative forcing by tying a two-moment treatment of cloud ice (mass and number) to precipitation (the Morrison cloud microphysics scheme) and two radiation schemes (RRTMG and CAM) in the WRF model. Calculation of the ice effective radius is complicated by the non-spherical geometry of ice crystals. In the Morrison cloud microphysical scheme, the parameterization of $\mathrm{Fu}$ (1996) for derivation of the ice effective diameter $\left(D_{\mathrm{e}, \mathrm{i}}\right)$ is employed as follows (Morrison and Grabowski, 2007):

$D_{\mathrm{e}, i}=2 \sqrt{3} \mathrm{IWC} /\left(3 \rho_{i} A_{\mathrm{c}}\right)$,

where IWC is the ice water content and $A_{\mathrm{c}}$ is the projected area of the crystals from the given A (projected area) to D (dimension) relationship integrated over the size distribution (Morrison and Grabowski, 2007). The A-D relationship varies as a function of crystal habit, degree of riming and particle size. These ice effective radii from the Morrison cloud microphysics scheme are used in the RRTMG and CAM radiation schemes directly, and this will affect the radiation fields accordingly.

\section{Observational data sets}

\section{1 $\mathrm{PM}_{2.5}$ and its chemical component observations at the surface sites}

Over the continental United States, four surface monitoring networks for $\mathrm{PM}_{2.5}$ measurements were employed in 
12 km (CERES) SWCF

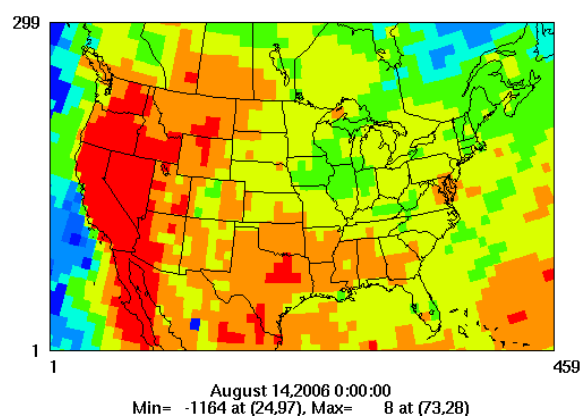

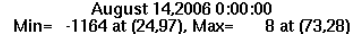

WRF-CMAQ (CAM)

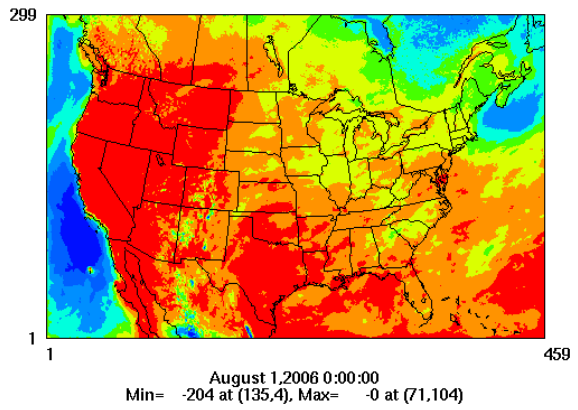

WRF-only (CAM)
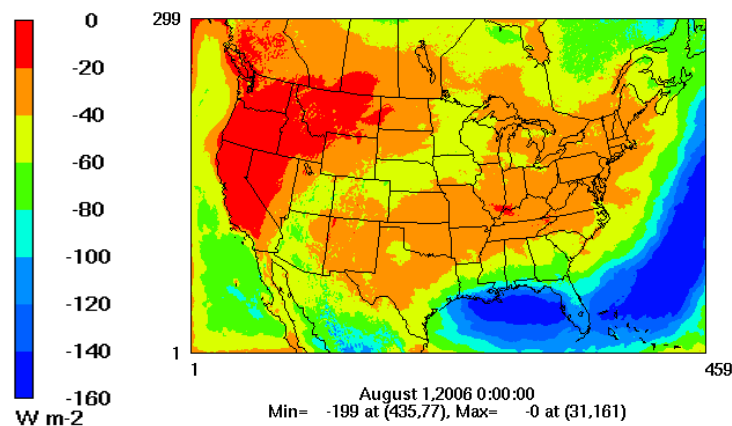

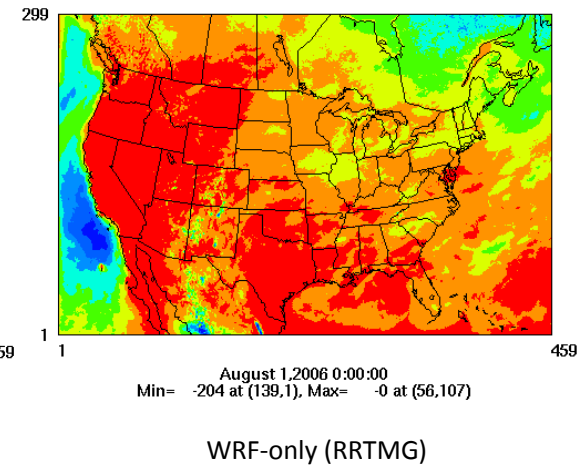

WRF-CMAQ (RRTMG)

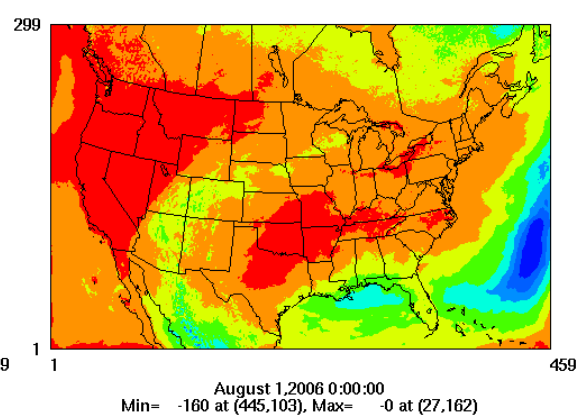

Figure 9. Monthly domain means of SWCF for the CERES observations and model results of WRF-CMAQ/CAM, WRF-CMAQ/RRTMG, WRF-only/CAM and WRF-only/RRTMG on the basis of the $12 \mathrm{~km}$ resolution simulation over the CONUS for August of 2006.

this evaluation: Interagency Monitoring of Protected Visual Environments (IMPROVE), the Speciated Trends Network (STN), the Clean Air Status Trends Network (CASTNET) and the Air Quality System (AQS), each with its own and often disparate sampling protocol and standard operating procedures. In the IMPROVE network, two $24 \mathrm{~h}$ samples are collected on quartz filters each week, on Wednesday and Saturday, beginning at midnight local time (Sisler and Malm, 2000). The observed $\mathrm{PM}_{2.5}, \mathrm{SO}_{4}^{2-}, \mathrm{NO}_{3}^{-}$, elemental carbon (EC) and organic carbon (OC) data are available at 155 rural sites across the continental United States. The STN (http://www.epa.gov/air/data/aqsdb.html) follows the protocol of the IMPROVE network (i.e., every third day collection), with the exception that most of the sites are in urban areas. The observed $\mathrm{PM}_{2.5}, \mathrm{SO}_{4}^{2-}, \mathrm{NO}_{3}^{-}$, and $\mathrm{NH}_{4}^{+}$data are available at 182 STN sites within the model domain. CASTNET (http://www.epa.gov/castnet/) collected the concentration data at predominately rural sites using filter packs that are exposed for one-week intervals (i.e., Tuesday to Tuesday). The aerosol species at the 82 CASTNET sites used in this evaluation include $\mathrm{SO}_{4}^{2-}, \mathrm{NO}_{3}^{-}$, and $\mathrm{NH}_{4}^{+}$. The hourly near-real-time $\mathrm{PM}_{2.5}$ data at 840 sites in the continental United States are measured by tapered element oscillating microbalance (TEOM) instruments at the US EPA's Air Quality System (AQS) network sites. The hourly, nearreal-time $\mathrm{O}_{3}$ data for 2006 at 1138 measurement sites in the continental United States are available from the US EPA's AIRNow network, resulting in nearly 1.2 million hourly $\mathrm{O}_{3}$ observations for the studied period.

\subsection{Satellite cloud observations from CERES}

The NASA Clouds and the Earth's Radiant Energy System (CERES) is a suite of satellite-based instruments designed to measure the top-of-atmosphere (TOA) radiation fields simultaneously with cloud properties. The CERES scanners operated on three satellites (the Tropical Rainfall Measuring Mission (TRMM) and the Moderate Resolution Imaging Spectroradiometer (MODIS) Terra and Aqua satellites) in which data from the TRMM visible infrared scanner (VIRS) (Kummerow et al., 1998) and the MODIS Terra and Aqua (Barnes et al., 1998) satellites are used for discriminating between clear and cloudy scenes, and for retrieving the properties of clouds and aerosols. In this study, the monthly data of cloud properties are obtained from the CERES SSF (Single Scanner Footprint) 1deg Product Edition2.6 (CERES Terra SSF1deg-lite_Ed2.6) that was released on 11 July 2011 (Wielicki et al., 1996; http://ceres-tool.larc.nasa.gov/ ord-tool/jsp/SSF1degSelection.jsp). Monthly means are calculated using the combination of observed and interpolated parameters from all days containing at least one CERES observation. CERES SSF1deg provides CERES-observed 
$4 \mathrm{~km}$ (CERES) SWCF

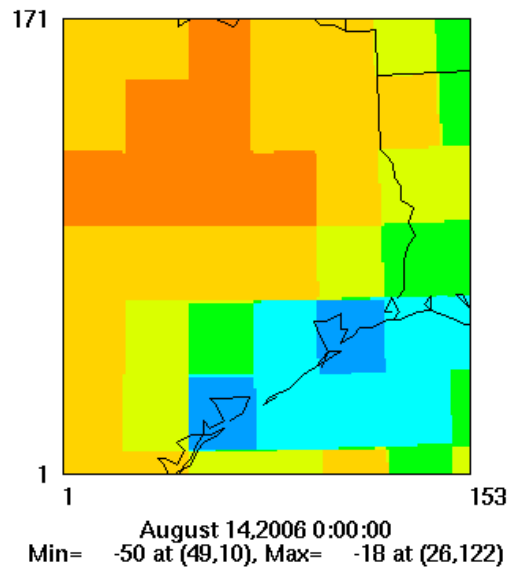

$\operatorname{Min}=$
WRF-CMAQ (CAM)
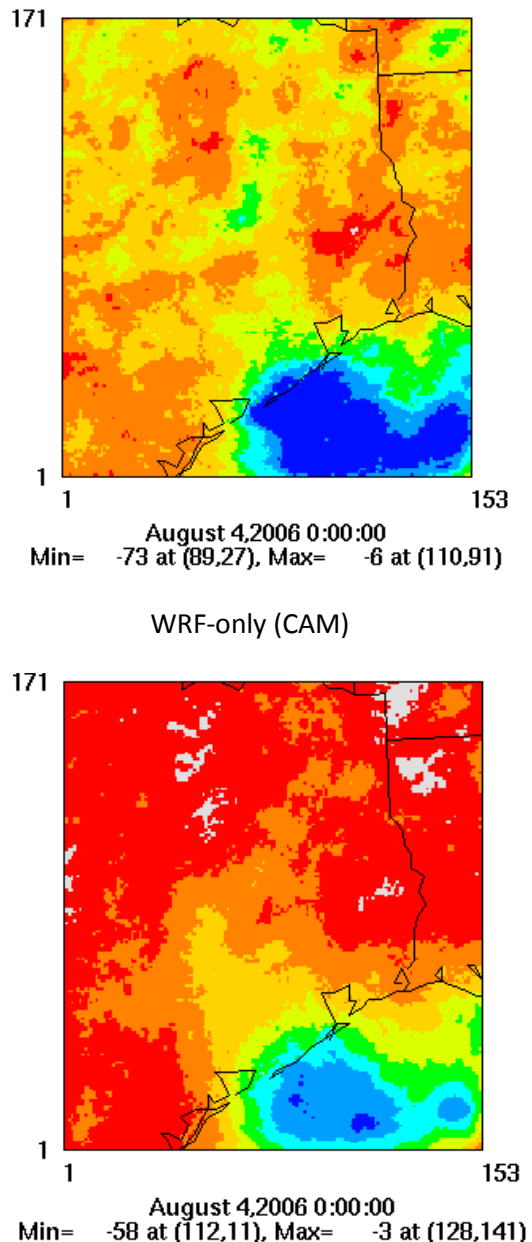

WRF-CMAQ (RRTMG)
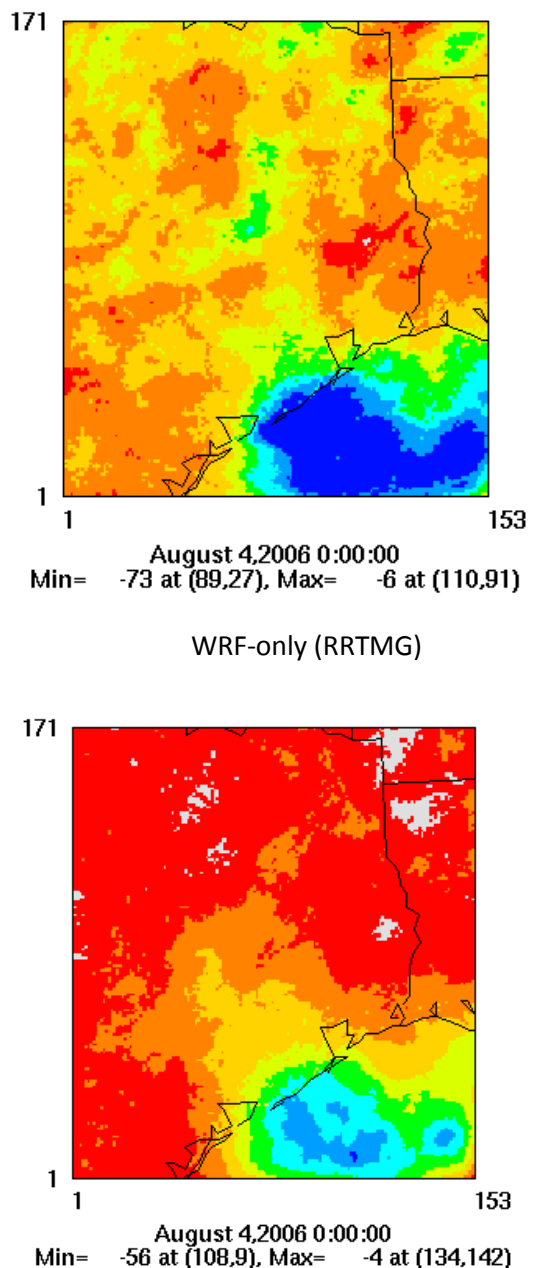

Figure 10. Same as Fig. 9, but for the eastern Texas domain on the basis of the $4 \mathrm{~km}$ resolution simulation for August of 2006.

temporally interpolated top-of-atmosphere (TOA) radiative fluxes and coincident MODIS-derived cloud and aerosol properties at daily and monthly $1^{\circ}$ regional, zonal and global time-space scales. The cloud parameters used in this study include cloud area fraction (day-night), liquid water path, water particle radius, ice particle effective radius, and cloud visible optical depth (day-night). The TOA radiation fluxes include (clear-sky and all-sky) shortwave fluxes and (clearsky and all-sky) longwave fluxes. Following Harrison et al. (1990), the shortwave (longwave) cloud forcing SWCF (LWCF) at the TOA was calculated as the difference between the clear-sky reflected shortwave (outgoing longwave) radiation and the all-sky reflected shortwave (outgoing longwave) radiation at the TOA for both models and observations.

\subsection{Model evaluation protocol}

The results over the eastern Texas domain for both the 4 and $12 \mathrm{~km}$ resolution simulations are summarized in Tables 6 and
8. For August of 2006, both WRF-CMAQ/CAM and WRFCMAQ/RRTMG overestimated the observed $\mathrm{PM}_{2.5}$ at the AQS sites, mainly because of the overestimation of total carbon (TC) according to the results at the STN urban sites as shown in Table 6 . Table 6 also shows that the fewer overestimations of $\mathrm{PM}_{2.5}$ for the $12 \mathrm{~km}$ resolution simulations relative to the $4 \mathrm{~km}$ resolution simulations are due to the fact that the results of the $12 \mathrm{~km}$ resolution simulations have more underestimations of $\mathrm{SO}_{4}^{2-}, \mathrm{NH}_{4}^{+}$, and $\mathrm{NO}_{3}^{-}$for both models. This is because of the underestimation of cloud fields in the $12 \mathrm{~km}$ resolution simulations, as indicated in Sect. 4.2 below. Similar performance trends in the two models are also noted for September of 2006, as shown in Table 8. However, the model performance for $\mathrm{SO}_{4}^{2-}$ is very good, with the $\mathrm{NMB}$ less than $\pm 6 \%$.

To evaluate model performance, regression statistics along with three measures of bias (the mean bias (MB), normalized MB (NMB) and normalized MB factor, NMBF), three measures of error (the root mean square error (RMSE), 
Table 9. Comparison of observation and models (WRF-CMAQ/CAM, WRF-CMAQ/RRTMG, WRF/CAM and WRF/RRTMG) for monthly SWCF $\left(\mathrm{W} \mathrm{m}^{-2}\right)$ over the land and ocean of the eastern US and the western US (in parentheses) of the CONUS from $12 \mathrm{~km}$ resolution simulations and over eastern Texas from the $4 \mathrm{~km}$ resolution simulations (the results in parentheses are from the $12 \mathrm{~km}$ resolution simulation) in August and September of 2006.

\begin{tabular}{|c|c|c|c|c|c|c|}
\hline & \multicolumn{3}{|c|}{ August } & \multicolumn{3}{|c|}{ September } \\
\hline & $12 \mathrm{~km}$, land & $12 \mathrm{~km}$, ocean & $4 \mathrm{~km}$ & $12 \mathrm{~km}$, land & $12 \mathrm{~km}$, ocean & $4 \mathrm{~km}$ \\
\hline & \multicolumn{6}{|c|}{ WRF-CMAQ/CAM } \\
\hline Mean (obs) & $-60.90(-37.18)$ & $-52.60(-62.29)$ & $-33.29(-34.34)$ & $-55.60(-34.63)$ & $-50.79(-49.24)$ & $-37.02(-36.63)$ \\
\hline Mean (model) & $-53.75(-27.58)$ & $-48.53(-68.02)$ & $-31.58(-24.06)$ & $-54.97(-33.01)$ & $-58.62(-54.78)$ & $-32.61(-33.57)$ \\
\hline Number & 982(1385) & 1124(997) & $309(79.00)$ & $866(1104)$ & $1080(783)$ & $256(55.00)$ \\
\hline Correlation & $0.96(0.96)$ & $0.90(0.91)$ & $0.70(0.82)$ & $0.91(0.94)$ & $0.95(0.90)$ & $0.79(0.91)$ \\
\hline MB & $7.15(9.60)$ & $4.08(-5.73)$ & $1.71(10.29)$ & $0.63(1.62)$ & $-7.83(-5.53)$ & $4.41(3.06)$ \\
\hline RMSE & $10.29(11.10)$ & $14.53(19.08)$ & $6.89(11.68)$ & $6.56(5.53)$ & $11.76(11.45)$ & $6.34(5.71)$ \\
\hline NMB & $(\%)-11.74(-25.82)$ & $-7.75(9.20)$ & $-5.13(-29.95)$ & $-1.13(-4.67)$ & $15.41(11.24)$ & $-11.90(-8.36)$ \\
\hline \multirow[t]{2}{*}{ NME } & $(\%)-14.41(-27.14)$ & $-24.12(-25.51)$ & $-16.09(-30.98)$ & $-9.10(-11.81)$ & $-18.85(-17.26)$ & $-13.67(-12.98)$ \\
\hline & \multicolumn{6}{|c|}{ WRF-CMAQ/RRTMG } \\
\hline Mean (obs) & $-60.90(-37.18)$ & $-52.60(-62.29)$ & $-33.29(-34.34)$ & $-55.60(-34.63)$ & $-50.79(-49.24)$ & $-37.02(-36.63)$ \\
\hline Mean (model) & $-47.23(-24.76)$ & $-40.14(-53.17)$ & $-30.90(-21.14)$ & $-63.26(-37.84)$ & $-67.43(-60.09)$ & $-38.15(-38.78)$ \\
\hline Number & 982(1385) & 1124(997) & $309(79.00)$ & $866(1104)$ & $1080(783)$ & $256(55.00)$ \\
\hline Correlation & $0.96(0.95)$ & $0.93(0.92)$ & $0.45(0.85)$ & $0.91(0.95)$ & $0.95(0.89)$ & $0.85(0.91)$ \\
\hline MB & $13.67(12.42)$ & $12.46(9.12)$ & $2.38(13.21)$ & $-7.66(-3.21)$ & $-16.64(-10.85)$ & $-1.13(-2.15)$ \\
\hline RMSE & $14.74(14.13)$ & $14.25(15.44)$ & $9.55(14.21)$ & $10.76(7.25)$ & $20.55(16.22)$ & $4.42(6.27)$ \\
\hline $\operatorname{NMB}(\%)$ & $-22.45(-33.40)$ & $-23.69(-14.64)$ & $-7.16(-38.45)$ & $13.77(9.27)$ & $32.75(22.03)$ & $3.05(5.87)$ \\
\hline \multirow[t]{2}{*}{ NME (\%) } & $-22.72(-34.62)$ & $-24.13(-20.12)$ & $-22.41(-38.45)$ & $-16.13(-15.73)$ & $-33.73(-26.57)$ & $-9.12(-13.53)$ \\
\hline & \multicolumn{6}{|c|}{ WRF/CAM } \\
\hline Mean (obs) & $-60.90(-37.18)$ & $-52.60(-62.29)$ & $-33.29(-34.34)$ & $-55.60(-34.63)$ & $-50.79(-49.24)$ & $-37.02(-36.63)$ \\
\hline Mean (model) & $-51.13(-39.54)$ & $-98.18(-75.41)$ & $-25.42(-67.60)$ & $-73.91(-44.80)$ & $-100.61(-104.76)$ & $-30.03(-48.61)$ \\
\hline Number & 982(1385) & 1124(997) & $309(79.00)$ & $866(1104)$ & $1080(783)$ & $256(55.00)$ \\
\hline Correlation & $0.37(0.39)$ & $-0.69(-0.54)$ & $0.75(0.28)$ & $0.60(0.78)$ & $0.18(0.41)$ & $0.85(0.65)$ \\
\hline $\mathrm{MB}$ & $9.77(-2.36)$ & $-45.57(-13.12)$ & $7.86(--33.26)$ & $-18.31(-10.18)$ & $-49.82(-55.52)$ & $6.98(-11.98)$ \\
\hline RMSE & $22.29(17.10)$ & $65.55(53.41)$ & $10.71(46.63)$ & 27.79(17.96) & $59.71(62.96)$ & $8.33(26.28)$ \\
\hline $\operatorname{NMB}(\%)$ & $-16.04(6.34)$ & $86.64(21.07)$ & $-23.63(96.84)$ & $32.93(29.39)$ & 98.09(112.74) & $-18.87(32.70)$ \\
\hline \multirow[t]{2}{*}{ NME $(\%)$} & $-31.26(-37.33)$ & $-101.43(-74.98)$ & $-27.89(-102.13)$ & $-37.42(-35.08)$ & $-98.19(-112.76)$ & $-19.12(-51.08)$ \\
\hline & \multicolumn{6}{|c|}{ WRF/RRTMG } \\
\hline Mean (obs) & $-60.90(-37.18)$ & $-52.60(-62.29)$ & $-33.29(-34.34)$ & $-55.60(-34.63)$ & $-50.79(-49.24)$ & $-37.02(-36.63)$ \\
\hline Mean (model) & $-39.36(-27.71)$ & $-78.20(-51.05)$ & $-23.84(-43.09)$ & $-65.77(-40.67)$ & $-92.61(-94.48)$ & $-26.57(-44.63)$ \\
\hline Number & 982(1385) & 1124(997) & $309(79.00)$ & $866(1104)$ & $1080(783)$ & $256(55.00)$ \\
\hline Correlation & $0.72(0.59)$ & $-0.52(-0.54)$ & $0.76(0.34)$ & $0.57(0.76)$ & $0.10(0.35)$ & $0.84(0.62)$ \\
\hline MB & $21.54(9.47)$ & $-25.60(11.24)$ & $9.44(-8.74)$ & $-10.17(-6.04)$ & $-41.82(-45.23)$ & $10.44(-7.99)$ \\
\hline RMSE & $25.30(17.63)$ & $45.41(49.62)$ & $11.54(27.39)$ & $22.69(14.95)$ & $54.15(54.49)$ & $11.32(24.53)$ \\
\hline NMB $(\%)$ & $-35.37(-25.46)$ & $48.67(-18.04)$ & $-28.37(25.46)$ & $18.29(17.44)$ & 82.33(91.86) & $-28.21(21.82)$ \\
\hline NME (\%) & $-37.99(-37.94)$ & $-69.04(-68.10)$ & $-30.56(-55.10)$ & $-29.66(-28.01)$ & $-82.69(-92.08)$ & $-28.25(-50.55)$ \\
\hline
\end{tabular}

normalized mean error (NME) and normalized mean error factor, NMEF), and the correlation coefficient $(r)$ (Yu et al., 2006, Gustafson and Yu, 2012) were calculated. Following the protocol of the IMPROVE network, the daily $(24 \mathrm{~h})$ $\mathrm{PM}_{2.5}$ concentrations at the AQS sites were calculated from midnight to midnight local time of the next day on the basis of hourly $\mathrm{PM}_{2.5}$ observations. To evaluate the model performance on cloud properties, following Harrison et al. (1990), the shortwave (longwave) cloud forcing SWCF (LWCF) at the TOA was calculated as the difference between the clearsky reflected shortwave (outgoing longwave) radiation and the all-sky reflected shortwave (outgoing longwave) radia- tion at the TOA for both configurations and CERES observations.

\section{Results and discussion}

To evaluate the newly developed two-way coupled WRFCMAQ with an aerosol indirect effect, the results of the model performance on air quality (aerosol and $\mathrm{O}_{3}$ ) are presented, followed by the results of the model performance on cloud properties. 
Table 10. Same as Table 9, but for monthly LWCF in August and September of 2006.

\begin{tabular}{|c|c|c|c|c|c|c|}
\hline & \multicolumn{3}{|c|}{ August } & \multicolumn{3}{|c|}{ September } \\
\hline & $12 \mathrm{~km}$, land & $12 \mathrm{~km}$, ocean & $4 \mathrm{~km}$ & $12 \mathrm{~km}$, land & $12 \mathrm{~km}$, ocean & $4 \mathrm{~km}$ \\
\hline & \multicolumn{6}{|c|}{ WRF-CMAQ/CAM } \\
\hline Mean (obs) & $30.26(30.33)$ & $29.34(21.97)$ & $25.36(27.45)$ & $29.65(25.84)$ & $34.16(27.89)$ & $27.06(28.03)$ \\
\hline Mean (model) & 21.83(19.97) & $23.47(15.84)$ & $26.04(20.67)$ & $18.56(16.68)$ & $34.93(28.24)$ & $21.53(21.38)$ \\
\hline Number & 982(1404) & 1124(1013) & 309(79.00) & 866(1108) & 1080(783) & $256(55.00)$ \\
\hline Correlation & $0.78(0.85)$ & $0.77(0.90)$ & $0.59(0.82)$ & $0.77(0.87)$ & $0.85(0.88)$ & $0.90(0.76)$ \\
\hline $\mathrm{MB}$ & $-8.43(-10.36)$ & $-5.86(-6.13)$ & $0.68(-6.78)$ & $-11.08(-9.17)$ & $0.77(0.35)$ & $-5.53(-6.65)$ \\
\hline RMSE & $8.76(11.05)$ & $6.71(7.03)$ & 7.47(7.45) & $11.44(9.61)$ & $5.90(4.84)$ & 7.04(8.89) \\
\hline $\operatorname{NMB}(\%)$ & $-27.86(-34.15)$ & $-19.99(-27.90)$ & $2.69(-24.69)$ & $-37.39(-35.46)$ & $2.25(1.25)$ & $-20.44(-23.74)$ \\
\hline \multirow[t]{2}{*}{ NME (\%) } & 27.91(34.18) & $20.44(28.28)$ & $23.41(24.93)$ & $37.66(35.92)$ & $13.97(13.74)$ & $22.22(28.85)$ \\
\hline & \multicolumn{6}{|c|}{ WRF-CMAQ/RRTMG } \\
\hline Mean (obs) & $30.26(30.33)$ & $29.34(21.97)$ & $25.36(27.45)$ & $29.65(25.84)$ & $34.16(27.89)$ & $27.06(28.03)$ \\
\hline Mean (model) & 20.95(19.58) & $21.21(14.33)$ & $23.29(19.86)$ & $18.69(16.15)$ & $31.66(25.49)$ & $23.13(20.05)$ \\
\hline Number & 982(1404) & 1124(1013) & 309(79.00) & 866(1108) & 1080(783) & $256(55.00)$ \\
\hline Correlation & $0.75(0.85)$ & $0.79(0.91)$ & $0.63(0.82)$ & $0.80(0.89)$ & $0.87(0.89)$ & $0.86(0.77)$ \\
\hline MB & $-9.31(-10.75)$ & $-8.13(-7.64)$ & $-2.07(-7.59)$ & $-10.96(-9.69)$ & $-2.50(-2.40)$ & $-3.93(-7.97)$ \\
\hline RMSE & $9.63(11.42)$ & $8.66(8.37)$ & 7.38(8.17) & $11.27(10.07)$ & $5.56(4.82)$ & $6.31(9.22)$ \\
\hline NMB (\%) & $-30.76(-35.45)$ & $-27.70(-34.79)$ & $-8.15(-27.64)$ & $-36.96(-37.51)$ & $-7.32(-8.62)$ & $-14.52(-28.45)$ \\
\hline \multirow[t]{2}{*}{$\operatorname{NME}(\%)$} & $30.80(35.47)$ & $27.80(34.81)$ & 24.07(27.84) & $37.19(37.82)$ & 13.34(14.15) & $20.57(29.54)$ \\
\hline & \multicolumn{6}{|c|}{ WRF/CAM } \\
\hline Mean (obs) & $30.26(30.33)$ & $29.34(21.97)$ & $25.36(27.45)$ & $29.65(25.84)$ & $34.16(27.89)$ & $27.06(28.03)$ \\
\hline Mean (model) & $37.28(46.10)$ & $81.49(55.94)$ & $26.39(76.03)$ & $23.22(19.77)$ & $50.28(50.90)$ & $26.21(25.28)$ \\
\hline Number & 982(1404) & 1124(1013) & 309(79.00) & 866(1108) & 1080(783) & $256(55.00)$ \\
\hline Correlation & $0.31(0.27)$ & $-0.23(0.55)$ & $0.65(-0.10)$ & $0.10(0.54)$ & $-0.30(-0.20)$ & $0.86(0.67)$ \\
\hline MB & 7.02(15.77) & $52.15(33.97)$ & $1.03(48.58)$ & $-6.42(-6.07)$ & $16.12(23.01)$ & $-0.85(-2.75)$ \\
\hline RMSE & 18.64(22.29) & 61.99(47.38) & $8.79(54.47)$ & $15.07(10.45)$ & $32.85(33.46)$ & 6.44(17.69) \\
\hline $\operatorname{NMB}(\%)$ & $23.20(52.00)$ & $177.77(154.64)$ & $4.06(177.01)$ & $-21.66(-23.49)$ & $47.20(82.52)$ & $-3.13(-9.82)$ \\
\hline \multirow[t]{2}{*}{ NME (\%) } & $32.84(56.35)$ & 178.14(159.98) & $28.18(177.01)$ & $39.66(32.59)$ & $62.71(87.55)$ & 21.31(54.15) \\
\hline & \multicolumn{6}{|c|}{ WRF/RRTMG } \\
\hline Mean (obs) & $30.26(30.33)$ & $29.34(21.97)$ & $25.36(27.45)$ & $29.65(25.84)$ & $34.16(27.89)$ & $27.06(28.03)$ \\
\hline Mean (model) & $26.98(29.23)$ & $61.25(38.51)$ & $22.02(43.34)$ & 22.61(18.95) & $44.92(46.00)$ & $21.82(22.98)$ \\
\hline Number & 982(1404) & 1124(1013) & 309(79.00) & 866(1108) & 1080(783) & $256(55.00)$ \\
\hline Correlation & $0.24(0.43)$ & $-0.16(0.61)$ & $0.65(0.06)$ & $0.09(0.54)$ & $-0.31(-0.22)$ & $0.87(0.66)$ \\
\hline MB & $-3.28(-1.10)$ & $31.91(16.55)$ & $-3.34(15.89)$ & $-7.04(-6.89)$ & $10.76(18.11)$ & $-5.24(-5.05)$ \\
\hline RMSE & $9.64(9.14)$ & $40.06(26.74)$ & 7.77(25.71) & $15.05(10.85)$ & $28.73(28.98)$ & $7.05(16.31)$ \\
\hline $\operatorname{NMB}(\%)$ & $-10.84(-3.63)$ & $108.78(75.33)$ & $-13.18(57.91)$ & $-23.74(-26.67)$ & $31.51(64.92)$ & $-19.36(-18.03)$ \\
\hline
\end{tabular}

\subsection{Model performance evaluation for $\mathrm{PM}_{2.5}, \mathrm{O}_{3}$ and $\mathbf{P M}_{2.5}$ chemical composition}

The results of model performance evaluation are summarized in Tables 4, 5 and 6 for August of 2006 and in Tables 7 and 8 for September of 2006.

\subsection{1 $\mathrm{PM}_{2.5}$ and $\mathrm{O}_{3}$ at the $\mathrm{AQS}$ sites}

Table 4 and Fig. 4a clearly indicate that over the CONUS, both models (WRF-CMAQ/CAM and WRFCMAQ/RRTMG) reproduced the majority of the observed daily maximum $8 \mathrm{~h} \mathrm{O} \mathrm{O}_{3}$ with values greater than $40 \mathrm{ppbv}$ within a factor of 1.5 for August of 2006. The NMB and $\mathrm{NME}$ are $-0.1 \%(15.0 \%)$ and $-0.4 \%(14.8 \%)$ for WRFCMAQ/CAM (WRF-CMAQ/RRTMG), respectively, when only data of maximum $8 \mathrm{~h} \mathrm{O}_{3}$ with concentrations greater than $40 \mathrm{ppbv}$ are considered. These values are much lower than the corresponding results when all data are considered, indicating that the overestimation in the low $\mathrm{O}_{3}$ concentration range contributes significantly to the overall overestimation for both models, especially when only data over the eastern Texas domain are used, as shown in Table 4. The overestimation in the low $\mathrm{O}_{3}$ concentration range could be indicative 
Table 11. Same as Table 9, but for monthly COD in August and September of 2006.

\begin{tabular}{|c|c|c|c|c|c|c|}
\hline & \multicolumn{3}{|c|}{ August } & \multicolumn{3}{|c|}{ September } \\
\hline & $12 \mathrm{~km}$, land & $12 \mathrm{~km}$, ocean & $4 \mathrm{~km}$ & $12 \mathrm{~km}$, land & $12 \mathrm{~km}$, ocean & $4 \mathrm{~km}$ \\
\hline & \multicolumn{6}{|c|}{ WRF-CMAQ/CAM } \\
\hline Mean (obs) & $6.86(4.99)$ & $5.17(6.09)$ & $2.66(3.72)$ & $8.43(7.30)$ & $6.21(6.01)$ & $6.06(5.71)$ \\
\hline Mean (model) & $5.83(2.39)$ & $5.21(5.85)$ & $2.35(1.83)$ & $8.05(5.21)$ & $6.80(6.44)$ & $3.63(4.67)$ \\
\hline Number & $790(924)$ & $738(513)$ & $255(45.00)$ & $987(1195)$ & $826(509)$ & $580(63.00)$ \\
\hline Correlation & $0.82(0.91)$ & $0.87(0.92)$ & $0.11(0.50)$ & $0.85(0.93)$ & $0.89(0.90)$ & $0.64(0.84)$ \\
\hline MB & $-1.02(-2.59)$ & $0.04(-0.24)$ & $-0.30(-1.89)$ & $-0.38(-2.08)$ & $0.58(0.43)$ & $-2.44(-1.04)$ \\
\hline RMSE & $1.85(2.70)$ & $2.02(1.53)$ & $1.04(2.00)$ & $1.64(2.34)$ & $1.91(1.46)$ & $3.02(1.78)$ \\
\hline $\operatorname{NMB}(\%)$ & $-14.92(-52.02)$ & $0.83(-4.01)$ & $-11.43(-50.74)$ & $-4.47(-28.56)$ & $9.39(7.15)$ & $-40.22(-18.28)$ \\
\hline \multirow[t]{2}{*}{ NME (\%) } & $22.16(52.03)$ & $34.23(21.09)$ & $27.92(50.74)$ & $14.82(28.81)$ & $25.14(20.01)$ & $40.72(25.35)$ \\
\hline & \multicolumn{6}{|c|}{ WRF-CMAQ/RRTMG } \\
\hline Mean (obs) & $6.86(4.99)$ & $5.17(6.09)$ & $2.66(3.72)$ & $8.43(7.30)$ & $6.21(6.01)$ & $6.06(5.71)$ \\
\hline Mean (model) & $3.67(1.44)$ & $2.83(2.95)$ & $1.90(1.02)$ & $5.35(3.48)$ & $4.46(3.93)$ & $3.43(3.06)$ \\
\hline Number & 790(924) & 738(513) & $255(45.00)$ & $987(1195)$ & $826(509)$ & $580(63.00)$ \\
\hline Correlation & $0.81(0.90)$ & $0.90(0.88)$ & $0.59(0.64)$ & $0.85(0.93)$ & $0.91(0.89)$ & $0.55(0.87)$ \\
\hline $\mathrm{MB}$ & $-3.18(-3.55)$ & $-2.34(-3.15)$ & $-0.76(-2.70)$ & $-3.08(-3.82)$ & $-1.76(-2.08)$ & $-2.63(-2.66)$ \\
\hline RMSE & $3.43(3.67)$ & $2.52(3.47)$ & $1.05(2.75)$ & $3.43(4.02)$ & $2.12(2.32)$ & $3.27(2.94)$ \\
\hline $\operatorname{NMB}(\%)$ & $-46.43(-71.10)$ & $-45.19(-51.63)$ & $-28.60(-72.56)$ & $-36.49(-52.32)$ & $-28.26(-34.56)$ & $-43.44(-46.48)$ \\
\hline \multirow[t]{2}{*}{$\operatorname{NME}(\%)$} & $46.62(71.10)$ & $45.23(51.63)$ & $32.95(72.56)$ & $36.70(52.32)$ & $29.32(34.61)$ & $43.82(46.48)$ \\
\hline & \multicolumn{6}{|c|}{ WRF/CAM } \\
\hline Mean (obs) & $6.86(4.99)$ & $5.17(6.09)$ & $2.66(3.72)$ & $8.43(7.30)$ & $6.21(6.01)$ & $6.06(5.71)$ \\
\hline Mean (model) & $2.42(1.28)$ & $1.62(1.56)$ & $0.70(1.43)$ & $10.00(6.59)$ & $10.84(10.05)$ & $1.22(6.05)$ \\
\hline Number & 790(924) & $738(513)$ & 255(45.00) & 987(1195) & $826(509)$ & $580(63.00)$ \\
\hline Correlation & $0.54(0.81)$ & $0.18(0.81)$ & $0.55(-0.23)$ & $0.67(0.85)$ & $0.75(0.76)$ & $0.10(0.73)$ \\
\hline MB & $-4.44(-3.70)$ & $-3.55(-4.53)$ & $-1.96(-2.29)$ & $1.57(-0.70)$ & $4.63(4.04)$ & $-4.84(0.34)$ \\
\hline RMSE & $4.79(3.94)$ & $4.14(5.09)$ & $2.08(2.45)$ & $3.40(1.79)$ & $5.55(4.65)$ & $5.35(2.22)$ \\
\hline $\operatorname{NMB}(\%)$ & $-64.72(-74.27)$ & $-68.62(-74.33)$ & $-73.64(-61.53)$ & $18.65(-9.62)$ & $74.53(67.28)$ & $-79.80(5.99)$ \\
\hline \multirow[t]{2}{*}{$\operatorname{NME}(\%)$} & $65.11(74.27)$ & $69.70(74.33)$ & 73.67(61.64) & $28.20(18.65)$ & $74.87(67.38)$ & 79.81(28.66) \\
\hline & \multicolumn{6}{|c|}{ WRF/RRTMG } \\
\hline Mean (obs) & $6.86(4.99)$ & $5.17(6.09)$ & $2.66(3.72)$ & $8.43(7.30)$ & $6.21(6.01)$ & $6.06(5.71)$ \\
\hline Mean (model) & $0.72(0.31)$ & $0.45(0.37)$ & $0.34(0.26)$ & $6.78(4.46)$ & $7.48(6.70)$ & $0.56(4.08)$ \\
\hline Number & 790(924) & $738(513)$ & $255(45.00)$ & $987(1195)$ & $826(509)$ & $580(63.00)$ \\
\hline Correlation & $0.71(0.89)$ & $0.42(0.72)$ & $0.61(0.59)$ & $0.66(0.84)$ & $0.73(0.72)$ & $0.06(0.72)$ \\
\hline MB & $-6.13(-4.67)$ & $-4.72(-5.73)$ & $-2.32(-3.47)$ & $-1.65(-2.83)$ & $1.26(0.69)$ & $-5.50(-1.63)$ \\
\hline RMSE & $6.41(4.93)$ & $5.15(6.31)$ & $2.43(3.52)$ & $2.88(3.24)$ & $2.55(1.86)$ & $5.96(2.38)$ \\
\hline $\operatorname{NMB}(\%)$ & $-89.43(-93.71)$ & $-91.33(-93.96)$ & $-87.33(-93.12)$ & $-19.56(-38.85)$ & $20.35(11.56)$ & $-90.76(-28.57)$ \\
\hline
\end{tabular}

of titration by NO in urban plumes that the model does not resolve, because many AQS sites are located in urban areas, as pointed out by $\mathrm{Yu}$ et al. (2007). One of the reasons for more $\mathrm{O}_{3}$ overestimation for the $4 \mathrm{~km}$ resolution simulations relative to the $12 \mathrm{~km}$ resolution simulations over the eastern Texas domain is the boundary conditions used in the $4 \mathrm{~km}$ simulations, although the model performance for $\mathrm{O}_{3}$ is still reasonably good, because the NMB values are less than $37 \%$, as listed in Table 4. The model performance for both models for $\mathrm{O}_{3}$ concentrations is similar.

The model performance for $\mathrm{PM}_{2.5}$ at the AQS sites for August of 2006 is summarized in Tables 5 and 6, and in
Fig. 5. Following Eder and Yu (2006), the results over the CONUS were separated into the eastern (EUS, longitude greater than $-100^{\circ} \mathrm{W}$ ) and western US (WUS, longitude less than $\left.-100^{\circ} \mathrm{W}\right)$. Figure 5 indicates that both models captured the majority of observed daily $\mathrm{PM}_{2.5}$ values within a factor of 2, but generally underestimated the observations in the high $\mathrm{PM}_{2.5}$ concentration range. The domainwide mean values of $\mathrm{MB}$ and RMSE for all daily $\mathrm{PM}_{2.5}$ at the AQS sites for August of 2006 over the EUS are 0.81 $(-0.02)$ and $10.70(10.20) \mu \mathrm{g} \mathrm{m}^{-3}$, respectively, for $\mathrm{WRF}-$ CMAQ/CAM (WRF-CMAQ/RRTMG), and those for NMB and NME are $5.3(-0.1) \%$ and 49.9 (48.6) \%, respectively, 
Table 12. Same as Table 9, but for monthly cloud fractions in August and September of 2006.

\begin{tabular}{|c|c|c|c|c|c|c|}
\hline & \multicolumn{3}{|c|}{ August } & \multicolumn{3}{|c|}{ September } \\
\hline & $12 \mathrm{~km}$, land & $12 \mathrm{~km}$, ocean & $4 \mathrm{~km}$ & $12 \mathrm{~km}$, land & $12 \mathrm{~km}$, ocean & $4 \mathrm{~km}$ \\
\hline & \multicolumn{6}{|c|}{ WRF-CMAQ/CAM } \\
\hline Mean (obs) & $0.51(0.38)$ & $0.50(0.56)$ & $0.34(0.35)$ & $0.52(0.37)$ & $0.52(0.51)$ & $0.37(0.38)$ \\
\hline Mean (model) & $0.47(0.35)$ & $0.47(0.58)$ & $0.38(0.31)$ & $0.51(0.34)$ & $0.54(0.49)$ & $0.33(0.35)$ \\
\hline Number & $560(1031)$ & 644(764) & $276(61.00)$ & $556(888)$ & $713(685)$ & $168(43.00)$ \\
\hline Correlation & $0.92(0.97)$ & $0.91(0.86)$ & $0.74(0.94)$ & $0.95(0.97)$ & $0.97(0.87)$ & $0.93(0.78)$ \\
\hline MB & $-0.05(-0.03)$ & $-0.03(0.02)$ & $0.04(-0.04)$ & $-0.01(-0.03)$ & $0.01(-0.01)$ & $-0.04(-0.02)$ \\
\hline RMSE & $0.06(0.05)$ & $0.05(0.11)$ & $0.07(0.05)$ & $0.04(0.05)$ & $0.04(0.09)$ & $0.07(0.05)$ \\
\hline NMB (\%) & $-9.08(-8.37)$ & $-5.67(2.85)$ & $11.13(-11.21)$ & $-2.84(-7.98)$ & $2.60(-2.89)$ & $-11.75(-6.52)$ \\
\hline \multirow[t]{2}{*}{ NME (\%) } & 9.42(10.79) & $8.92(13.36)$ & 17.06(11.81) & $5.34(10.65)$ & $5.49(9.05)$ & $14.48(10.58)$ \\
\hline & \multicolumn{6}{|c|}{ WRF-CMAQ/RRTMG } \\
\hline Mean (obs) & $0.51(0.38)$ & $0.50(0.56)$ & $0.34(0.35)$ & $0.52(0.37)$ & $0.52(0.51)$ & $0.37(0.38)$ \\
\hline Mean (model) & $0.43(0.34)$ & $0.44(0.51)$ & $0.35(0.30)$ & $0.48(0.33)$ & $0.51(0.45)$ & $0.37(0.35)$ \\
\hline Number & $560(1031)$ & $644(764)$ & $276(61.00)$ & $556(888)$ & 713(685) & $168(43.00)$ \\
\hline Correlation & $0.92(0.97)$ & $0.91(0.90)$ & $0.84(0.93)$ & $0.94(0.97)$ & $0.95(0.74)$ & $0.91(0.70)$ \\
\hline MB & $-0.08(-0.05)$ & $-0.06(-0.05)$ & $0.02(-0.05)$ & $-0.05(-0.04)$ & $-0.01(-0.05)$ & $0.00(-0.03)$ \\
\hline RMSE & $0.08(0.06)$ & $0.07(0.10)$ & $0.05(0.06)$ & $0.06(0.05)$ & $0.04(0.13)$ & $0.06(0.06)$ \\
\hline NMB (\%) & $-15.28(-12.19)$ & $-12.38(-8.69)$ & $4.50(-14.74)$ & $-9.22(-11.05)$ & $-1.77(-10.76)$ & $-1.22(-8.16)$ \\
\hline \multirow[t]{2}{*}{ NME (\%) } & $15.30(14.52)$ & 12.64(13.85) & $12.64(14.91)$ & $9.65(12.30)$ & $6.09(14.45)$ & $15.02(12.41)$ \\
\hline & \multicolumn{6}{|c|}{ WRF/CAM } \\
\hline Mean (obs) & $0.51(0.38)$ & $0.50(0.56)$ & $0.34(0.35)$ & $0.52(0.37)$ & $0.52(0.51)$ & $0.37(0.38)$ \\
\hline Mean (model) & $0.58(0.59)$ & $0.75(0.76)$ & $0.38(0.80)$ & $0.59(0.39)$ & $0.72(0.72)$ & $0.35(0.50)$ \\
\hline Number & $560(1031)$ & 644(764) & 276(61.00) & $556(888)$ & 713(685) & $168(43.00)$ \\
\hline Correlation & $-0.20(0.48)$ & $-0.72(0.14)$ & $0.79(-0.69)$ & $0.71(0.86)$ & $0.01(0.39)$ & $0.93(-0.02)$ \\
\hline MB & $0.07(0.21)$ & $0.25(0.20)$ & $0.04(0.45)$ & $0.06(0.02)$ & $0.19(0.21)$ & $-0.03(0.12)$ \\
\hline RMSE & $0.16(0.26)$ & $0.32(0.30)$ & $0.07(0.49)$ & $0.15(0.10)$ & $0.26(0.28)$ & $0.07(0.27)$ \\
\hline NMB (\%) & $13.69(54.86)$ & $49.70(35.47)$ & $10.54(127.18)$ & $11.61(5.43)$ & $37.01(41.77)$ & $-7.42(31.05)$ \\
\hline \multirow[t]{2}{*}{ NME (\%) } & $23.43(55.49)$ & $53.58(41.82)$ & $17.49(127.18)$ & $21.70(22.08)$ & $37.83(43.45)$ & $14.79(57.15)$ \\
\hline & \multicolumn{6}{|c|}{ WRF/RRTMG } \\
\hline Mean (obs) & $0.51(0.38)$ & $0.50(0.56)$ & $0.34(0.35)$ & $0.52(0.37)$ & $0.52(0.51)$ & $0.37(0.38)$ \\
\hline Mean (model) & $0.53(0.53)$ & $0.72(0.68)$ & $0.38(0.71)$ & $0.56(0.38)$ & $0.70(0.70)$ & $0.34(0.49)$ \\
\hline Number & $560(1031)$ & $644(764)$ & $276(61)$ & $556(888)$ & 713(685) & $168(43.00)$ \\
\hline Correlation & $0.08(0.50)$ & $-0.62(-0.02)$ & $0.78(-0.62)$ & $0.69(0.85)$ & $-0.05(0.35)$ & $0.93(-0.02)$ \\
\hline $\mathrm{MB}$ & $0.02(0.15)$ & $0.21(0.12)$ & $0.04(0.35)$ & $0.03(0.01)$ & $0.17(0.19)$ & $-0.04(0.11)$ \\
\hline RMSE & $0.12(0.20)$ & $0.28(0.27)$ & $0.08(0.40)$ & $0.14(0.10)$ & $0.26(0.26)$ & $0.07(0.27)$ \\
\hline NMB (\%) & $3.98(38.62)$ & $42.66(20.72)$ & $11.30(100.80)$ & $6.19(2.26)$ & $33.09(37.74)$ & $-9.93(28.42)$ \\
\hline
\end{tabular}

for WRF-CMAQ/CAM (WRF-CMAQ/RRTMG). The results over the WUS are similar to those over the EUS. Generally, WRF-CMAQ/CAM simulated higher PM2.5 levels than WRF-CMAQ/RRTMG.

The model performance for $\mathrm{PM}_{2.5}$ at the AQS sites during September of 2006 is summarized in Tables 7 and 8. There are greater overestimations of $\mathrm{PM}_{2.5}$ in September relative to those in August. Over the EUS, both WRFCMAQ/CAM and WRF-CMAQ/RRTMG overestimated the observed $\mathrm{PM}_{2.5}$ at the AQS sites by factors of 1.30 and 1.27, respectively, as indicated by the normalized mean bias factor (NMBF) (Yu et al., 2006). According to the results at these
STN urban sites that also have consistent overestimation of $\mathrm{PM}_{2.5}$, the overestimations of $\mathrm{PM}_{2.5}$ at these urban locations by both models primarily result from the overestimations of $\mathrm{SO}_{4}^{2-}, \mathrm{NH}_{4}^{+}, \mathrm{NO}_{3}^{-}$, and TC over the EUS. Over the WUS, both WRF-CMAQ/CAM and WRF-CMAQ/RRTMG overestimated the observed $\mathrm{PM}_{2.5}$ at the AQS sites by factors of 1.65 and 1.55 , respectively, mainly due to the overestimations of TC according to the results at the STN urban sites in Table $7 \mathrm{~b}$. 
Table 13. Comparison of observation (PRISM) and models (WRF-CMAQ/CAM, WRF-CMAQ/RRTMG, WRF/CAM and WRF/RRTMG) for monthly precipitation (inch month ${ }^{-1}$ ) over the land of the eastern US and the western US from $12 \mathrm{~km}$ resolution simulations and over the eastern Texas domain from the $4 \mathrm{~km}$ resolution simulations in August and September of 2006.

\begin{tabular}{|c|c|c|c|c|c|c|}
\hline & \multicolumn{3}{|c|}{ August } & \multicolumn{3}{|c|}{ September } \\
\hline & 12 km (east) & 12 km (west) & $4 \mathrm{~km}$ & $12 \mathrm{~km}$ (east) & 12 km (west) & $4 \mathrm{~km}$ \\
\hline & \multicolumn{6}{|c|}{ WRF-CMAQ/CAM } \\
\hline Mean (obs) & 3.86 & 1.58 & 1.77 & 3.99 & 1.48 & 3.35 \\
\hline Mean (model) & 5.40 & 2.91 & 1.39 & 3.12 & 1.40 & 2.72 \\
\hline Number & 28391 & 25527 & 25085 & 28391 & 25680 & 25088 \\
\hline Correlation & 0.45 & 0.75 & 0.10 & 0.63 & 0.77 & 0.20 \\
\hline MB & 1.54 & 1.33 & -0.37 & -0.87 & -0.08 & -0.63 \\
\hline RMSE & 3.14 & 2.43 & 1.79 & 1.78 & 0.75 & 2.44 \\
\hline $\operatorname{NMB}(\%)$ & 39.96 & 83.77 & -21.13 & -21.81 & -5.58 & -18.81 \\
\hline \multirow[t]{2}{*}{ NME (\%) } & 59.46 & 94.98 & 71.46 & 35.01 & 35.14 & 54.04 \\
\hline & \multicolumn{6}{|c|}{ WRF-CMAQ/RRTMG } \\
\hline Mean (obs) & 3.86 & 1.58 & 1.77 & 3.99 & 1.48 & 3.35 \\
\hline Mean (model) & 5.84 & 3.03 & 1.49 & 3.27 & 1.45 & 3.56 \\
\hline Number & 28391 & 25527 & 25085 & 28391 & 25680 & 25088 \\
\hline Correlation & 0.43 & 0.77 & 0.23 & 0.62 & 0.77 & 0.33 \\
\hline MB & 1.98 & 1.45 & -0.27 & -0.71 & -0.03 & 0.21 \\
\hline RMSE & 3.61 & 2.56 & 1.71 & 1.78 & 0.75 & 2.66 \\
\hline NMB (\%) & 51.34 & 91.30 & -15.40 & -17.85 & -2.32 & 6.22 \\
\hline \multirow[t]{2}{*}{ NME (\%) } & 67.58 & 100.97 & 69.03 & 34.33 & 35.15 & 54.46 \\
\hline & \multicolumn{6}{|c|}{ WRF/CAM } \\
\hline Mean (obs) & 3.86 & 1.58 & 1.77 & 3.99 & 1.48 & 3.35 \\
\hline Mean (model) & 4.38 & 3.44 & 1.24 & 2.40 & 1.23 & 2.94 \\
\hline Number & 28391 & 25527 & 25085 & 28391 & 25680 & 25088 \\
\hline Correlation & 0.39 & 0.66 & 0.26 & 0.51 & 0.65 & 0.36 \\
\hline MB & 0.52 & 1.86 & -0.53 & -1.59 & -0.26 & -0.42 \\
\hline RMSE & 5.40 & 3.13 & 1.57 & 2.37 & 0.90 & 2.12 \\
\hline NMB (\%) & 13.38 & 117.52 & -30.00 & -39.89 & -17.30 & -12.39 \\
\hline \multirow[t]{2}{*}{ NME (\%) } & 70.66 & 127.25 & 63.49 & 47.06 & 42.54 & 45.27 \\
\hline & \multicolumn{6}{|c|}{ WRF/RRTMG } \\
\hline Mean (obs) & 3.86 & 1.58 & 1.77 & 3.99 & 1.48 & 3.35 \\
\hline Mean (model) & 3.93 & 3.56 & 1.25 & 2.45 & 1.25 & 2.85 \\
\hline Number & 28391 & 25527 & 25085 & 28391 & 25680 & 25088 \\
\hline Correlation & 0.44 & 0.57 & 0.25 & 0.50 & 0.63 & 0.36 \\
\hline $\mathrm{MB}$ & 0.07 & 1.98 & -0.52 & -1.54 & -0.24 & -0.50 \\
\hline RMSE & 2.71 & 3.56 & 1.56 & 2.36 & 0.91 & 2.10 \\
\hline $\operatorname{NMB}(\%)$ & 1.87 & 124.83 & -29.20 & -38.58 & -16.06 & -14.87 \\
\hline $\operatorname{NME}(\%)$ & 50.34 & 141.06 & 63.38 & 46.24 & 42.66 & 45.13 \\
\hline
\end{tabular}

\subsubsection{PM $_{2.5}$ and its chemical composition at the CASTNET, IMPROVE and STN sites}

Over the EUS for the $12 \mathrm{~km}$ resolution simulations of August 2006, the examination of the domain-wide bias and errors (Table 5a and Figs. 6-7) for different networks reveals that the WRF-CMAQ/CAM (WRF-CMAQ/RRTMG) consistently underestimated the observed $\mathrm{SO}_{4}^{2-}$ by $-23.0 \%$ $(-27.7 \%),-12.5 \%(-18.9 \%)$ and $-7.9 \%(-14.8 \%)$ at the CASTNET, IMPROVE and STN sites, respectively. Both models underestimated the observed $\mathrm{NH}_{4}^{+}$at the CASTNET sites (by $-23.0 \%$ for WRF-CMAQ/CAM and $-27.7 \%$ for WRF-CMAQ/RRTMG), and had a good performance at the STN sites, with the NMB less than $\pm 7 \%$. Both models overestimated the observed $\mathrm{SO}_{2}$ by more than $98 \%$ at the CASTNET sites. The comparison of the modeled and observed total sulfur $\left(\mathrm{SO}_{4}^{2-}+\mathrm{SO}_{2}\right)$ at the CASTNET sites in Fig. 8 and Table 5a reveals that both models overestimated the observed 

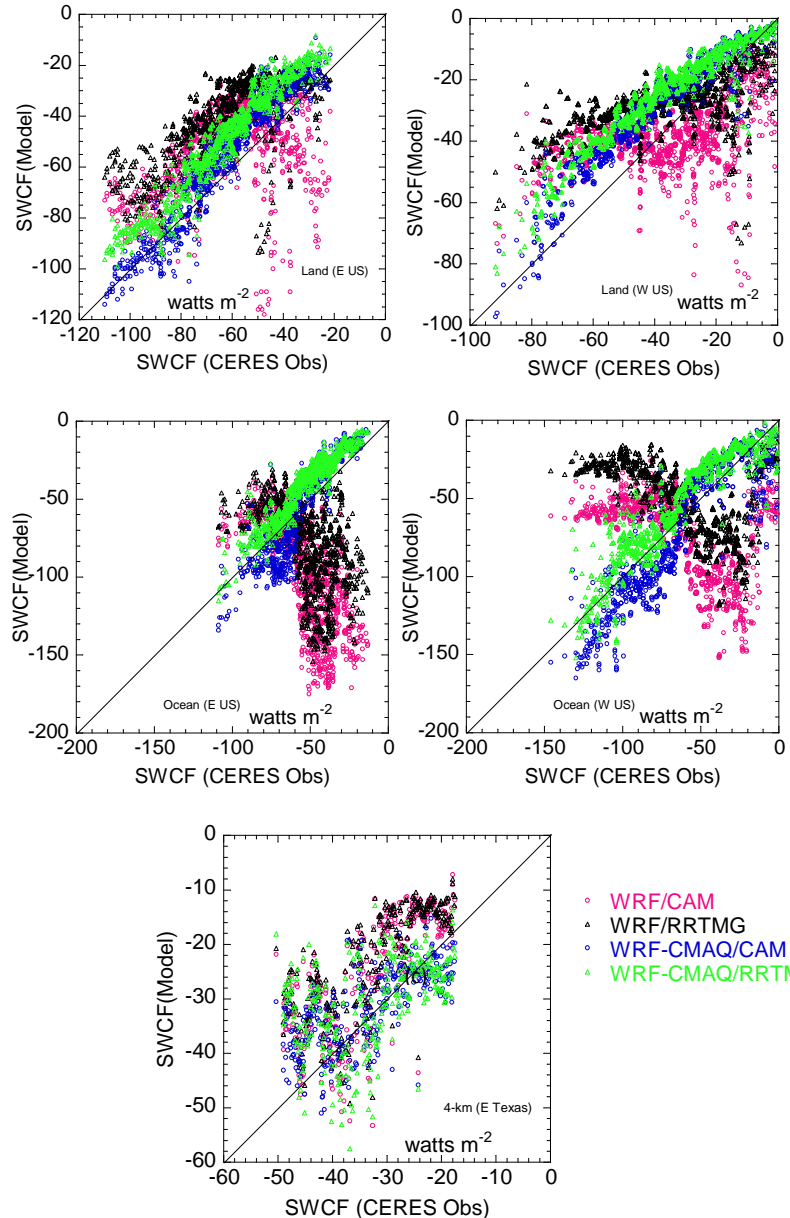

Figure 11. Scatter plots of modeled (WRF-CMAQ/CAM, WRFCMAQ/RRTMG, WRF/CAM and WRF/RRTMG) and observed monthly mean SWCF over the land and ocean of the eastern and western US for the $12 \mathrm{~km}$ resolution simulations (see Fig. 9) and over the eastern Texas domain for the $4 \mathrm{~km}$ resolution simulations (see Fig. 10) for August of 2006.

total sulfur systematically and that the modeled mean total sulfur values are higher than the observations by 25.3 and $21.8 \%$ for WRF-CMAQ/CAM and WRF-CMAQ/RRTMG, respectively. This indicates too much $\mathrm{SO}_{2}$ emission in the emissions inventory and that not enough gaseous $\mathrm{SO}_{2}$ concentrations were oxidized to produce aerosol $\mathrm{SO}_{4}^{2-}$ in the models. Although the NMB values for aerosol $\mathrm{NO}_{3}^{-}$are less than $60 \%$, as shown in Table 5a, the poor model performance for $\mathrm{NO}_{3}^{-}$(see the scatter plot in Fig. 6a and the correlation of less than 0.40 in Table 5a) is related in part to volatility issues for measurements associated with $\mathrm{NO}_{3}^{-}$and their exacerbation because of uncertainties associated with $\mathrm{SO}_{4}^{2-}$ and total $\mathrm{NH}_{4}^{+}$simulations in the model (Yu et al., 2005). Table 5a indicates that both models overestimated the observed mean OC, EC and TC concentrations at the IMPROVE sites by $25.9,54.9$ and $31.9 \%$ for WRF-CMAQ/CAM, respectively,
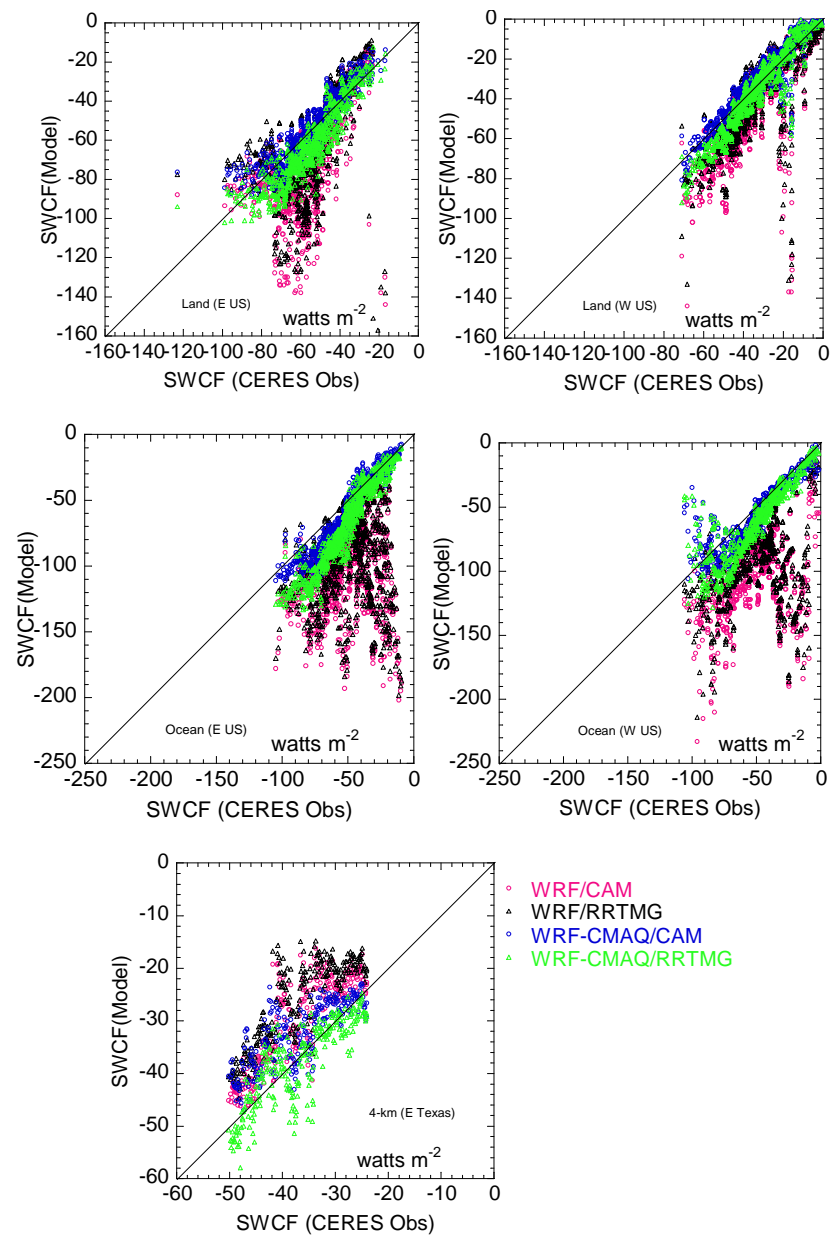

WRF/CAM WRF/RRTMG WRF-CMAQ/CAM WRF-CMAQ/RRTMG

Figure 12. Same as Fig. 11, but for September of 2006.

and by $23.8,52.2$ and $29.7 \%$ for WRF-CMAQ/RRTMG, respectively. As pointed out by Yu et al. (2012), since IMPROVE and the model emissions inventory use the thermooptical reflectance (TOR) method to define the split between OC and EC, while the STN network used the thermo-optical transmittance (TOT) method, only the determination of total carbon $(\mathrm{TC}=\mathrm{OC}+\mathrm{EC})$ is comparable between these two analysis protocols. Therefore, Table $5 \mathrm{a}$ only lists the performance results for TC comparisons from the STN sites. The very small NMB values $(< \pm 3 \%)$ but large NME values (> $48 \%$ ) for both models indicated that there is a large compensation error between the overestimation and underestimation of the observed TC concentrations at the STN sites in the model simulations. The model performances for $\mathrm{PM}_{2.5}$ at the IMPROVE and STN sites are reasonably good, with NMB values of -13.2 and $-0.7 \%$ for WRF-CMAQ/CAM, respectively, and -16.8 and $-6.2 \%$ for WRF-CMAQ/RRTMG, respectively. One of the reasons for the consistent underestimations of $\mathrm{PM}_{2.5}$ is the consistent underestimation of $\mathrm{SO}_{4}^{2-}$ due to the fact that the model generally underestimated the 
$12 \mathrm{~km}$ (CERES) LWCF

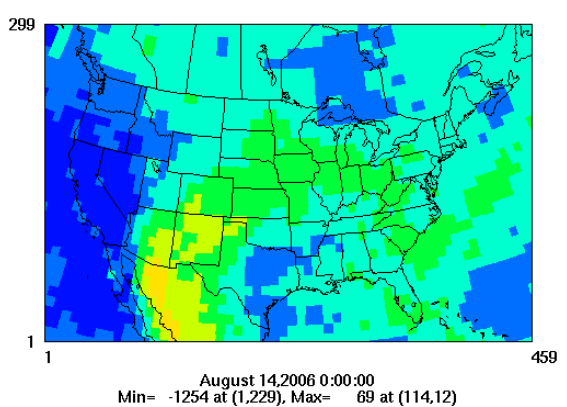

August $14,20060: 00: 00$
Min $=-1254$ at $(1,229), \operatorname{Max}=\quad 69$ at $(114,12)$
WRF-CMAQ (CAM)

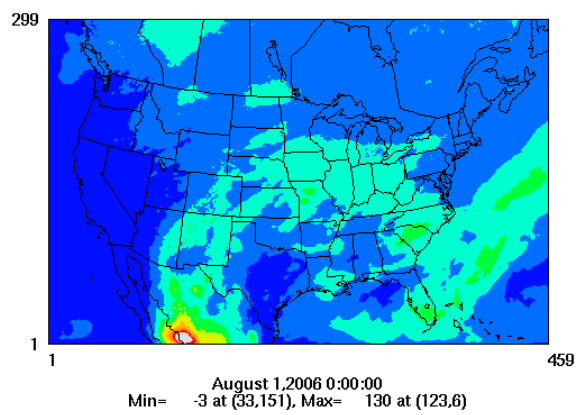

WRF-only (CAM)

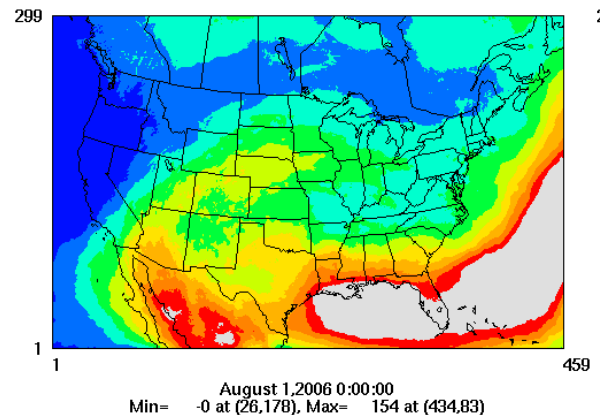

WRF-CMAQ (RRTMG)

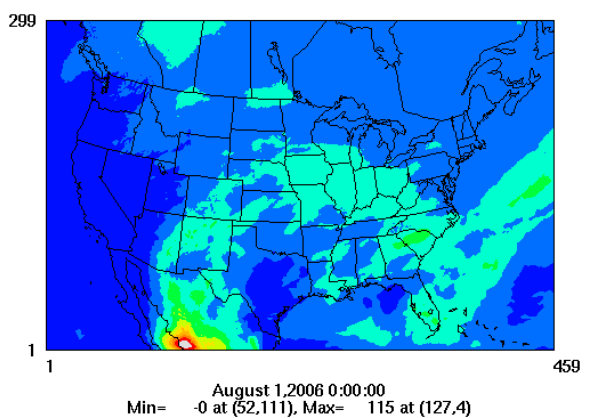

WRF-only (RRTMG)

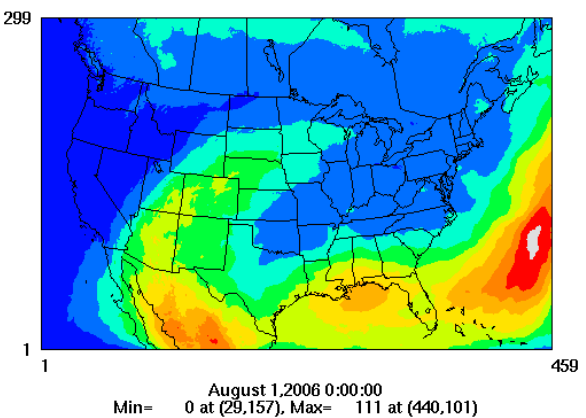

Figure 13. Same as Fig. 9, but for LWCF.

cloud field as analyzed below, which caused underestimation of aqueous $\mathrm{SO}_{4}^{2-}$ production.

Over the WUS for the $12 \mathrm{~km}$ resolution simulations of $\mathrm{Au}-$ gust 2006, Table 5b shows that WRF-CMAQ/CAM (WRFCMAQ/RRTMG) still consistently underestimated the observed $\mathrm{SO}_{4}^{2-}$ by $-23.9 \%(-24.5 \%)$ and $-4.2 \%(-9.5 \%)$ at the CASTNET and STN sites, respectively, while both models had slight overestimations of the observed $\mathrm{SO}_{4}^{2-}$ at the IMPROVE sites, with the NMB less than $15 \%$. Both models underestimated the observed $\mathrm{NH}_{4}^{+}$at both the CASTNET and STN sites by more than $34 \%$. Both models also overestimated the observed $\mathrm{SO}_{2}$ by more than $47 \%$ at the CASTNET sites. The comparison of the modeled and observed total sulfur $\left(\mathrm{SO}_{4}^{2-}+\mathrm{SO}_{2}\right)$ at the CASTNET sites in Fig. 8 and Table $5 \mathrm{~b}$ reveals that both models had a good performance for the observed total sulfur, with NMB less than $6 \%$. This indicates a reasonable total $\mathrm{SO}_{2}$ emission in the emissions inventory and that gaseous $\mathrm{SO}_{2}$ concentrations were not oxidized enough to produce aerosol $\mathrm{SO}_{4}^{2-}$ in the models over the WUS. Like the EUS, both models have poor performance for aerosol $\mathrm{NO}_{3}^{-}$, but had serious underestimations in all networks by a factor of more than 2, especially at both the CASTNET and STN sites, as shown in Fig. $6 \mathrm{~b}$ and Table $5 \mathrm{~b}$. This indicates overly low $\mathrm{NO}_{\mathrm{x}}$ emissions in the emissions inventory over the WUS. Table $5 \mathrm{~b}$ indicates that both models overestimated the observed mean OC, EC and TC concentrations at the IMPROVE sites by more than $38.6 \%$, while both models had slight underestimations of TC at the STN sites by less than $13 \%$. The model performances for $\mathrm{PM}_{2.5}$ at the IMPROVE and STN sites are reasonably good, with NMB values of less than $15 \%$.

The results for September are different from those of $\mathrm{Au}-$ gust in the following respects over the EUS and the WUS. Over the EUS, both models had slight overestimations of $\mathrm{SO}_{4}^{2-}$ at both the IMPROVE and STN sites, with the NMB less than $20 \%$, but with slight underestimations at the CASTNET sites, with NMB less than $-11 \%$, as shown in Table 7a. This is consistent with the fact that both models generally overestimated the cloud field for September, as analyzed below. Both models consistently overestimated $\mathrm{NH}_{4}^{+}$in September by more than $20 \%$, especially at the CASTNET sites. Both models also had consistent overestimations of the observed $\mathrm{SO}_{2}$ and total sulfur at the CASTNET sites, like in August, and consistent overestimations of mean OC, EC and TC concentrations at the IMPROVE sites by more than $32 \%$. The model performance for $\mathrm{PM}_{2.5}$ at the IMPROVE and STN sites is reasonably good, with general consistent overestimations instead of underestimations. Table 7a shows that both models generally overestimated all $\mathrm{PM}_{2.5}$ species $\left(\mathrm{SO}_{4}^{2-}, \mathrm{NO}_{3}^{-}, \mathrm{NH}_{4}^{+}, \mathrm{OC}, \mathrm{EC}, \mathrm{TC}\right)$ at the IMROVE and STN sites.

Over the WUS for September, both models had similar performances for $\mathrm{SO}_{4}^{2-}, \mathrm{NH}_{4}^{+}, \mathrm{SO}_{2}$, and total sulfur to those of August for different networks. Like August, both models 
$4 \mathrm{~km}$ (CERES) LWCF

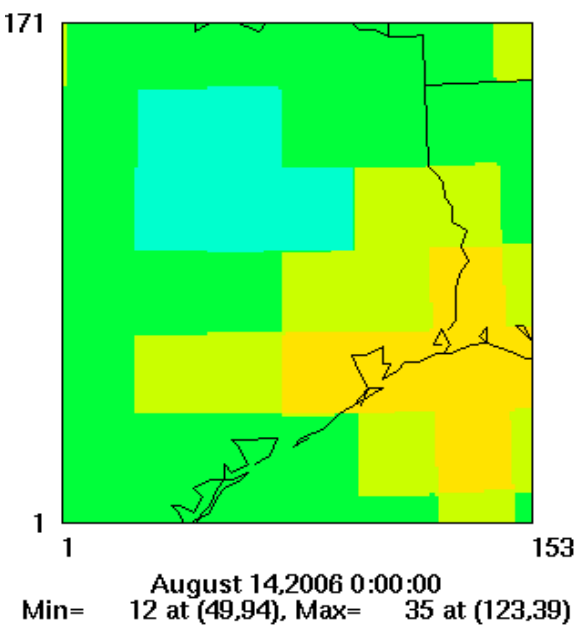

WRF-CMAQ (CAM)

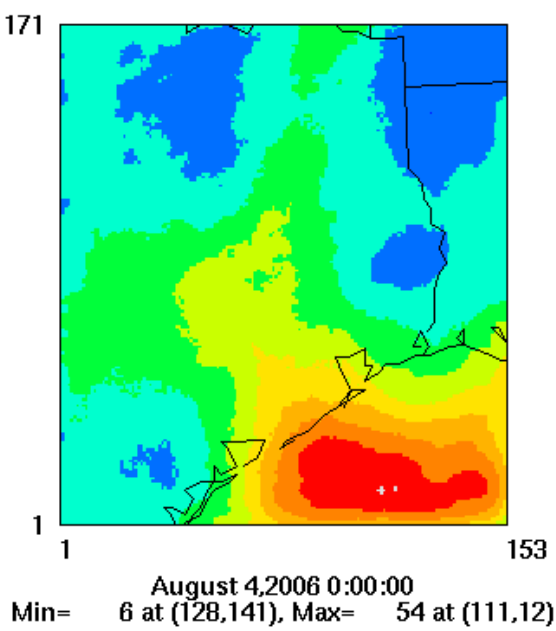

WRF-only (CAM)

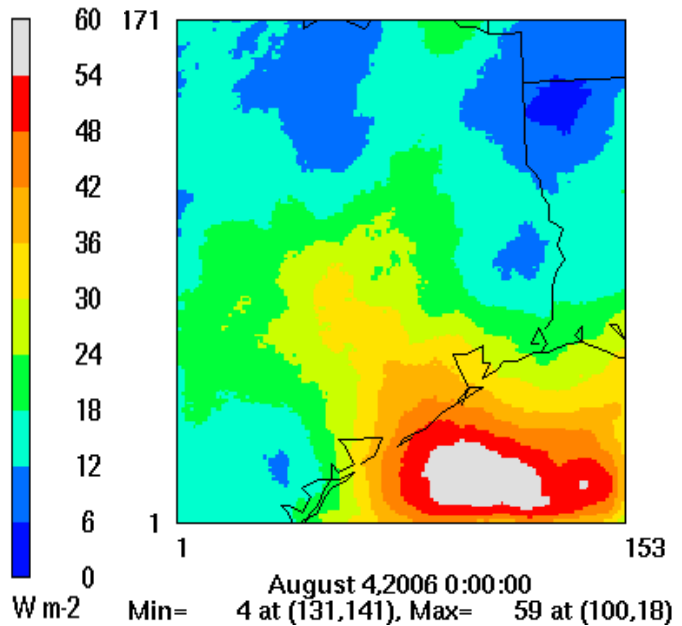

WRF-CMAQ (RRTMG)

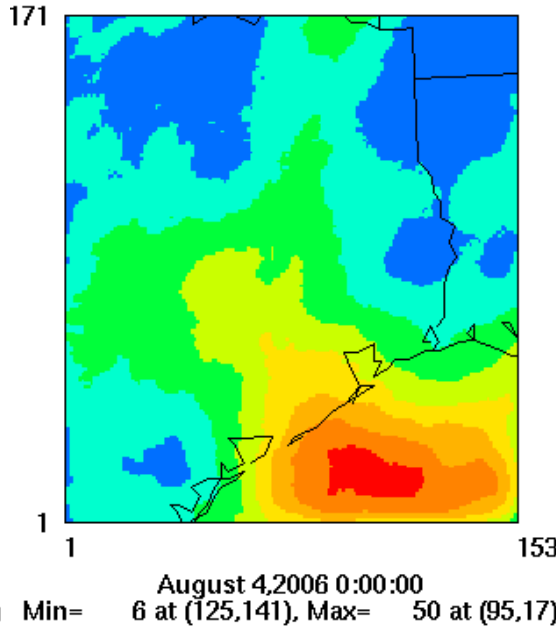

WRF-only (RRTMG)

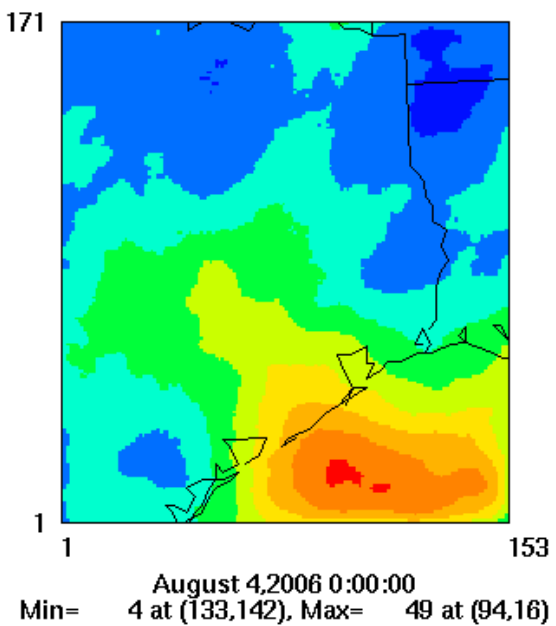

Figure 14. Same as Fig. 10, but for LWCF.

had consistent overestimations of OC, EC and TC concentrations at the IMPROVE sites, but also had an overestimation of TC at the STN sites, as shown in Table 7b in September. Both models had more overestimations of $\mathrm{PM}_{2.5}$ at the IMPROVE and STN sites in September than in August over the WUS due to the fact that both models overestimated TC more in September than in August.

\subsection{Model performance evaluation for cloud properties (SWCF, LWCF, COD, and cloud fraction) with CERES satellite observations}

To gain insights into the model performance for the parameterizations of cloud-mediated radiative forcing due to aerosols (i.e., indirect aerosol forcing) in the two-way coupled WRF-CMAQ modeling system, the CERES satellite observations of cloud properties (SWCF, LWCF, COD and cloud fraction) were used. To compare the model results with the CERES observations, the $1.0^{\circ} \times 1.0^{\circ}$ CERES data are interpolated to the model domains for the $12 \mathrm{~km}$ resolution over the CONUS, and the $4 \mathrm{~km}$ resolution over eastern Texas. The results for SWCF, LWCF, $|\mathrm{SWCF}| / \mathrm{LWCF}, \mathrm{COD}$ and cloud fractions over the land and ocean areas of the EUS and WUS are shown in Figs. 9 to 12, 13 to 16, 17 to 18,19 to 21 and 22 to 23, respectively. Tables 9 to 12 statistically summarize the model performance for each case in August and September. For reference, the results for the WRF only with the RRTMG and CAM radiation schemes are also shown in the figures and tables. Since the CERES observational data are at a coarser resolution than the model, model results with the same observation are averaged to represent the model results for that observation when scatter plots in Figs. 11, 12, 15, 16, 17, 18, 20, 21, 22 and 23 are drawn. As shown in Figs. 9, 11, 12, 

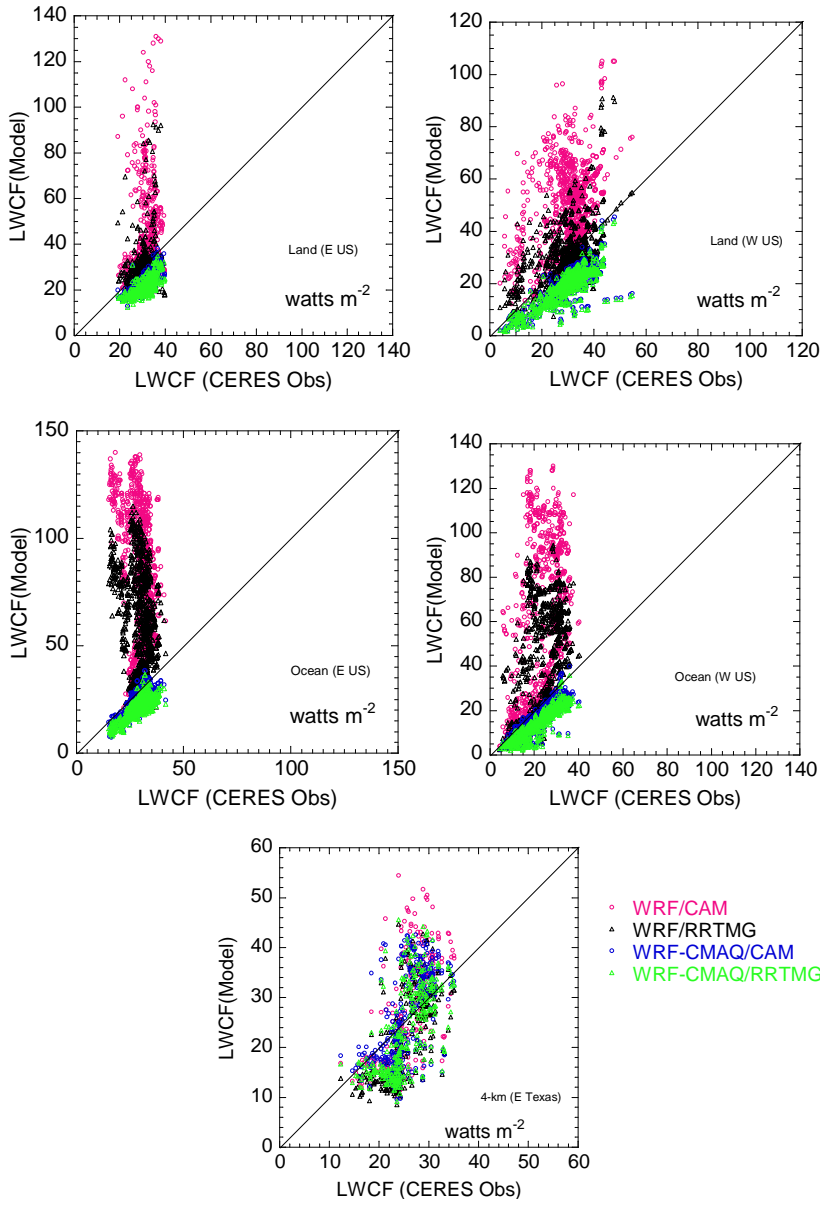

Figure 15. Same as Fig. 11, but for LWCF.

$13,15,16,17,18,19,20$ and 21 , the model performances are very different over the land and ocean areas for the $12 \mathrm{~km}$ resolution simulations over the CONUS domain. Therefore, the results over the land and ocean areas are presented separately for these simulations in the following analysis.

\subsubsection{SWCF and LWCF comparisons}

Over the land areas of the EUS in August of 2006, as shown in Tables 9 and 10, the domain means of the CERES observations, WRF-CMAQ/CAM, WRF-CMAQ/RRTMG, WRF/CAM, and WRF/RRTMG for SWCF (LWCF), are -60.90 (30.26), -53.75 (21.83), -47.23 (20.95), -51.13 (37.28), and $-39.36(26.98) \mathrm{W} \mathrm{m}^{-2}$, respectively. Over the land areas of the WUS in August of 2006, the domain means of the CERES observations, WRF-CMAQ/CAM, WRFCMAQ/RRTMG, WRF/CAM, and WRF/RRTMG for SWCF (LWCF), are -37.18 (30.33), -27.58 (19.97), -24.76 (19.58), -39.54 (46.10), and $-27.71(29.23) \mathrm{W} \mathrm{m}^{-2}$, respectively. According to the CERES observations, the SWCF values over the land of the EUS are much more negative than those of the WUS, whereas their LWCF values are very
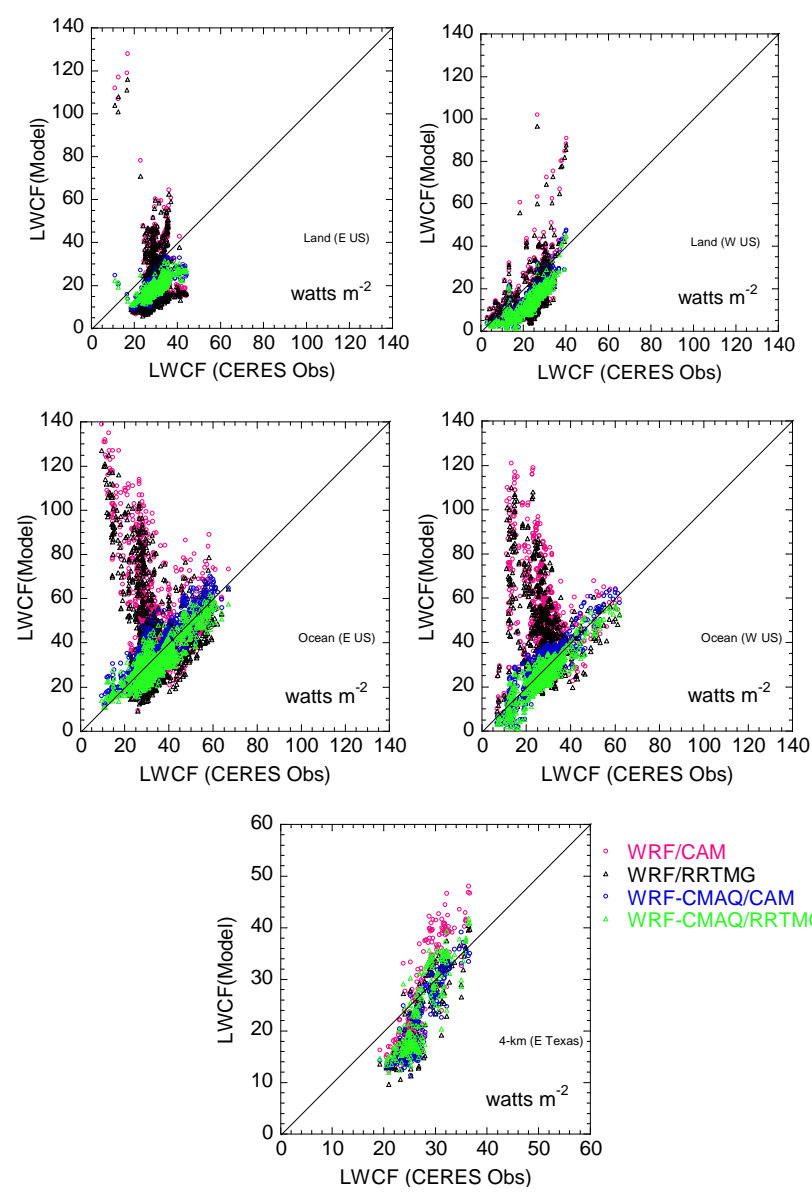

WRF/CAM WRF/RRTMG WRF-CMAQ/CAM
WRF-CMAQ/RRTMG

Figure 16. Same as Fig. 15, but for September of 2006.

close. The NMB values for SWCF (LWCF) over the land of the EUS in August of 2006 are $-11.74 \%(-27.86 \%)$ and $-22.45 \%(-30.76 \%)$ for WRF-CMAQ/CAM and WRFCMAQ/RRTMG, respectively, whereas over the land of the WUS, they are $-25.82 \%(-34.15 \%)$ and $-33.40 \%$ $(-35.45 \%)$, respectively. The consistent underestimations of SWCF and LWCF by both WRF-CMAQ/CAM and WRFCMAQ/RRTMG indicate that the WRF-CMAQ model generally underestimated the cloud field, although the WRF-CMAQ/CAM produced more cloud than the WRFCMAQ/RRTMG over the CONUS (both EUS and WUS) in August of 2006. The model performance for the land of the EUS is slightly better than that of the WUS. The results over eastern Texas from the $12 \mathrm{~km}$ resolution simulations are similar to those over the CONUS, as shown in Table 9. One of the reasons for the underestimation of cloud in both WRFCMAQ/CAM and WRF-CMAQ/RRTMG is that the subgrid convective clouds do not include these aerosol indirect effects that may pose an issue for these $12 \mathrm{~km}$ simulations. This is in agreement with the fact that both WRF-CMAQ/CAM and WRF-CMAQ/RRTMG captured SWCF and LWCF very 

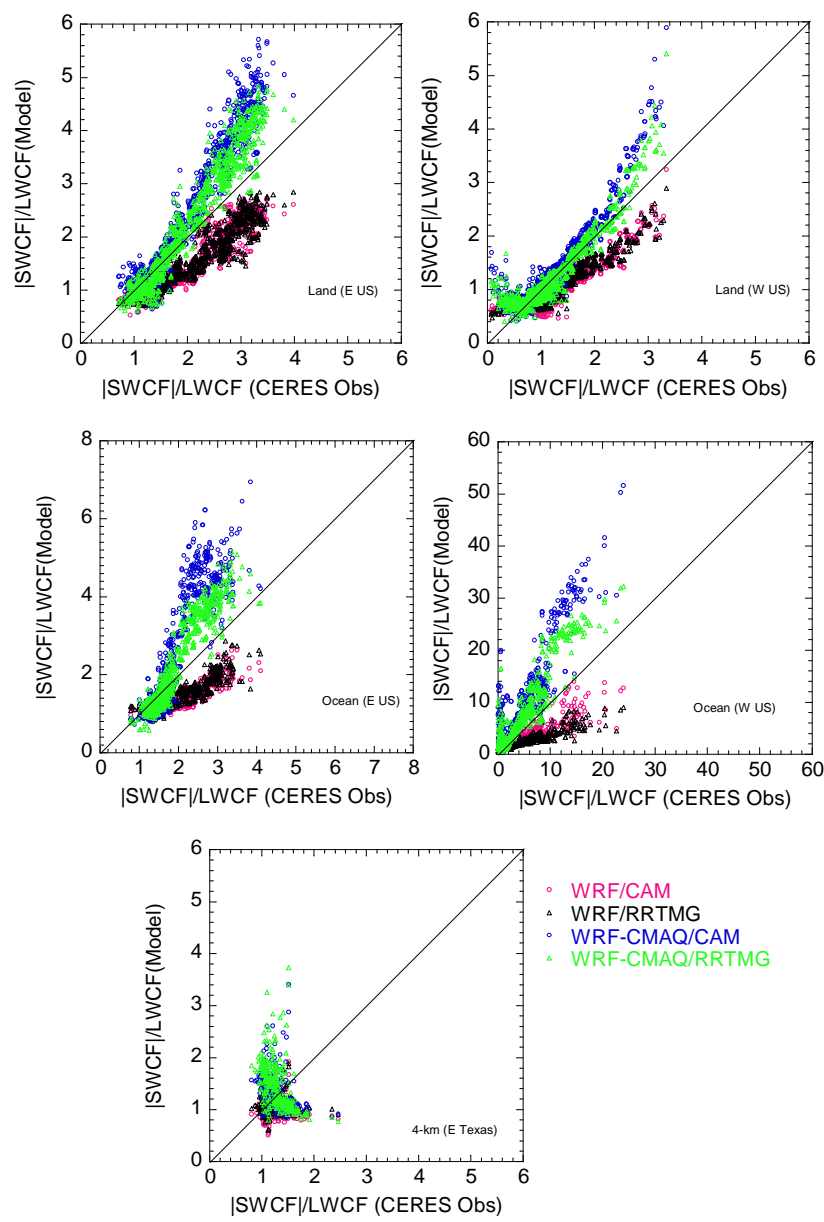

WRF/CAM WRF/RRTMG WRF-CMAQ/CAM WRF-CMAQ/RRTMG

Figure 17. Same as Fig. 11, but for the ratios of monthly mean absolute (SWCF) to LWCF for August of 2006.

well for the $4 \mathrm{~km}$ simulations over eastern Texas, with NMBs within $\pm 10 \%$, as shown in Figs. 10, 11, 14 and 15 and Tables 9 and 10. This is because the $4 \mathrm{~km}$ simulations were able to resolve subgrid convective clouds and include the aerosol effects. On the other hand, underestimation of $\mathrm{PM}_{2.5}$ over the land areas of the EUS in August of 2006 as shown in Table 5a may also cause the underestimation of the CCN concentrations, leading to the underestimation of cloud fields.

Over the ocean areas of the EUS in August 2006, the NMB values for SWCF (LWCF) are $-7.75 \%(-19.99 \%)$ and $-23.69 \%(-27.70 \%)$ for WRF-CMAQ/CAM and WRF-CMAQ/RRTMG, respectively, whereas over the ocean areas of the WUS, they are $9.20 \%(-27.90 \%)$ and $-14.64 \%(-34.79 \%)$, respectively. WRF-CMAQ/CAM performed better for both SWCF and LWCF than WRFCMAQ/RRTMG. CAM and RRTMG radiation schemes used different parameterizations to calculate the optical properties of cloud, in part leading to the different results for WRFCMAQ/CAM and WRF-CMAQ/RRTMG. Figures 11 and 15 and Tables 9 and 10 indicate that the WRF-only cases (both WRF/CAM and WRF/RRTMG) did not perform as well as
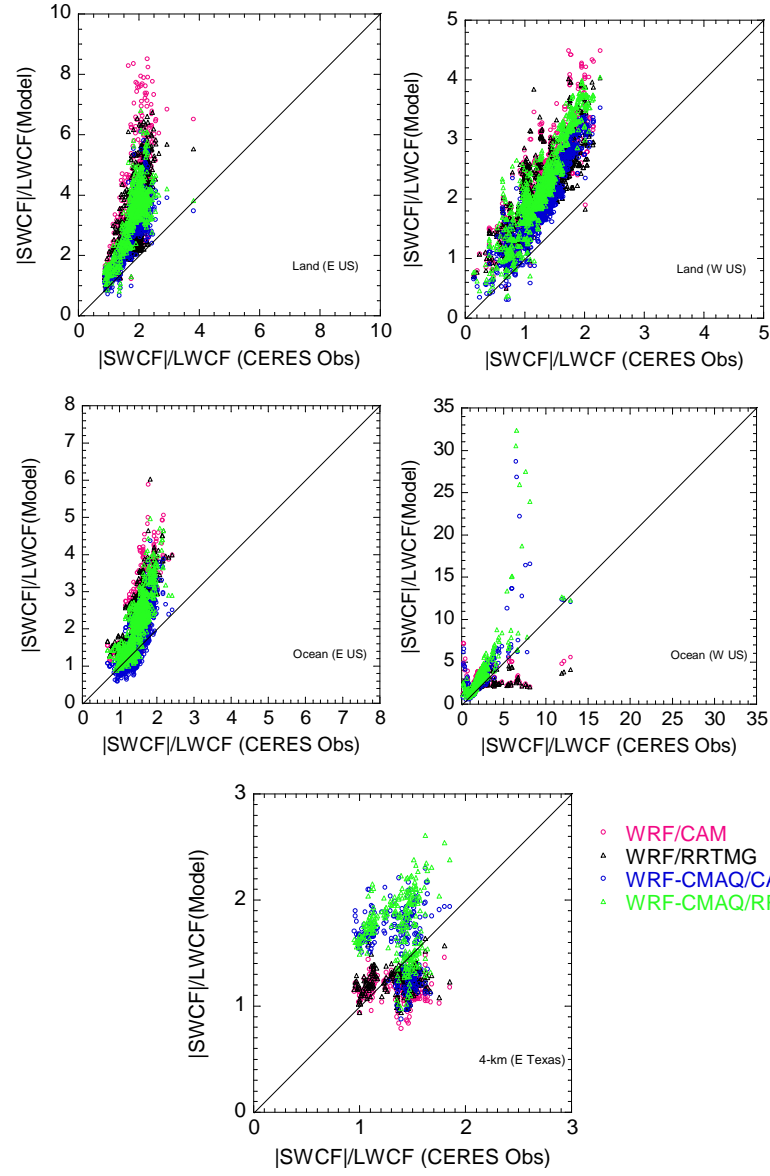

WRF/CAM WRF/RRTMG WRF-CMAQ/CAM
WRF-CMAQ/RRTMG

Figure 18. Same as Fig. 17, but for September of 2006.

WRF-CMAQ, especially over the ocean areas, due to the fact that in the default WRF, cloud effective radii over the land and ocean are assumed to be 8.0 and $14.0 \mu \mathrm{m}$, respectively, and ice effective radius is assumed to be $14.0 \mu \mathrm{m}$ in the formulation for the calculation of the effective radius originally developed by Kiehl (1994a). The results in Figs. 11 and 15 strongly indicate that the assumption of $14.0 \mu \mathrm{m}$ of cloud effective radius over the ocean is not reasonable, because the WRF-only cases completely misplaced cloud locations, with negative correlations as shown in Tables 9 and 10. The results of WRF-CMAQ/CAM and WRF-CMAQ/RRTMG have significant improvements for both SWCF and LWCF predictions over both the ocean and land relative to those of the WRF-only cases. Grabowski (2006) also found that the formulations for the calculations of the cloud effective radius have a significant impact on the estimation of aerosol indirect effects.

Over the land areas of both the EUS and WUS for September 2006, both WRF-CMAQ/CAM and WRFCMAQ/RRTMG captured SWCF slightly better than those of August of 2006, with NMBs within $-5 \%$, as shown in Table 9, and Figs. 11 and 12. Both WRF-CMAQ/CAM and WRF-CMAQ/RRTMG also underestimated both SWCF 
$12 \mathrm{~km}$ (CERES) COD

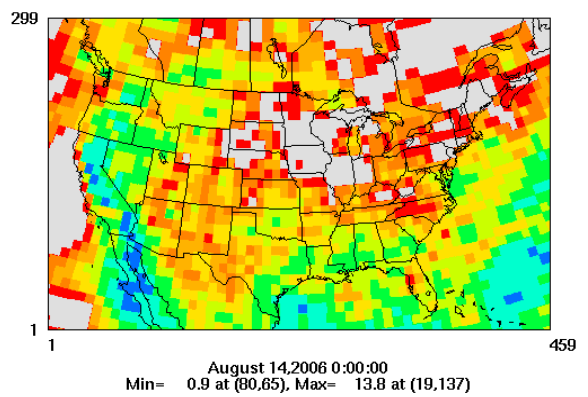

Min= $\quad \begin{aligned} & \text { August } 14,20060: 00: 00 \\ & 0.9 \text { at }(80,65), \operatorname{Max}=13.8 \text { at } \\ & (19,137)\end{aligned}$
WRF-CMAQ (CAM)

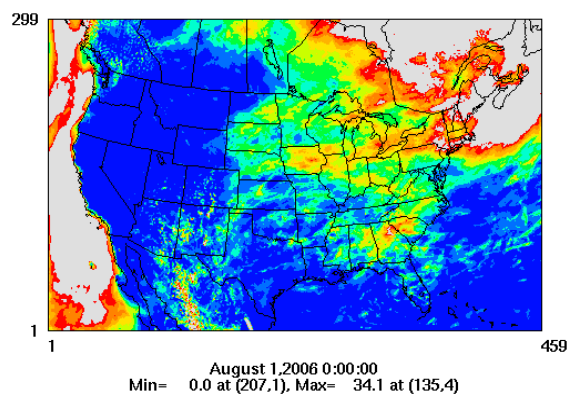

WRF-only (CAM)

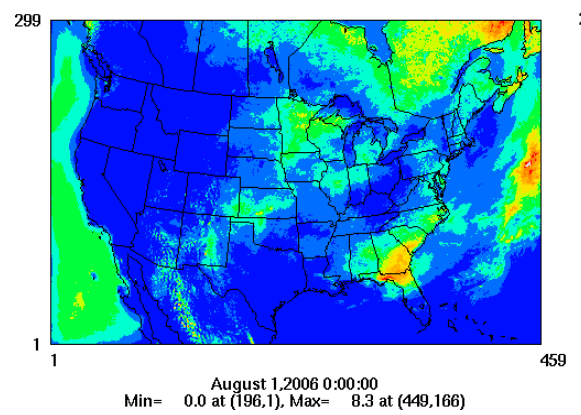

WRF-CMAQ (RRTMG)

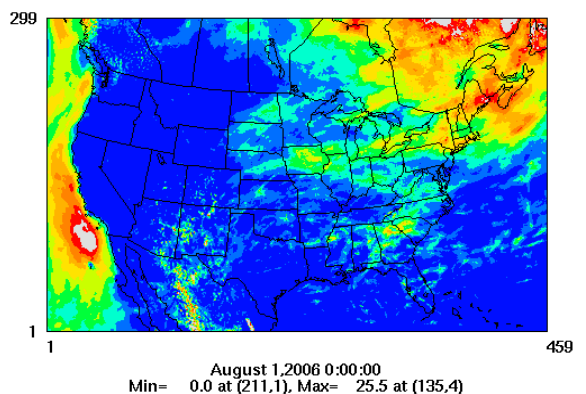

WRF-only (RRTMG)

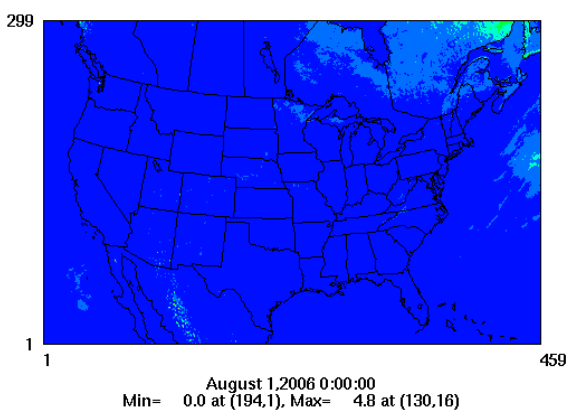

Figure 19. Same as Fig. 9, but for COD for August of 2006.

and LWCF values over the land areas as in August 2006, possibly because the AIE on subgrid convective clouds are not included for the model simulations at the $12 \mathrm{~km}$ resolution. With cloud resolving and global models, several studies showed the effects of anthropogenic aerosols on convective clouds, pointing to invigoration of deep convective clouds. For example, Isaksen et al. (2009) found that the impacts of anthropogenic aerosols on net radiation at the TOA ranged from -3.5 to $-1.0 \mathrm{~W} \mathrm{~m}^{-2}$ for convective clouds with satellite data and models. In a recent global modeling study, Wang et al. (2014) concluded that anthropogenic pollution for the present-day (2000) conditions as compared to pre-industrial conditions (1850) impacted the convective clouds through increases in cloud droplet number concentration and liquid and ice water paths, leading to broadened anvils of the convective clouds. These changes in convective cloud micro- and macrophysical parameters resulted in increases in SWCF of about $2.5 \mathrm{~W} \mathrm{~m}^{-2}$ and LWCF of about $1.3 \mathrm{~W} \mathrm{~m}^{-2}$ at TOA (Wang et al., 2014). Other reasons for underestimations in SWCF and LWCF in the present study may be related to model configuration such as placement of the model top at about $50 \mathrm{hPa}$, resulting in a less accurate representation of cirrus clouds or even the absence of very high-altitude cirrus clouds. Neglecting AIE on shallow subgrid-scale convective clouds as well as subgrid-scale layer clouds and subgrid-scale mixed phase clouds may also lead to the underestimations in SWCF and LWCF in the current work. The SWCF values for Septem- ber are about $10 \%$ lower than August over the land areas, as shown in Table 9. Over the ocean areas for September of 2006, both WRF-CMAQ/CAM and WRF-CMAQ/RRTMG captured both SWCF and LWCF very well, with slight overestimations (NMB values less than 16\%). For the $4 \mathrm{~km}$ simulations over eastern Texas in September as in August, both WRF-CMAQ/CAM and WRF-CMAQ/RRTMG captured SWCF and LWCF very well, with NMBs within $\pm 12 \%$ for SWCF and NMB values less than $\pm 21 \%$ for LWCF, as shown in Figs. 12 and 16 and Tables 9 and 10. Similar to August 2006, the results of WRF-CMAQ/CAM and WRF-CMAQ/RRTMG have significant improvements for both SWCF and LWCF, with much better correlations relative to those of WRF default cases at $12 \mathrm{~km}$ resolutions, especially over the ocean. For the $4 \mathrm{~km}$ simulations over eastern Texas, both WRF-CMAQ/CAM and WRF-CMAQ/RRTMG have significantly better performances for SWCF than the corresponding WRF/CAM and WRF/RRTMG in both August and September in terms of the NMB values as listed in Table 9, whereas for LWCF in Table 10, both WRFCMAQ/CAM and WRF-CMAQ/RRTMG have better performances in August and close performances in September relative to the corresponding WRF/CAM and WRF/RRTMG. This indicates that it is necessary to include the aerosol fields from the air quality model (CMAQ here) in the meteorological models (WRF here) to simulate cloud fields. Note that other factors such as the turbulence, convection and/or 

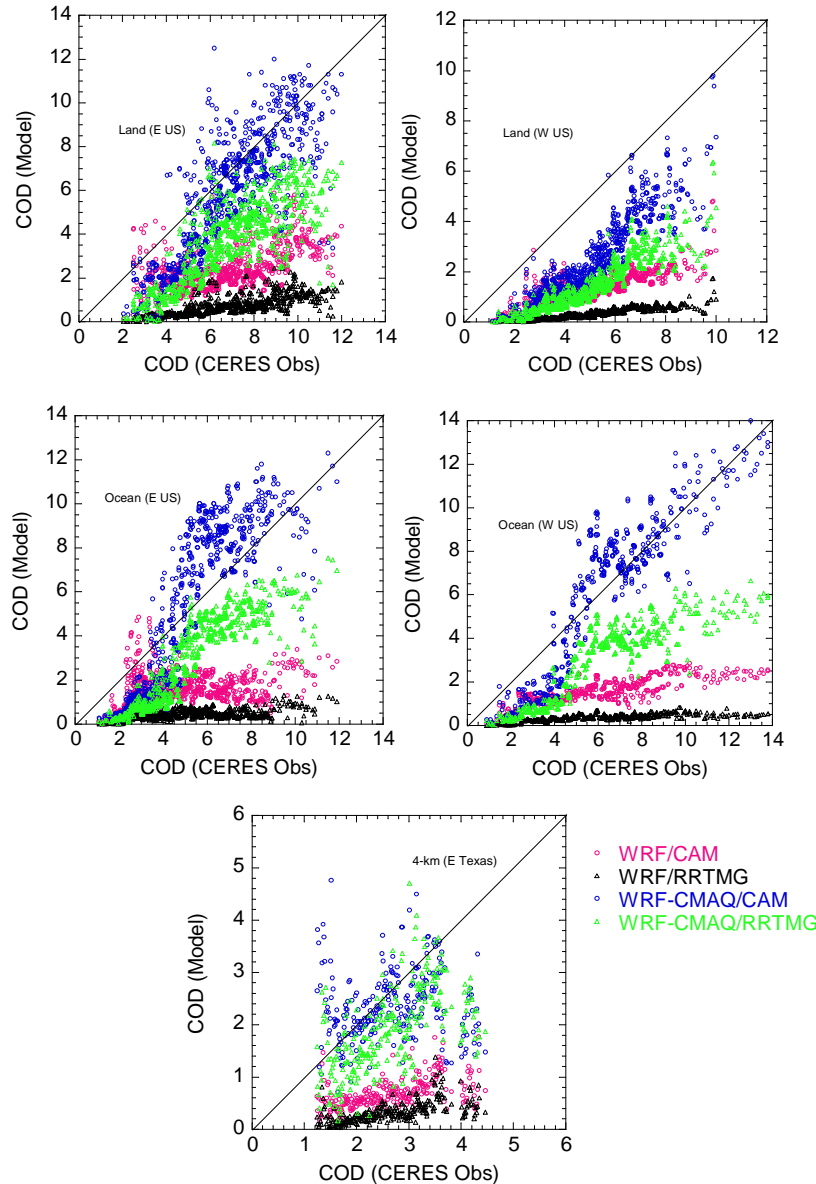

Figure 20. Same as Fig. 11, but for COD for August of 2006.

microphysics parameterizations can also be very important for simulating cloud fields.

Cloud radiative forcing depends on both cloud radiative properties and cloud microphysical properties. The SWCF is mostly dominated by low and middle clouds, except in regions of deep convection, where very bright stratiform anvils may contribute significantly, whereas the LWCF is mostly dominated by high clouds (Lauer et al., 2009). The ratio of $|\mathrm{SWCF}|$ and LWCF $(N=|\mathrm{SWCF}| / \mathrm{LWCF})$ can be used to indicate averaged cloud height, e.g., smaller $N$ with higher clouds (Su et al., 2010). As summarized by Taylor (2012), $|\mathrm{SWCF}| \gg$ LWCF for low clouds, stratocumulus and cumulus and LWCF $\gg|S W C F|$ for high clouds, cirrus and cirrostratus (Hartmann and Doelling, 1991; Stephens, 2005), whereas there is a cancelation between SWCF and LWCF $(|\mathrm{SWCF}| \approx \mathrm{LWCF})$ for deep convective clouds (Kiehl and Ramanathan, 1990; Kiehl, 1994b). The ratios of $|\mathrm{SWCF}|$ and LWCF ( $N$ values) in Fig. 17 show that over both the land and ocean areas of the EUS in August 2006, both WRFCMAQ/CAM and WRF-CMAQ/RRTMG performed very well when the $N$ values were less than $\sim 2.5$, but significantly overestimated observed $\mathrm{N}$ values when $N$ was greater
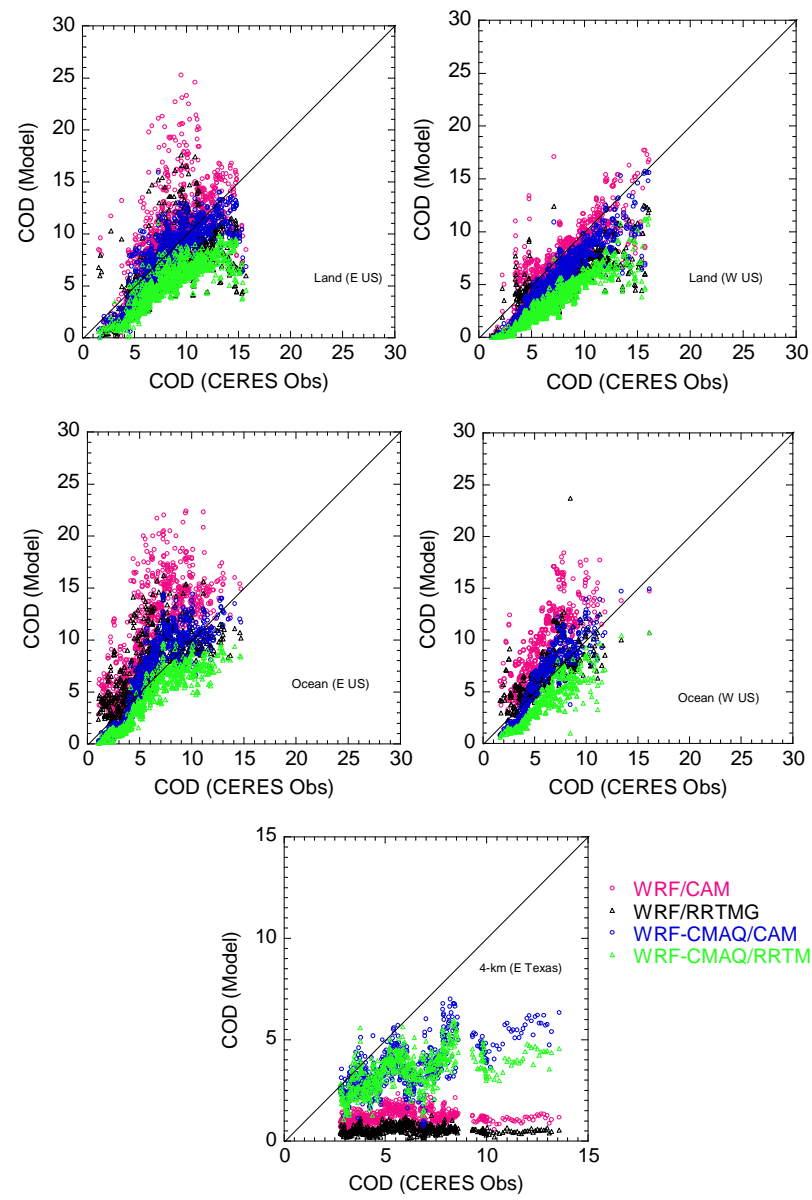

WRF/CAM WRF/RRTMG WRF-CMAQ/CAM WRF-CMAQ/RRTMG

Figure 21. Same as Fig. 11, but for COD for September of 2006.

than $\sim 2.5$, indicating that both configurations overestimated low clouds, stratocumulus and cumulus. On the other hand, over both the land and ocean areas of the WUS in August 2006, both WRF-CMAQ/CAM and WRF-CMAQ/RRTMG performed very well when $\sim 0.2<N<\sim 2.5$, and significantly overestimated the observed $N$ values when $N$ was greater than $\sim 2.5$ or when $N$ was less than $\sim 0.2$, as shown in Fig. 17, suggesting that both configurations underestimated high clouds, cirrus and cirrostratus but overestimated low clouds, stratocumulus and cumulus over the land and ocean areas of the WUS. Figure 17 also shows that there are not many high clouds, cirrus and cirrostratus over both the land and ocean areas of the EUS in August 2006, according to both observations and model results. The results also indicate that the WRF default cases underestimate the observed $N$ values when $N$ is greater than $\sim 2.0$ for the whole domain, indicating that both WRF/CAM and WRF/RRTMG underestimated low clouds, stratocumulus and cumulus everywhere. Both WRF-CMAQ/CAM and WRF-CMAQ/RRTMG performed very well when $\sim 0.2<N<\sim 2.5$ over the model domain, much better than the corresponding WRF/CAM and 

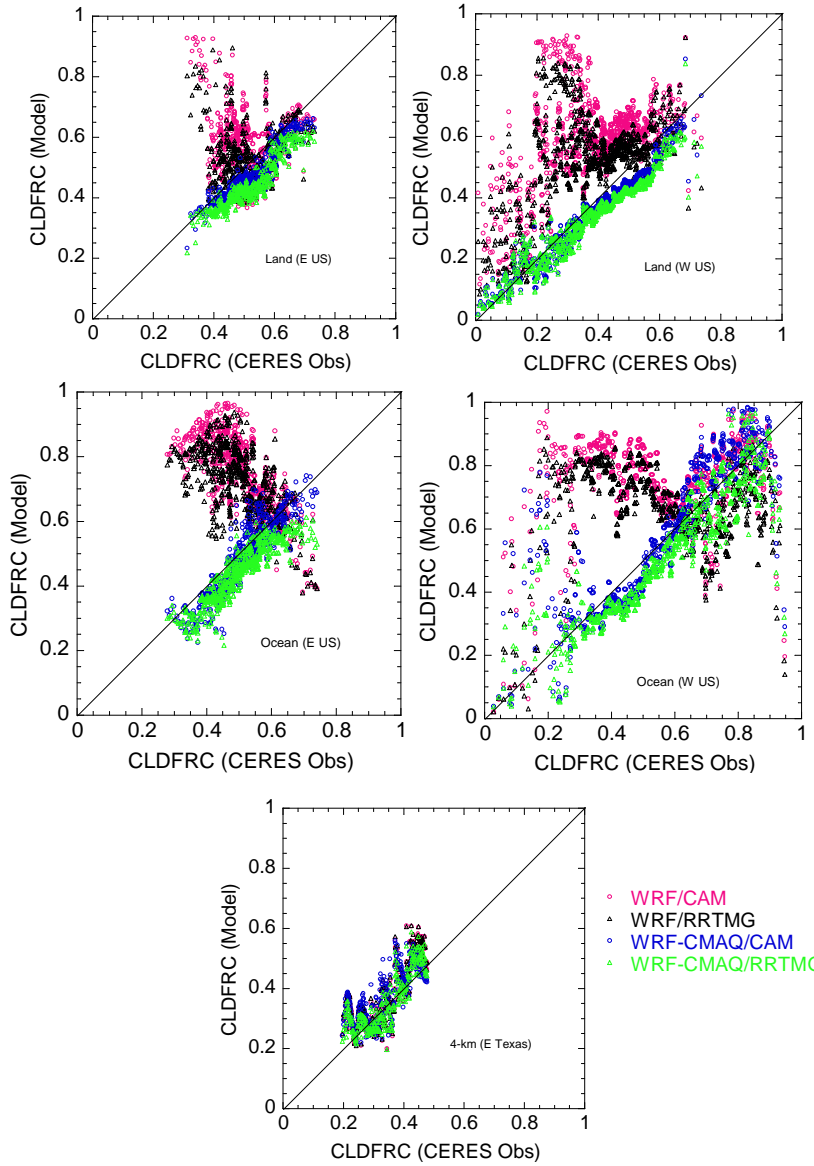
WRF/CAM
WRF/RRTMG WRF-CMAQ/CAM WRF-CMAQ/RRTMG

Figure 22. Same as Fig. 11, but for cloud fractions (CLDFRC) for August of 2006.

WRF/RRTMG, indicating the importance of including the aerosol effect in the meteorological models.

The results of the $N$ values for September 2006 in Fig. 18 are similar to those for August, except that the WRF default cases (WRF/CAM and WRF/RRTMG) also overestimated low clouds, stratocumulus and cumulus over the model domain and the land areas of the WUS and that there were not many high clouds, cirrus and cirrostratus, according to both observations and model results in September.

\subsubsection{COD comparisons}

The COD values are determined by the cloud liquid water path (LWP) and the cloud effective radius, and the LWP is strongly dependent on external dynamical forcing parameters, such as the large-scale divergence rate (Ghan et al., 2001a; Lu and Seinfeld, 2005; Seinfeld and Pandis, 1998). Comparisons of mean COD from models with observations for August are shown in Fig. 19, and their scatter plots are shown in Figs. 20 and 21. Table 11 statistically summarizes the results of model performances. Over the land areas of both the EUS and the WUS in August and Septem-
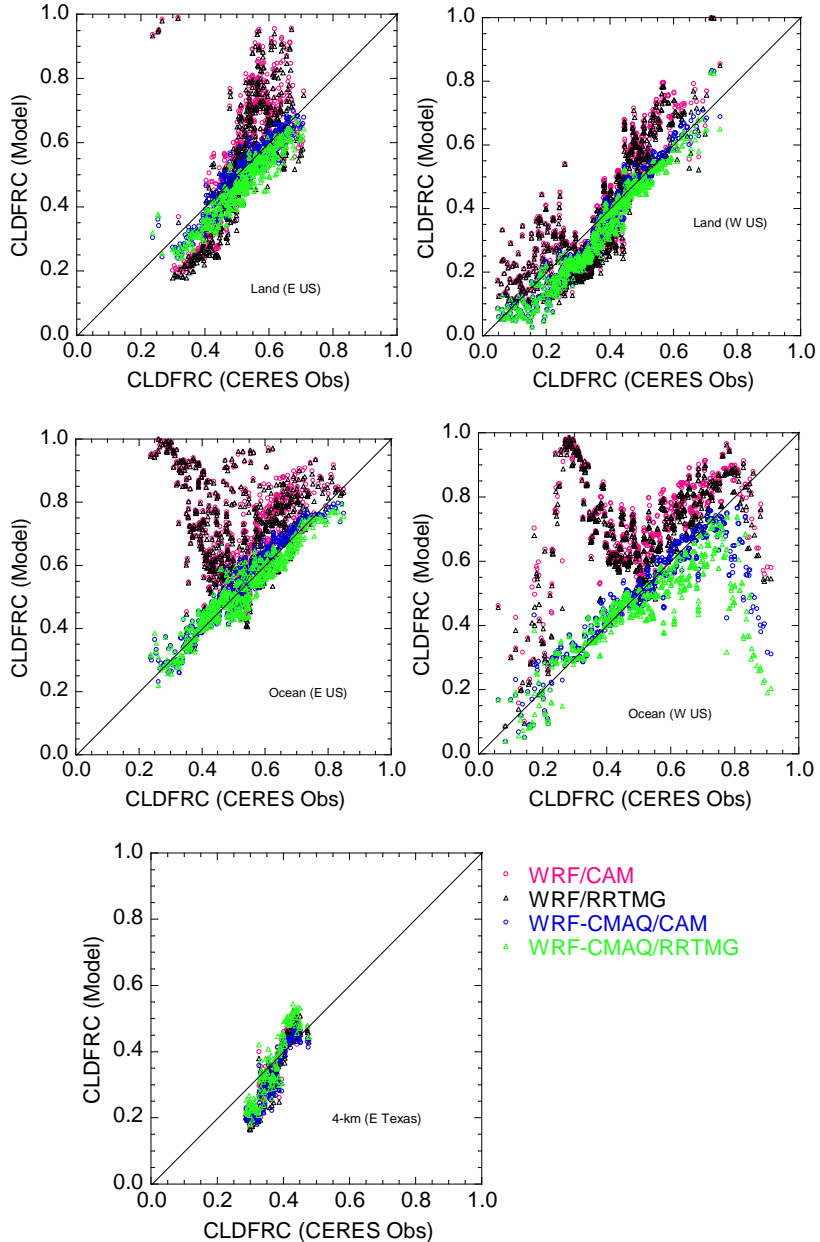

WRF/CAM

WRF/RRTMG

WRF-CMAQ/CAM

WRF-CMAQ/RRTMG

Figure 23. Same as Fig. 11, but for cloud fractions (CLDFRC) for September of 2006.

ber, both WRF-CMAQ/CAM and WRF-CMAQ/RRTMG consistently underestimated the observed COD, with more underestimation over the WUS, as shown in Table 11 and Figs. 20 and 21, being consistent with the general underestimations of SWCF as indicated in Sect. 4.2.1. Over the ocean areas of both the EUS and the WUS in August and September, WRF-CMAQ/CAM captured the observed COD very well, with NMBs within $\pm 10 \%$, whereas WRFCMAQ/RRTMG underestimates the observed COD by more than $28 \%$. The results of COD for the $4 \mathrm{~km}$ simulations over the eastern Texas domain are better than those of the $12 \mathrm{~km}$ simulations over the land of the EUS in August for both WRF-CMAQ/CAM and WRF-CMAQ/RRTMG, as shown in Table 11. However, in September, the results of COD for the $4 \mathrm{~km}$ simulations over the eastern Texas domain are not better relative to those of the $12 \mathrm{~km}$ simulations. One of the reasons for this is that in September, all model results (WRF-CMAQ/CAM, WRF-CMAQ/RRTMG, WRF/CAM and WRF/RRTMG) underestimated COD significantly in the $4 \mathrm{~km}$ simulations, but not in the $12 \mathrm{~km}$ simulations, as 
WRF-CMAQ /CAM minus Obs

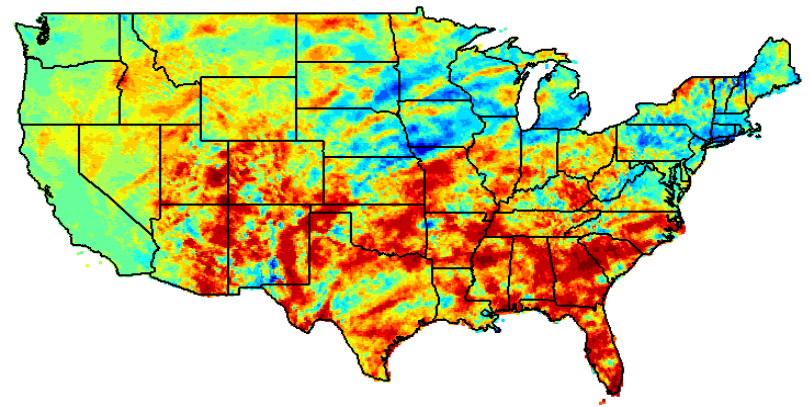

WRF/CAM minus Obs
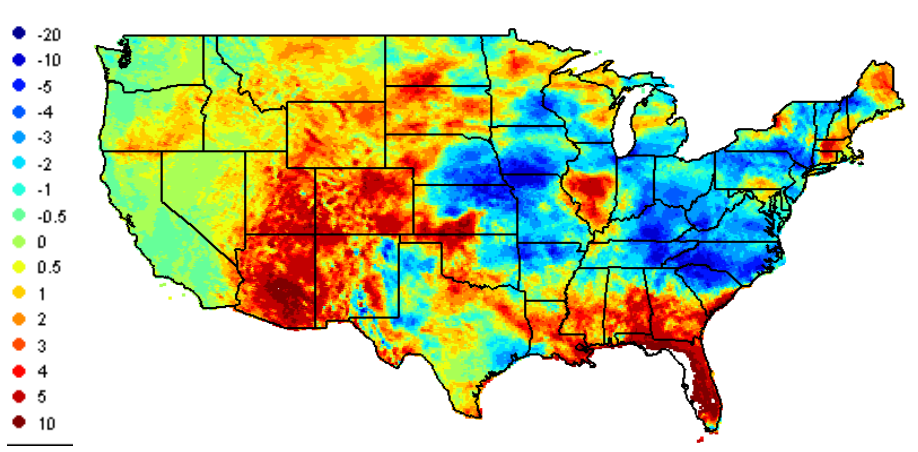

WRF-CMAQ /RRTMG minus Obs

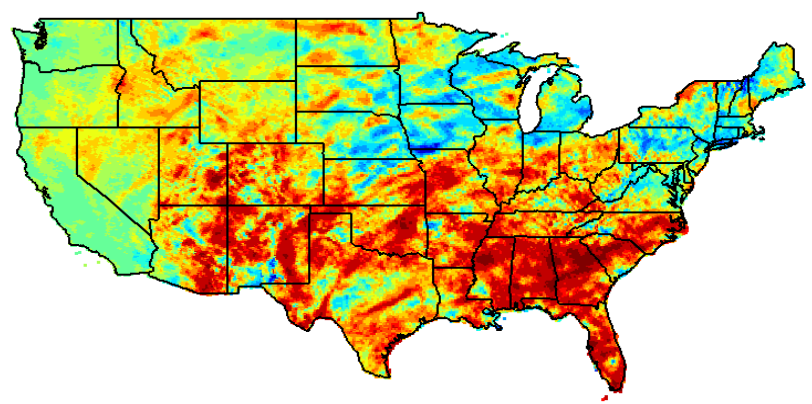

WRF/RRTMG minus Obs

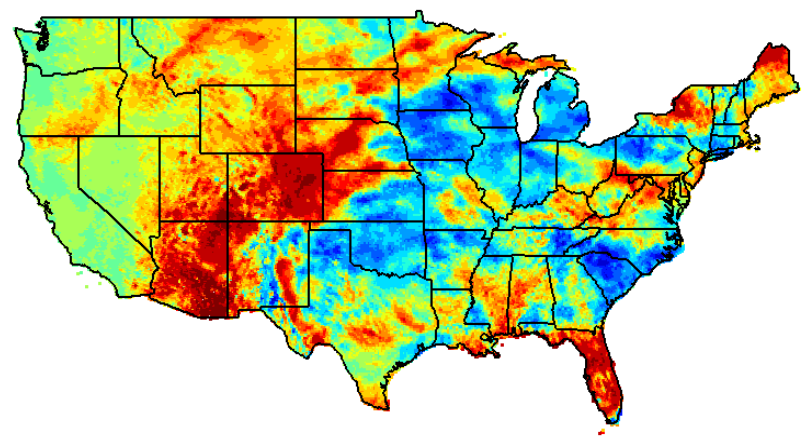

Figure 24. The difference (inch/month) of monthly domain means of precipitation between the observations and model results of WRFCMAQ/CAM, WRF-CMAQ/RRTMG, WRF-only/CAM and WRF-only/RRTMG on the basis of a $12 \mathrm{~km}$ resolution simulation over the CONUS for August of 2006.

shown in Table 11 and Fig. 21. Relative to the WRF default cases (WRF/CAM and WRF/RRTMG), the results of WRFCMAQ/CAM and WRF-CMAQ/RRTMG have significant improvements for COD performance, as shown in Table 1 and Figs. 20 and 21.

\subsubsection{Cloud fraction comparisons}

In the satellite observation, cloud fraction or cloud cover is defined as the number of cloudy pixels divided by the total number of pixels. In the WRF model, cloud fraction is calculated on the basis of the relative humidity and liquid water substance with the parameterization of Randall (1995) following Hong et al. (1998). The model performances for the cloud fractions are shown in the scatter plots of Figs. 22 and 23 and are summarized in Table 12. WRFCMAQ/CAM captured cloud fractions very well over the whole model domain (land and ocean) in both August and September, with NMBs within $\pm 10 \%$ and correlations better than 0.9, and WRF-CMAQ/RRTMG also did very well, with the slightly higher NMB values and lower correlations as shown in Table 12 and Figs. 22 and 23. All configurations (WRF-CMAQ/CAM, WRF-CMAQ/RRTMG, WRF/CAM and WRF/RRTMG) captured the observed cloud fractions well for the $4 \mathrm{~km}$ simulation over the eastern Texas domain in both August and September, with NMBs within $\pm 12 \%$ and correlations better than 0.74, as shown in Table 12 . On the other hand, the WRF default cases (WRF/CAM and WRF/RRTMG) significantly misplaced the locations of clouds over the land and ocean in both August and September, even with negative correlations, especially for August and over the ocean areas as shown in Figs. 22 and 23. This is consistent with the results of SWCF in Sect. 4.2.1.

\subsection{Precipitation evaluation}

The monthly gridded cumulative precipitation data at $4 \mathrm{~km}$ resolution over the CONUS from the Parameter-Elevation Regressions on Independent Slopes Model (PRISM; Daly et al., 1994; Daly, 2002) were regridded to the $12 \mathrm{~km}$ CONUS domain to evaluate the model performance for precipitation. The spatial differences in monthly mean precipitation between observations and models are shown in Figs. 24 (August) and 25 (September). The scatter plots are shown in Fig. 26, and statistical results are summarized in Table 13. Figure 24 and Table 12 indicate that both WRFCMAQ/CAM and WRF-CMAQ/RRTMG generally overestimated the observed precipitation by more than $40 \%$, 
WRF-CMAQ/CAM minus Obs

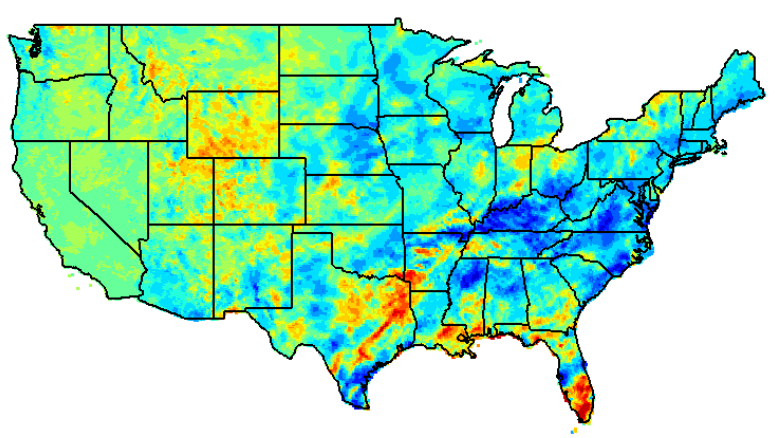

WRF/CAM minus Obs

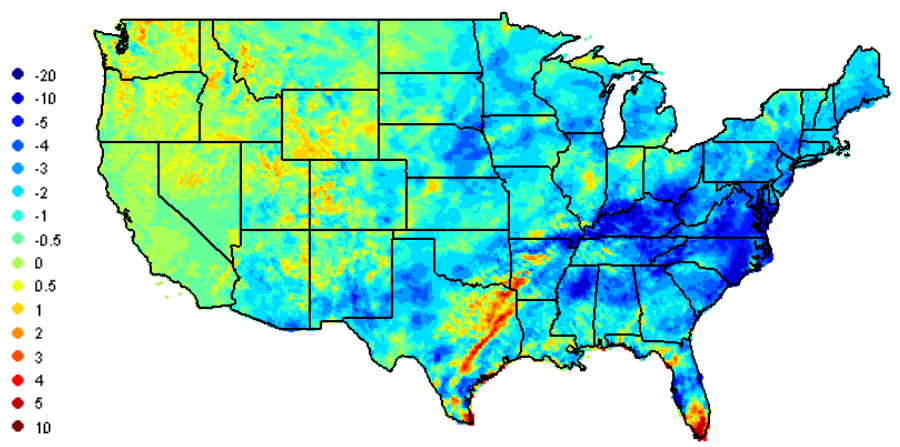

WRF-CMAQ/RRTMG minus Obs

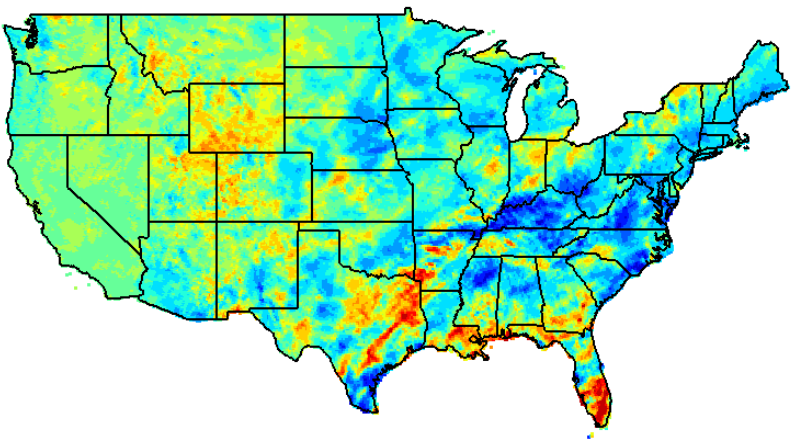

WRF/RRTMG minus Obs

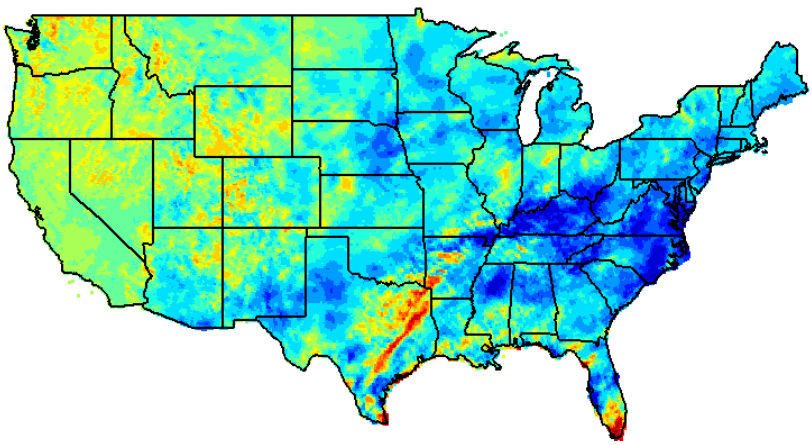

Figure 25. Same as Fig. 24, but for September of 2006.

mainly because of significant overestimation in the southern part of the CONUS in August. Both WRF-CMAQ/CAM and WRF-CMAQ/RRTMG significantly improved the underestimation of precipitation over the central part of the CONUS and the overestimation over the New Mexico regions in August relative to their corresponding WRF default cases (WRF/CAM and WRF/RRTMG), as shown in Fig. 24. This is because of the fact that inclusion of aerosol indirect effects in the case of WRF-CMAQ can improve the model simulations of cloud fields, as shown before relative to the WRF default cases, leading to the improvement in precipitation simulations. In September, all models (WRF-CMAQ/CAM, WRF-CMAQ/RRTMG, WRF/CAM, and WRF/RRTMG) reproduce the observed precipitation reasonably well, with NMBs within $40 \%$, although all models consistently underestimated the observations, as shown in Table 13 and Fig. 25. Both WRF-CMAQ/CAM and WRFCMAQ/RRTMG improved the underestimation of precipitation over the EUS in September, with smaller NMB values relative to their corresponding WRF default cases (WRF/CAM and WRF/RRTMG), as shown in Fig. 25. It is generally accepted in the meteorological community that small-scale summertime convection is more difficult to replicate with convective parameterizations because of the stochastic nature of these grid cells, which are often triggered by mesoscale surface forcing or outflow boundaries from other convective cells (Grell and Devenyi, 2002). September has fewer convection effects relative to August. For the $4 \mathrm{~km}$ simulations over eastern Texas, both WRF-CMAQ/CAM and WRF-CMAQ/RRTMG improved the underestimation of precipitation in August, with smaller NMB values relative to their corresponding WRF default cases (WRF/CAM and WRF/RRTMG), as shown in Table 13, whereas in September, all models captured the observed precipitation well, with NMBs within $\pm 20 \%$.

\section{Conclusions}

In this study, the AIE on the microphysical and radiative properties of clouds (including first, second and glaciation indirect aerosol forcing) have been implemented in the twoway coupled WRF-CMAQ modeling system by including parameterizations for both cloud drop and ice number concentrations on the basis of the CMAQ-predicted aerosol distributions, chemical and microphysical properties, and the WRF meteorological conditions, with a new subroutine, CMAQ-mixactivate. The cloud drop number concentrations were estimated from the activation of CMAQ-predicted aerosol particles using an aerosol activation scheme for multiple externally mixed lognormal modes, each mode composed of uniform internal mixtures of soluble and insoluble 

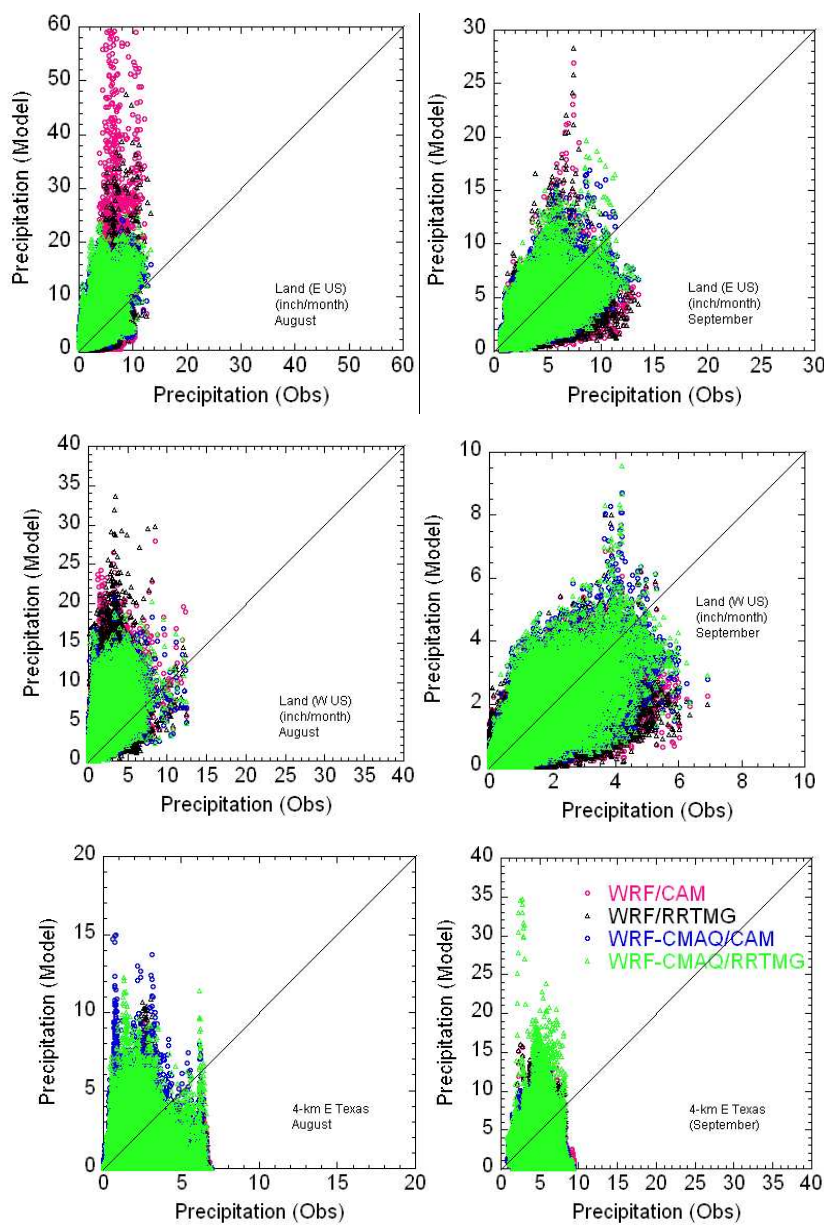

Figure 26. Scatter plots of modeled (WRF-CMAQ/CAM, WRFCMAQ/RRTMG, WRF/CAM and WRF/RRTMG) and observed monthly mean precipitation (inch/month) over the land of the eastern and western US for the $12 \mathrm{~km}$ resolution simulations and over the eastern Texas domain for the $4 \mathrm{~km}$ resolution simulations for August and September of 2006.

material developed by Abdul-Razzak and Ghan (2000, 2002), while the cloud ice number concentrations were estimated from the activation of the CMAQ-predicted sulfate, black carbon, dust and organic aerosols with an ice nucleation scheme adopted from the NCAR CAM. The resulting cloud drop and ice number concentrations are supplied to the Morrison et al. two-moment cloud microphysics scheme by tying a two-moment treatment of cloud water (mass and number) and cloud ice (mass and number) to precipitation in the Morrison et al. two-moment cloud microphysics scheme and two separate radiation schemes (RRTMG and CAM) in the WRF model. This allows us to estimate aerosol effects on cloud and ice optical depth and microphysical process rates for first, second and glaciation AIE. The cloud drop effective radius and cloud ice effective radius from the output of the Morrison cloud microphysics scheme are used in the RRTMG and CAM radiation schemes directly, and these affect the computed radiation fields accordingly. The model performance was carried out by comparison of the model simulations with the observations from satellite and surface networks over the CONUS ( $12 \mathrm{~km}$ resolution) and eastern Texas (4 km resolution) domains in August and September of 2006.

The results at the AQS surface sites show that in August over the EUS, the NMB and NME values for $\mathrm{PM}_{2.5}$ are $5.3(-0.1) \%$ and $49.9(48.6) \%$, respectively, for WRFCMAQ/CAM (WRF-CMAQ/RRTMG). The results over the WUS are similar to those over the EUS. Over the EUS in August, WRF-CMAQ/CAM (WRF-CMAQ/RRTMG) consistently underestimated the observed $\mathrm{SO}_{4}^{2-}$ by $-23.0 \%$ $(-27.7 \%),-12.5 \%(-18.9 \%)$ and $-7.9 \%(-14.8 \%)$ at the CASTNET, IMPROVE and STN sites, respectively. Both configurations systematically overestimated the observed total sulfur $\left(\mathrm{SO}_{4}^{2-}+\mathrm{SO}_{2}\right)$ at the CASTNET sites, and the modeled mean total sulfur values were higher than the observations by 25.3 and $21.8 \%$ for WRF-CMAQ/CAM and WRF-CMAQ/RRTMG, respectively. One of the reasons is too many $\mathrm{SO}_{2}$ emissions in the emissions inventory. The observed mean OC, EC and TC concentrations over the EUS in August at the IMPROVE sites were overestimated by 25.9, 54.9 and $31.9 \%$, respectively, for the WRF-CMAQ/CAM, and by $23.8,52.2$ and $29.7 \%$, respectively, for the WRFCMAQ/RRTMG. The model performances for $\mathrm{PM}_{2.5}$ at the IMPROVE and STN sites over the EUS in August are reasonably good, with NMB values of -13.2 and $-0.7 \%$, respectively, for WRF-CMAQ/CAM, and -16.8 and $-6.2 \%$, respectively, for WRF-CMAQ/RRTMG. The results over the WUS in August are similar to those over the EUS, except that both configurations had slight overestimations of the observed $\mathrm{SO}_{4}^{2-}$ at the IMPROVE sites, with NMBs within $15 \%$ and slight underestimations of TC at the STN urban sites by less than $13 \%$.

According to the CERES observations in August, the SWCF values over the land of the EUS are much higher than those of the WUS, whereas their LWCF values are very close. The NMB values for SWCF (LWCF) over the land of the EUS in August are $-11.74 \%(-27.86 \%)$ and $-22.45 \%(-30.76 \%)$ for WRF-CMAQ/CAM and WRFCMAQ/RRTMG, respectively, whereas over the land of the WUS, they are $-25.82 \%(-34.15 \%)$ and $-33.40 \%$ $(-35.45 \%)$, respectively. One of the reasons for the underestimation of clouds in both WRF-CMAQ/CAM and WRFCMAQ/RRTMG is that the subgrid convective clouds do not include aerosol effects in the model simulations at the $12 \mathrm{~km}$ resolution. This is in agreement with the fact that both configurations captured SWCF and LWCF very well for the $4 \mathrm{~km}$ simulation over eastern Texas, with NMBs within $\pm 10 \%$.

The results of the ratios of $|\mathrm{SWCF}|$ and LWCF indicate that in August, both configurations overestimated low clouds, stratocumulus and cumulus over the land and ocean areas of the EUS, and that both configurations underestimated high clouds, cirrus and cirrostratus but overestimated low clouds, 
stratocumulus and cumulus over the land and ocean areas of the WUS. Over the land areas of the CONUS in August, both configurations consistently underestimated observed COD, with more underestimation over the WUS being generally consistent with underestimations of SWCF. Over the ocean areas in August, WRF-CMAQ/CAM captured the observed COD very well, with NMBs within $\pm 10 \%$, whereas WRFCMAQ/RRTMG underestimated the observed COD by more than $28 \%$. Both configurations captured cloud fractions very well over the whole model domain (land and ocean) in August. Both WRF-CMAQ/CAM and WRF-CMAQ/RRTMG generally overestimated the observed precipitation by more than $40 \%$, mainly because of significant overestimation in the southern part of the CONUS in August. The results of WRF-CMAQ/CAM and WRF-CMAQ/RRTMG show significant improvements for SWCF, LWCF, COD, cloud fractions and precipitation over the ocean relative to those of WRF default cases in August.

The results of the model performances in September are similar to those in August, except that there is greater overestimation of $\mathrm{PM}_{2.5}$ due to the overestimations of $\mathrm{SO}_{4}^{2-}, \mathrm{NH}_{4}^{+}$, $\mathrm{NO}_{3}^{-}$, and TC over the EUS, and there are overestimations of TC over the WUS on the basis of the results at the STN urban sites. There is less underestimation of clouds (SWCF) over the land areas due to lower SWCF values, and fewer convective clouds relative to those in August, and all model results (WRF-CMAQ/CAM, WRF-CMAQ/RRTMG, WRF/CAM, and WRF/RRTMG) underestimated COD significantly in the $4 \mathrm{~km}$ simulations, but not in the $12 \mathrm{~km}$ simulations.

Since convective clouds play an important role in determining our climate state, especially for the summer season, it is imperative to include convection-aerosol interactions. Realistically, it is a big challenge to quantify the response of convective clouds to aerosols because of the complexity and nonlinearity of interactions involving photochemistry, aerosols, liquid- and ice-phase clouds and precipitation microphysics, radiation, dynamics and surface-atmosphere exchange over a wide range of spatiotemporal scales (Seifert et al., 2012; Tao et al., 2012). The developmental work for linking the CMAQ-predicted aerosol fields to the two-moment microphysics scheme in the modified Kain-Fritsch convective scheme is under way, and will be accomplished in the future.

Acknowledgements. The authors would like to thank Kathleen Fahey for the constructive and very helpful comments. The United States Environmental Protection Agency through its Office of Research and Development funded and managed the research described here. It has been subjected to the agency's administrative review and approved for publication. S. Yu would like to thank Weiping Liu from the College of Environment and Resource Sciences at Zhejiang University for his help and support. C. Zhao and X. Liu are partially supported by the Office of Science of the US Department of Energy as part of the Regional and Global Climate Modeling program. The CERES data were obtained from the NASA Langley Research Center EOSDIS Distributed Active Archive Center. The PRISM monthly precipitation data were downloaded from http://www.prism.oregonstate.edu/.

Edited by: F. Yu

\section{References}

Abdul-Razzak, H. and Ghan, S. J.: A parameterization of aerosol activation. Part 2: Multiple aerosol types, J. Geophys. Res., 105, 6837-6844, 2000.

Abdul-Razzak, H. and Ghan, S. J.: A Parameterization of Aerosol Activation. 3. Sectional Representation, J. Geophys. Res., 107, 4026, doi:10.1029/2001JD000483, 2002.

Abdul-Razzak, H., Ghan, S. J., and Rivera-Carpio, C.: A parameterization of aerosol activation. Part I: Single aerosol type, J. Geophys. Res., 103, 6123-6132, 1998.

Appel, K. W., Pouliot, G. A., Simon, H., Sarwar, G., Pye, H. O. T., Napelenok, S. L., Akhtar, F., and Roselle, S. J.: Evaluation of dust and trace metal estimates from the Community Multiscale Air Quality (CMAQ) model version 5.0, Geosci. Model Dev., 6, 883-899, doi:10.5194/gmd-6-883-2013, 2013.

Albrecht, B. A.: Aerosols, Cloud Microphysics, and Fractional Cloudiness, Science, 245, 1227-1230, 1989.

Barnes, W. L., Pagano, T. S., and Salomonson, V. V.: Prelaunch characteristics of the Moderate Resolution Imaging Spectroradiometer (MODIS) on EOS-AM1, IEEE T. Geosci. Remote, 36, 1088-1100, 1998.

Bey, I., Jacob, D. J., Yantosca, R. M., Logan, J. A., Field, B. D., Fiore, A. M., Li, Q., Liu, H. Y., Mickley, L. J., and Schultz, M. G.: Global modeling of tropospheric chemistry with assimilated meteorology: Model description and evaluation, J. Geophys. Res., 106, 23073-23096, 2001.

Bhave, P. V., Roselle, S. J., Binkowski, F. S., Nolte, C. G., Yu, S. C., Gipson, G. L., and Schere, K. L.: CMAQ aerosol module development: Recent enhancements and future plans, paper presented at 3rd Annual CMAS Models-3 Users' Conference, Commun. Model. and Anal. Syst. Cent., Chapel Hill, N. C., 18-20 October, 2004.

Binkowski, F. S. and Roselle, S. J.: Models-3 Community Multiscale Air Quality (CMAQ) model aerosol component: 1. Model description, J. Geophys. Res., 108, 4183, doi:10.1029/2001JD001409, 2003.

Carlton, A. G., Bhave, P. V., Napelenok, S. L., Edney, E. O., Sarwar, G., Pinder, R. W., Pouliot, G. A., and Houyoux, M.: Model representation of secondary organic aerosol in CMAQv4.7., Environ. Sci. Technol., 44, 8553-8560, 2010.

Cerveny, R. S. and Bailing Jr., R. C.: 1998. Weekly cycles of air pollutants, precipitation and tropical cyclones in the coastal NW Atlantic region, Nature, 394, 561-563, 1998.

Charlson, R. J., Schwartz, S. E., Hales, J. M., Cess, R. D., Coakley, Jr., J. A., Hansen, J. E., and Hofmann, D. J.: Climate Forcing by Anthropogenic Aerosols, Science, 255, 5043, doi:10.1126/science.255.5043.423, 1992.

Chapman, E. G., Gustafson Jr., W. I., Easter, R. C., Barnard, J. C., Ghan, S. J., Pekour, M. S., and Fast, J. D.: Coupling aerosolcloud-radiative processes in the WRF-Chem model: Investigating the radiative impact of elevated point sources, Atmos. Chem. Phys., 9, 945-964, doi:10.5194/acp-9-945-2009, 2009. 
Collins, W. D., Rasch, P. J., Boville, B. A., Hack, J. J., Mccaa, J. R., Williamson, D. L., Kiehl, J. T., Briegleb, B., Bitz, C., Lin, S.-J., Zhang, M., and Dai Y.: Description of the NCAR Community Atmosphere Model (CAM3.0), NCAR Technical Note, NCAR/TN-464+STR, 226 pp., 2004.

Daly, C.: Variable influence of terrain on precipitation patterns: Delineation and use of effective terrain height in PRISM, available at: http://www.ocs.orst.edu/pub/prism/docs/ effectiveterrain-daly.pdf (14 October 2014), 2002.

Daly, C., Neilson, R. P., and Phillips, D. L.: A statisticaltopographic model for mapping climatological precipitation over mountainous terrain, J. Appl. Meteorol., 33, 140-158, 1994.

DeFelice, T. P., Saxena, V. K., and Yu, S. C.:.On the measurements of cloud condensation nuclei (CCN) at Palmer Station, Antarctica, Atmos. Environ., 31, 4039-4044, 1997.

Eagen, R. C., Hobbs, P. V., and Radke, L. F.: Particle emissions from a large Kraft paper mill and their effects on the microstructure of warm clouds, J. App. Meteorol., 13, 535-552, 1974.

Eder, B. and Yu, S. C.: An evaluation of model performance of EPA models-3/CMAQ, Atmos. Environ., 40, 4811-4824, 2006.

Eder, B., Kang, D., Mathur, R., Pleim, J., Yu, S. C., Otte, T., and Pouliot, G.: A performance evaluation of the national air quality forecast capability for the summer of 2007, Atmos. Environ., 43, 2312-2320, 2009.

Eder, B., Kang, D., Rao, S. T., Mathur, R., Yu, S. C., Otte, T., Schere, K., Wayland, R., Jackson, S., Davidson, P., and McQueen, J.: A demonstration of the use of national air quality forecast guidance for developing local air quality index forecasts, B. Am. Meteorol. Soc., 91, 313-326, doi:10.1175/2009BAMS2734.1, 2010.

$\mathrm{Fu}, \mathrm{Q}$.: An accurate parameterization of the solar radiative properties of cirrus clouds for climate models, J. Climate, 9, 20582082, 1996.

Foley, K. M., Roselle, S. J., Appel, K. W., Bhave, P. V., Pleim, J. E., Otte, T. L., Mathur, R., Sarwar, G., Young, J. O., Gilliam, R. C., Nolte, C. G., Kelly, J. T., Gilliland, A. B., and Bash, J. O.: Incremental testing of the Community Multiscale Air Quality (CMAQ) modeling system version 4.7, Geosci. Model Dev., 3, 205-226, doi:10.5194/gmd-3-205-2010, 2010.

Ghan, S. J. and Easter, R. C.: Impact of cloud-borne aerosol representation on aerosol direct and indirect effects, Atmos. Chem. Phys., 6, 4163-4174, doi:10.5194/acp-6-4163-2006, 2006.

Ghan, S. J., Leung, L. R., Easter, R. C., and Abdul-Razzak, H.: Prediction of Droplet Number in a General Circulation Model, J. Geophys. Res., 102, 21777-21794, 1997.

Ghan, S. J., Easter, R. C., Chapman, E. G., Abdul-Razzak, H., Zhang, Y., and Leung, L. R., Laulainen, N. S., Saylor, R. D., and Zaveri, R. A.: A Physically Based Estimate of Radiative Forcing by Anthropogenic Sulfate Aerosol, J. Geophys. Res-Atmos., 106, 5279-5293, 2001a.

Ghan, S., Laulainen, N., Easter, R., Wagener, R., Nemesure, S., Chapman, E., Zhang, Y., and Leung, R.: Evaluation of Aerosol Direct Radiative Forcing in MIRAGE, J. Geophys. Res.-Atmos., 106, 5295-5316, 2001b.

Ghan, S. J., Easter, R. C., Hudson, J., and Breon, F.-M.: Evaluation of Aerosol Indirect Radiative Forcing in MIRAGE, J. Geophys. Res.-Atmos., 106, 5317-5334, 2001c.
Grabowski, W. W.: Indirect impact of atmospheric aerosols in idealized simulations of convective-radiative quasi equilibrium, J. Climate, 19, 4664-4682, 2006.

Granier, C. and Brasseur, G.: Ozone and other trace gases in the Arctic and Antarctic regions: Three-dimensional model simulations, J. Geophys. Res., 96, 2995-3011, doi:10.1029/90JD01779, 1991.

Grell, G. and Devenyi, D.: A generalized approach to parameterizing convection combining ensemble and data assimilation techniques, Geophys. Res. Lett., 29, 1693-1697, doi:10.1029/2002GL015311, 2002.

Grell, G. A., Emeis, S., Stockwell, W. R., Schoenemeyer, T., Forkel, R., Michalakes, J., Knoche, R., and Seidl, W.: Application of a multiscale, coupled MM5/chemistry model to the complex terrain of the VOTALP valley campaign, Atmos. Environ. 34, 14351453, 2000.

Grell, G. A., Peckham, S. E., Schmitz, R., McKenn, S. A., Frost, G., Skamarock, W. C., and Eder, B.: Fully Coupled "Online" chemistry within the WRF Model, Atmos. Environ., 39, 6957-6975, 2005.

Gustafson Jr., W. I., Chapman, E. G., Ghan, S. J., Easter, R. C., and Fast, J. D.: Impact on Modeled Cloud Characteristics Due to Simplified Treatment of Uniform Cloud Condensation Nuclei During NEAQS 2004, Geophys. Res. Lett., 34, L19809, doi:10.1029/2007GL030021, 2007.

Gustafson Jr., W. I. and Yu, S. C.: Generalized approach for using unbiased symmetric metrics with negative values: normalized mean bias factor and normalized mean absolute error factor, Atmos. Sci. Lett., 13, 262-267, doi:10.1002/asl.393, 2012.

Han, Q., Rossow, W. B., and Lacis, A. A.: Near-global survey of effective droplet radii in liquid water clouds using ISCCP data, J. Climate, 7, 465-497, doi:10.1175/15200442(1994)0072.0.CO;2, 1994.

Hanel, G.: The properties of atmospheric aerosol particles as functions of the Relative humidityat thermodynamic equilibrium with the surrounding moist air, Adv. Geophys., 19, 73-188, 1976.

Hansen, J., Sato, M., and Ruedy, R.: Radiative Forcing and Climate Response, J. Geophys. Res., 102, 6831-6864, 1997.

Harrison, E. F., Minnis, P., Barkstrom, B. R., Ramanathan, V., Cess, R. D., and Gibson, G. G.: Seasonal Variation of Cloud Radiative Forcing Derived From the Earth Radiation Budget Experiment. J. Geophys. Res., 95, 18687-18703, doi:10.1029/JD095iD11p18687, 1990.

Hartmann, D. L. and Doelling, D.: On the net radiative effectiveness of clouds, J. Geophys. Res., 96, 869-891, 1991.

Haywood, J. and Boucher, O.: Estimates of the Direct and Indirect Radiative Forcing Due to Tropospheric Aerosols: A Review., Rev. Geophys., 38, 513-543, 2000.

Henderson, B. H., Akhtar, F., Pye, H. O. T., Napelenok, S. L., and Hutzell, W. T.: A database and tool for boundary conditions for regional air quality modeling: description and evaluation, Geosci. Model Dev., 7, 339-360, doi:10.5194/gmd-7-3392014, 2014.

Hong, S.-Y., Juang, H.-M., and Zhao, Q.: Implementation of Prognostic Cloud Scheme for a Regional Spectral Model, Mon. Weather Rev., 126, 2621-2639, 1998.

Iacono, M. J., Delamere, J. S., Mlawer, E. J., Shephard, M. W., Clough, S. A., and Collins, W. D.: Radiative forcing by long-lived greenhouse gases: Calculations with the AER 
radiative transfer models, J. Geophys. Res., 113, D13103, doi:10.1029/2008JD009944, 2008.

Intergovernmental Panel on Climate Change (IPCC), Climate Change 2007: The Physical Science Basis, Contribution of Working Group I to the Fourth Assessment Report of the Intergovernmental Panel on Climate Change, Cambridge Univ. Press, New York, 2007.

Isaksen, I. S. A., Granier, C., Myhre, G., Berntsen, T. K., Dalsøren, S. B., Gauss, M., Klimont, Z., Benestad, R., Bousquet, P., Collins, W., Cox, T., Eyring, V., Fowler, D., Fuzzi, S., Jöckel, P., Laj, P., Lohmann, U., Maione, M., Monks, P., Prevot, A. S. H., Raes, F., Richter, A., Rognerud, B., Schulz, M., Shindell, D., Stevenson, D. S., Storelvmo, T., Wang, W.-C., van Weele, M., Wild, M., and Wuebbles, D.: Atmospheric composition change: Climate-Chemistry interactions, Atmos. Environ., 43, 5138-5192, 2009.

Jacobson, M. Z.: Developing, coupling, and applying a gas, aerosol, transport, and radiation model to study urban and regional air pollution, Ph. D. Thesis, Department of Atmospheric Sciences, University of California, Los Angeles, 436 pp., 1994.

Jacobson, M. Z.: GATOR-GCMM: A global- through urban-scale air pollution and weather forecast model 1 . Model design and treatment of subgrid soil, vegetation, roads, rooftops, water, sea, ice, and snow, J. Geophys. Res., 106, 5385-5401, 2001 a.

Jacobson, M. Z.: GATOR-GCMM: 2. A study of day- and nighttime ozone layers aloft, ozone in national parks, and weather during the SARMAP Field Campaign, J. Geophys. Res., 106, 5403-5420, 2001b.

Jacobson, M. Z.: Effects of absorption by soot inclusions within clouds and precipitation on global climate, J. Phys. Chem., 110, 6860-6873, 2006

Jauregui, E. and Romales, E.: Urban effects on convective precipitation in Mexico city, Atmos. Environ., 30, 3383-3389, 1996.

Jimenez, J. L., Canagaratna, M. R., Donahue, N. M., Prevot, A. S., Zhang, Q., Kroll, J. H., DeCarlo, P. F., Allan, J. D., Coe, H., Ng, N. L., Aiken, A. C., Docherty, K. S., Ulbrich, I. M., Grieshop, A. P., Robinson, A. L., Duplissy, J., Smith, J. D., Wilson, K. R., Lanz, V. A., Hueglin, C., Sun, Y. L., Tian, J., Laaksonen, A., Raatikainen, T., Rautiainen, J., Vaattovaara, P., Ehn, M., Kulmala, M., Tomlinson, J. M., Collins, D. R., Cubison, M. J., Dunlea, E. J., Huffman, J. A., Onasch, T. B., Alfarra, M. R., Williams, P. I., Bower, K., Kondo, Y., Schneider, J., Drewnick, F., Borrmann, S., Weimer, S., Demerjian, K., Salcedo, D., Cottrell, L., Griffin, R., Takami, A., Miyoshi, T., Hatakeyama, S., Shimono, A., Sun, J. Y., Zhang, Y. M., Dzepina, K., Kimmel, J. R., Sueper, D., Jayne, J. T., Herndon, S. C., Trimborn, A. M., Williams, L. R., Wood, E. C., Middlebrook, A. M., Kolb, C. E., Baltensperger, U., and Worsnop, D. R.: Evolution of organic aerosols in the atmosphere, Science, 326, 1525-1529, 2009.

Kain, J. S.: The Kain-Fritsch convective parameterization: An update, J. Appl. Meteorol., 43, 170-181, 2004.

Kain, J. S. and Fritsch, J. M.: A one-dimensional entraining/detraining plume model and its application in convective parameterization, J. Atmos. Sci., 47, 2784-2802, 1990.

Kain, J. S. and Fritsch, J. M.: Convective parameterization for mesoscale models: The Kain-Fritcsh scheme, The representation of cumulus convection in numerical models, edited by: Emanuel, K. A. and Raymond, D. J., Amer. Meteor. Soc., 246 pp., 1993.
Khvorostyanov, V. I. and Curry, J. A.: A simple analytical model of aerosol properties with account for hygroscopic growth, Part 1, Equilibrium size spectra and CCN activity spectra, J. Geophys. Res., 104, 2163-2174, 1999.

Kiehl, J. T.: On the observed near cancellation between longwave and shortwave cloud forcing in tropical regions, J. Climate, 7, 559-656, 1994a.

Kiehl, J. T.: Sensitivity of a GCM climate simulation to differences in continental versus maritime cloud drop size, J. Geophys. Res., 99, 23107-23115, 1994b.

Kiehl, J. T. and Ramanathan, V.: Comparison of cloud forcing derived from the earth radiation budget experiment with that simulated by the NCAR community climate model, J. Geophys. Res., 95, 11679-11698, 1990.

King, S. M., Rosenoern, T., Shilling, J. E., Chen, Q., Wang, Z., Biskos, G., McKinney, K. A., Pöschl, U., and Martin, S. T.: Cloud droplet activation of mixed organic-sulfate particles produced by the photooxidation of isoprene, Atmos. Chem. Phys., 10, 3953-3964, doi:10.5194/acp-10-3953-2010, 2010.

Koehler, K. A., Kreidenweis, S. M., DeMott, P. J., Petters, M. D., Prenni, A. J., and Carrico, C. M.: Hygroscopicity and cloud droplet activation of mineral dust aerosol, Geophys. Res. Lett., 36, L08805, doi:10.1029/2009GL037348, 2009.

Kummerow, C., Barnes, W., Kozu, T., Shine, J., and Simpson, J.: The Tropical Rainfall Measuring Mission System (TRMM) sensor package, J. Atmos. Ocean. Technol., 15, 809-827, 1998.

Lauer, A., Wang, Y., Phillips, V. T. J., McNaughton, C. S., Bennartz, R., and Clarke, A. D.: Simulation marine boundary layer clouds over the eastern Pacific in a regional climate model with doublemoment cloud microphysics, J. Geophys. Res., 114, D21205, doi:10.1029/2009JD012201, 2009.

Leaitch, W. R., Strapp, J. W., Wiebe, H. A., Anlauf, K. G., and Isaac, G. A.: Chemical and microphysical studies of nonprecipitating summer cloud in Ontario, Canada, J. Geophys. Res., 91, 11821$11831,1986$.

Li, Z., Niu, F., Fan, J., Liu, Y., Rosenfeld, D., and Ding Y.: The long-term impacts of aerosols on the vertical development of clouds and precipitation, Nat. Geosci., 4, 888-894, doi:10.1038/ngeo1313, 2011.

Lin, J. C., Matsui, T., Pielke Sr., R. A., and Kummerow, C.: Effects of biomass-burning-derived aerosols on precipitation and clouds in the Amazon Basin: a satellite-based empirical study, J. Geophys. Res., 111, D19204, doi:10.1029/2005JD006884, 2006.

Liu, P., Zhang, Y., Yu, S. C., and Schere, K. L.: Use of a Process Analysis Tool for Diagnostic Study on Fine Particulate Matter Predictions in the U.S. Part II: Process Analysis and Sensitivity Simulations, Atmos. Pollut. Res., 2, 61-71, 2011.

Liu, X. and Penner, J. E.: Ice nucleation parameterization for global models, Meteorol. Z., 14, 499-514, 2005.

Liu, X. and Wang, J.: How Important Is Organic Aerosol Hygroscopicity to Aerosol Indirect Forcing?, Environ. Res. Lett., 5, 044010, doi:10.1088/1748-9326/5/4/044010, 2010.

Liu, X., Penner, J. E., Ghan, S. J., and Wang, M.: Inclusion of ice microphysics in the NCAR community atmospheric model version 3 (CAM3), J. Climate, 20, 4526-4547, 2007.

Lohmann, U.: A glaciation indirect aerosol effect caused by soot aerosols, Geophys. Res. Lett., 29, 1052, doi:10.1029/2001GL014357, 2002. 
Lohmann, U. and Feichter, J.: Global indirect aerosol effects: a review, Atmos. Chem. Phys., 5, 715-737, doi:10.5194/acp-5-7152005, 2005.

Lu, M.-L. and Seinfeld, J.H.: Study of the aerosol indirect effect by large-eddy simulation of marine stratocumulus, J. Atmos. Sci., 62, 3909-3932, 2005.

Martin, G. M., Johnson, D. W., and Spice, A.: The measurement and parameterization of effective radius of droplets in warm stratiform clouds, J. Atmos. Sci., 51, 1823-1842, 1994.

Mathur, R., Yu, S. C., Kang, D., and Schere, K. L.: Assessment of the Winter-time Performance of Developmental Particulate Matter Forecasts with the Eta-CMAQ Modeling System, J. Geophys. Res., 113, D02303, doi:10.1029/2007JD008580, 2008.

Mathur, R., Pleim, J., Wong, D., Otte, T., Gilliam, R., Roselle, S., Young, J., Binkowski, F., and Xiu, A.: The WRF-CMAQ integrated on-line modeling system: development, testing and initial application, Air Pollution Modeling and Its Application XX, edited by: Steyn, D. G. and Rao, S. T., 155159, doi:10.1007/978-90-481-3812-8, Springer, the Netherlands, 2010.

McKeen, S., Chung, S. H., Wilczak, J., Grell, G., Djalalova, I., Peckham, S., Gong, W., Bouchet, V., Moffet, R., Tang, Y., Carmichael, G. R., Mathur, R., and Yu, S. C: The evaluation of several $\mathrm{PM}_{2.5}$ forecast models using data collected during the ICARTT/NEAQS 2004 field study, J. Geophys. Res., 112, D10S20, doi:10.1029/2006JD007608, 2007.

Menon, S., Hansen, J. E., Nazarenko, L., and Luo, Y.: Climate effects of black carbon aerosols in China and India, Science, 297, 2250-2253, 2002.

Menon, S., Del Genio, A. D., Kaufman, Y. J., Koch, D., Bennartz, R., Loeb, N., and Orlikowski, D.: Analyzing signatures of aerosol-cloud interactions with satellite retrievals and the GISS GCM to constrain the aerosol indirect effect. J. Geophys. Res., 113, D14S22, doi:10.1029/2007JD009442, 2008.

Meyers, M. P., DeMott, P. J., and Cotton, W. R.: New primary ice nucleation parameterization in an explicit model, J. Appl. Meteorol., 31, 708-721, 1992.

Morrison, H. and Grabwski, W. W.: Comparison of bulk and bin warm-rain microphysics models using a kinematic framework, J. Atmos. Sci., 64, 2839-2861, 2007.

Morrison, H. and Pinto, J. O.: Intercomparison of bulk microphysics schemes in mesoscale simulations of springtime Arctic mixedphase stratiform clouds, Mon. Weather Rev., 134, 1880-1900, 2006.

Morrison, H., Curry, J. A., and Khvorostyanov, V. I.: A new doublemoment microphysics parameterization for application in cloud and climate models, Part I: Description, J. Atmos. Sci., 62, 16651677, 2005.

Morrison, H., Thompson, G., and Tatarskii, V.: Impact of Cloud Microphysics on the Development of Trailing Stratiform Precipitation in a Simulated Squall Line: Comparison of One- and TwoMoment Schemes, Mon. Weather Rev., 137, 991-1007, 2009.

Petters, M. D. and Kreidenweis, S. M.: A single parameter representation of hygroscopic growth and cloud condensation nucleus activity, Atmos. Chem. Phys., 7, 1961-1971, doi:10.5194/acp-71961-2007, 2007.

Phillips, V. T. J., DeMott, P. J., and Andronache, C.: An Empirical Parameterization of Heterogeneous Ice Nucleation for Multi- ple Chemical Species of Aerosol, J. Atmos. Sci., 65, 2757-2783, doi:10.1175/2007JAS2546.1, 2008.

Pleim, J. E.: A combined local and non-local closure model for the atmospheric boundary layer. Part 1: Model description and testing, J. Appl. Meteorol. Clim., 46, 1383-1395, 2007a.

Pleim, J. E.: A combined local and nonlocal closure model for the atmospheric boundary layer. Part II: application and evaluation in a mesoscale meteorological model, J. Appl. Meteorol. Clim., 46, 1396-1409, 2007b.

Pleim, J. E. and Xiu, A.: Development and testing of a surface flux and planetary boundary layer model for application in mesoscale models, J. Appl. Meteorol., 34, 16-32, 1995.

Pleim, J. E. and Xiu, A.: Development of a land surface model. Part II: Data Assimilation, J. Appl. Meteorol., 42, 1811-1822, 2003.

Pleim, J., Young, J., Wong, D., Gilliam, R., Otte, T., and Mathur, R.: Two-Way Coupled Meteorology and Air Quality Modeling, Air Pollution Modeling and Its Application XIX, edited by: Borrego, C. and Miranda, A. I., 496-504, ISBN 978-1-4020-8452-2, Springer, the Netherlands, 2008.

Prenni, A. J., Petters, M. D., Kreidenweis, S. M., DeMott, P. J., and Ziemann, P. J.: Cloud droplet activation of secondary organic aerosol, J. Geophys. Res., 112, D10223, doi:10.1029/2006JD007963, 2007.

Pruppacher, H. R. and Klett, J. D.: Microphysics of Clouds and Precipitation, 2 Edn., Kluwer Academic Publishers, Dordrecht, the Netherlands, 954 pp., 1997.

Ramanathan, V., Crutzen, P. J., Kiehl, J. T., and Rosenfeld, D.: Aerosols, Climate and the Hydrological Cycle, Science, 294, 2119-2124, 2001.

Randall, D. A.: Parameterizing fractional cloudiness produced by cumulus entrainment. Preprints, Workshop on Cloud Microphysics Parameterizations in Global Atmospheric Circulation Models, Kananaskis, AB, Canada, WMO, 1-16, 1995.

Rasch, P. J., Barth, M. C., Kiehl, J. T., Schwartz, S. E., and Benkovitz, C. M.: A description of the global sulfur cycle and its controlling processes in the National Center for Atmospheric Research Community Climate Model Version 3, J. Geophys. Res., 105, 1367-1385, 2000.

Rotstayn, L.: Indirect forcing by anthropogenic aerosols: A global climate model calculation of the effective-radius and cloudlifetime effects, J. Geophys. Res, 104, 9369-9380, 1999.

Rosenfeld, D.: TRMM observed first direct evidence of smoke from forest fires inhibiting rainfall, Geophys. Res. Lett., 26, 31053108, 1999.

Rosenfeld, D.: Suppression of rain and snow by urban and industrial air pollution, Science, 287, 1793-1796, doi:10.1126/science.287.5459.1793, 2000.

Rosenfeld, D., Dai, J., Yu, X., Yao, Z., Xu, X., Yang, X., and $\mathrm{Du}, \mathrm{C} .:$ Inverse relations between amounts of air pollution and orographic precipitation, Science, 315, 1396-1398, doi:10.1126/science.1137949, 2007.

Rosenfeld, D., Lohmann, U., Raga, G. B., O’Dowd, C. D., Kulmala, M., Fuzzi, S., Reissell, A., and Andreae, M. O.: Flood or drought: how do aerosols affect precipitation?, Science, 321, 1309-1313, 2008.

Saide, P. E., Spak, S. N., Carmichael, G. R., Mena-Carrasco, M. A., Yang, Q., Howell, S., Leon, D. C., Snider, J. R., Bandy, A. R., Collett, J. L., Benedict, K. B., de Szoeke, S. P., Hawkins, L. N., Allen, G., Crawford, I., Crosier, J., and Springston, S. R.: 
Evaluating WRF-Chem aerosol indirect effects in Southeast Pacific marine stratocumulus during VOCALS-REx, Atmos. Chem. Phys., 12, 3045-3064, doi:10.5194/acp-12-3045-2012, 2012.

Saxena, V. K. and Yu, S. C.: Searching for a regional fingerprint of aerosol forcing in the southeastern US, Geophys. Res. Lett., 25, 2833-2836, 1998.

Saxena, V. K., Yu, S. C., and Anderson, J.: Impact of stratospheric volcanic aerosols on climate: Evidence of aerosol radiative forcing in the southeastern US, Atmos. Environ., 31, 4211-4221, 1997.

Seifert, A., Köhler, C., and Beheng, K. D.: Aerosol-cloudprecipitation effects over Germany as simulated by a convectivescale numerical weather prediction model, Atmos. Chem. Phys., 12, 709-725, doi:10.5194/acp-12-709-2012, 2012.

Seinfeld, J. and Pandis, S.: Atmospheric Chemistry and Physics, John Wiley \& Sons, New York, NY, USA, 408-448, 1998.

Simon, H., Bhave, P. V., Swall, J. L., Frank, N. H., and Malm, W. C.: Determining the spatial and seasonal variability in OM/OC ratios across the US using multiple regression, Atmos. Chem. Phys., 11, 2933-2949, doi:10.5194/acp-11-2933-2011, 2011.

Sisler, J. F. and Malm, W. C.: Interpretation of trends of $\mathrm{PM}_{2.5}$ and reconstructed visibility from the IMPROVE Network, J. Air Waste Manage. Assoc., 50, 775-789, 2000.

Skamarock, W. C., Klemp, J. B., Dudhia, J., Gill, D. O., Barker, D. M., Duda, M. G., Huang, X.-Y., Wang, W., and Powers, J. G.: A description of the advanced research WRF version 3, Technical Note TN-475+STR, NCAR, 2008.

Slingo, A.: Sensitivity of the earth's radiation budget to changes in low clouds, Nature, 343, 49-51, 1990.

Stephen, G. L.: Cloud feedbacks in the climate system: a critical review, J. Climate, 18, 237-273, 2005.

Su, W., Bodas-Salcedo, A., Xu, K.-M., and Charlock, T. P.: Comparison of the tropical radiative flux and cloud radiative effect profiles in a climate model with Clouds and the Earth's Radiant Energy System (CERES) data, J. Geophys. Res., 115, D01105, doi:10.1029/2009JD012490, 2010.

Tao, W.-K., Chen, J.-P., Li, Z., Wang, C. and Zhang, C.: Impact of aerosols on convective clouds and precipitation, Rev. Geophys., 50, RG2001, doi:10.1029/2011RG000369, 2012.

Taylor, K. E. and Penner, J. E.: Response of the climate system to atmospheric aerosols and greenhouse gases, Nature, 369, 734737, doi:10.1038/369734a0, 1994.

Taylor, P. C.: The role of clouds: an introduction and rapporteur, Surv. Geophys., 33, 609-617, 2012.

Twomey, S.: Pollution and the Planetary Albedo, Atmos. Environ., 8, 1251-1256, 1974.

Twomey, S.: Aerosols, Clouds and Radiation, Atmos. Environ., 25, 2435-2442, 1991.

Wang, Y., Wang, M., Zhang, R., Ghan, S. J., Lin, Y., Hu, J., Pan, B., Levy, M., Jiang, J. H., and Molina, M. J.: Assessing the effects of anthropogenic aerosols on Pacific storm track using a multiscale global climate model, P. Natl. Acad. Sci. USA, 111, 6894-6899, doi:10.1073/pnas.1403364111, 2014.

Wielicki, B. A., Barkstrom, B. R., Harrison, E. F., Lee III, R. B., Smith, G. L., and Cooper, J. E.: Clouds and the Earth's Radiant Energy System (CERES): An Earth Observing System Experiment, B. Am. Meteorol. Soc., 77, 853-868, 1996.

Wong, D. C., Pleim, J., Mathur, R., Binkowski, F., Otte, T., Gilliam, R., Pouliot, G., Xiu, A., Young, J. O., and Kang, D.: WRF-
CMAQ two-way coupled system with aerosol feedback: software development and preliminary results, Geosci. Model Dev., 5, 299-312, doi:10.5194/gmd-5-299-2012, 2012.

Xiu, A. and Pleim, J. E.: Development of a land surface model. Part I: application in a mesoscale meteorological model, J. Appl. Meteorol., 40, 192-209, 2001.

Yang, Q., W. I. Gustafson Jr., Fast, J. D., Wang, H., Easter, R. C., Morrison, H., Lee, Y.-N., Chapman, E. G., Spak, S. N., and Mena-Carrasco, M. A.: Assessing regional scale predictions of aerosols, marine stratocumulus, and their interactions during VOCALS-REx using WRF-Chem, Atmos. Chem. Phys., 11, 11951-11975, doi:10.5194/acp-11-11951-2011, 2011.

Yarwood, G., Rao, S., Yocke, M. and Whitten, G. Z.: Final Report - Updates to the Carbon Bond Chemical Mechanism: CB05, Rep. RT-04-00675, 246 pp., Yocke and Co., Novato, California, available at: http://www.camx.com/publ/pdfs/CB05_Final_ Report_120805.pdf (last access: 15 October 2014), 2005.

Young, K. C.: Numerical-simulation of wintertime, orographic precipitation - 1. Description of model microphysics and numerical techniques, J. Atmos. Sci., 31, 1735-1748, 1974.

Yu, F., Luo, G., Liu, X., Easter, R. C., Ma, X., and Ghan, S. J.: Indirect radiative forcing by ion-mediated nucleation of aerosol, Atmos. Chem. Phys., 12, 11451-11463, doi:10.5194/acp-1211451-2012, 2012a.

Yu, F., Luo, G., and Ma, X.: Regional and global modeling of aerosol optical properties with a size, composition, and mixing state resolved particle microphysics model, Atmos. Chem. Phys., 12, 5719-5736, doi:10.5194/acp-12-5719-2012, 2012 b.

Yu, H., Kaufman, Y. J., Chin, M., Feingold, G., Remer, L. A., Anderson, T. L., Balkanski, Y., Bellouin, N., Boucher, O., Christopher, S., DeCola, P., Kahn, R., Koch, D., Loeb, N., Reddy, M. S., Schulz, M., Takemura, T., and Zhou, M.: A review of measurement-based assessments of the aerosol direct radiative effect and forcing, Atmos. Chem. Phys., 6, 613-666, doi:10.5194/acp-6-613-2006, 2006.

Yu, S. C.: The role of organic acids (formic, acetic, pyruvic and oxalic) in the formation of cloud condensation nuclei (CCN): a review, Atmos. Res., 53, 185-217, 2000.

Yu, S. C. and Zhang, Y.: An Examination of the Effects of Aerosol Chemical Composition and Size on Radiative Properties of Multi-Component Aerosols, Atmos. Clim. Sci., 1, 19-32, doi:10.4236/acs.2011.12003, 2011.

Yu, S. C., Saxena, V. K., Wenny, B. N., DeLuisi, J. J., Yue, G. K. and Petropavlovskikh, I. V.: A study of the aerosol radiative properties needed to compute direct aerosol forcing in the southeastern US, J. Geophys. Res., 105, 24739-24749, 2000.

Yu, S. C., Saxena, V. K. and Zhao, Z.: A comparison of signals of regional aerosol-induced forcing in eastern China and the southeastern United States, Geophys. Res. Lett., 28, 713-716, 2001a.

Yu, S. C., Zender, C. S. and Saxena, V. K.: Direct radiative forcing and atmospheric absorption by boundary layer aerosols in the southeastern US: model estimates on the basis of new observations, Atmos. Environ.,, 35, 3967-3977, 2001b.

Yu, S. C., Kasibhatla, P. S., Wright, D. L., Schwartz, S. E., McGraw, R., and Deng, A.: Moment-based simulation of microphysical properties of sulfate aerosols in the eastern United States: Model description, evaluation and regional analysis, J. Geophys. Res., 108, 4353, doi:10.1029/2002JD002890, 2003. 
Yu, S. C., Dennis, R., Bhave, P., and Eder, B.: Primary and secondary organic aerosols over the United States: Estimates on the basis of observed organic carbon (OC) and elemental carbon (EC), and air quality modeled primary OC/EC ratios, Atmos. Environ., 38, 5257-5268, 2004.

Yu, S. C., Dennis, R., Roselle, S., Nenes, A., Walker, J., Eder, B., Schere, K., Swall, J., and Robarge, W.: An assessment of the ability of 3-D air quality models with current thermodynamic equilibrium models to predict aerosol $\mathrm{NO}_{3}^{-}$, J. Geophys. Res., 110, D07S13, doi:10.1029/2004JD004718, 2005.

Yu, S. C., Eder, B., Dennis, R., Chu, S.-H., and Schwartz, S.: New unbiased symmetric metrics for evaluation of air quality models, Atmos. Sci. Lett., 7, 26-34, 2006.

Yu, S. C., Bhave, P. V., Dennis, R. L., and Mathur, R.: Seasonal and regional variations of primary and secondary organic aerosols over the continental United States: Semi-empirical estimates and model evaluation, Environ. Sci. Technol., 41, 4690-4697, 2007a.

Yu, S. C., Mathur, R., Schere, K., Kang, D., Pleim, J., and Otte, T. L.: A Detailed Evaluation of the Eta-CMAQ Forecast Model Performance for $\mathrm{O}_{3}$, Its Related Precursors, and Meteorological Parameters During the 2004 ICARTT Study, J. Geophys. Res., 112, D12S14, doi:10.1029/2006JD007715, 2007b.

Yu, S. C., Mathur, R., Schere, K., Kang, D., Pleim, J., Young, J., Tong, D., McKeen, S., and Rao, S. T.: Evaluation of realtime $\mathrm{PM}_{2.5}$ forecasts and process analysis for $\mathrm{PM}_{2.5}$ formation over the eastern U.S. using the Eta-CMAQ forecast model during the 2004 ICARTT Study, J. Geophys. Res., 113, D06204, doi:10.1029/2007JD009226, 2008.

Yu, S., Mathur, R., Pleim, J., Pouliot, G., Wong, D., Eder, B., Schere, K., Gilliam, R., and Rao, S. T.: Comparative evaluation of the impact of WRF/NMM and WRF/ARW meteorology on CMAQ simulations for $\mathrm{PM}_{2.5}$ and its related precursors during the 2006 TexAQS/GoMACCS study, Atmos. Chem. Phys., 12, 4091-4106, doi:10.5194/acp-12-4091-2012, 2012a.
Yu, S. C., Mathur, R., Pleim, J., Pouliot, G., Eder, B., Schere, K., Wong, D., Gilliam, R., and Rao, S. T.: Comparative evaluation of the impact of WRF-NMM and WRF-ARW meteorology on CMAQ simulations for $\mathrm{O}_{3}$ and related species during the 2006 TexAQS/GoMACCS campaign. Atmos. Pollut. Res., 3, 149-162, doi:10.5094/APR.2012.015, 2012b.

Zhang, Y.: Online-coupled meteorology and chemistry models: history, current status, and outlook, Atmos. Chem. Phys., 8, 28952932, doi:10.5194/acp-8-2895-2008, 2008.

Zhang, Y., Easter, R. C., Ghan, S. J., and Abdul-Razzak, H.: Impact of Aerosol Size Representation on Modeling Aerosol-Cloud Interactions, J. Geophys. Res., 107, 4558, doi:10.1029/2001JD001549, 2002.

Zhang, Y., Wen, X.-Y., and Jang, C. J.: Simulating ClimateChemistry-Aerosol-Cloud-Radiation Feedbacks in Continental U.S. using Online-Coupled WRF/Chem, Atmos. Environ., 44, 3568-3582, 2010a.

Zhang, Y., Liu, P., Liu, X.-H., Jacobson, M. Z., McMurry, P. H., Yu, F., Yu, S. C., and Schere, K. L.:. A comparative study of homogeneous nucleation parameterizations, part II. 3-D model simulations and evaluation, J. Geophys. Res., 115, D20213, doi:10.1029/2010JD014151, 2010b.

Zhang, Y., Chen, Y.-C., Sarwar, G., and Schere, K.: Impact of Gas-Phase Mechanisms on WRF/Chem Predictions: Mechanism Implementation and Comparative Evaluation, J. Geophys. Res., 117, D01301, doi:10.1029/2011JD015775, 2012. 